\title{
TESTING OF THE RADBALL TECHNOLOGY AT SAVANNAH RIVER NATIONAL LABORATORY
}

Eduardo B. Farfán, Trevor Q. Foley, G. Timothy Jannik, John R. Gordon, Larry J. Harpring, Ronald Blessing, Steven J. Stanley, Chris J. Holmes, Mark Oldham, and John Adamovics

Original Signed

Technical Reviewer

February 10, 2010

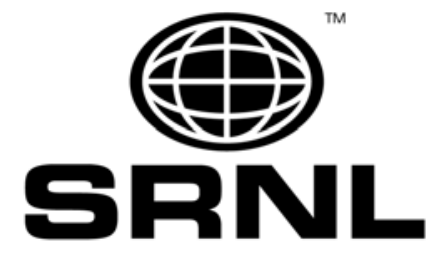

Savannah River National Laboratory

Savannah River Nuclear Solutions

Savannah River Site Aiken, SC 29808

THIS DOCUMENT WAS PREPARED IN CONJUNCTION WITH WORK ACCOMPLISHED UNDER CONTRACT NO. DE-AC09-08SR22470 WITH THE U.S. DEPARTMENT OF ENERGY. 


\section{DISCLAIMER}

This work was prepared under an agreement with and funded by the U.S. Government. Neither the U. S. Government or its employees, nor any of its contractors, subcontractors or their employees, makes any express or implied: 1 . warranty or assumes any legal liability for the accuracy, completeness, or for the use or results of such use of any information, product, or process disclosed; or 2. representation that such use or results of such use would not infringe privately owned rights; or 3. endorsement or recommendation of any specifically identified commercial product, process, or service. Any views and opinions of authors expressed in this work do not necessarily state or reflect those of the United States Government, or its contractors, or subcontractors. 
Key Words: $\quad$ Radiation Mapping 3-D Visualization

Hot Cell/Glove Box

Retention: Lifetime

\section{TESTING OF THE RADBALL TECHNOLOGY AT SAVANNAH RIVER NATIONAL LABORATORY}

Eduardo B. Farfán, Trevor Q. Foley, G. Timothy Jannik, John R. Gordon, Larry J. Harpring, Ronald Blessing, Steven J. Stanley, Chris J. Holmes, Mark Oldham, and John Adamovics

Issued: February 10, 2010

SRNL

SAVANNAH RIVER NATIONAL LABORATORY

AIKEN, SC 29808

Savannah River Nuclear Solutions

Savannah River Site

Aiken, SC 29808

THIS DOCUMENT WAS PREPARED IN CONJUNCTION WITH WORK ACCOMPLISHED UNDER CONTRACT NO. DE-AC09-08SR22470 WITH THE U.S. DEPARTMENT OF ENERGY. 
This Page Intentionally Left Blank 


\section{ABSTRACT}

The United Kingdom's National Nuclear Laboratory (NNL) has developed a remote, nonelectrical, radiation-mapping device known as RadBall (patent pending), which offers a means to locate and quantify radiation hazards and sources within contaminated areas of the nuclear industry. Positive results from initial deployment trials in nuclear waste reprocessing plants at Sellafield in the United Kingdom and the anticipated future potential use of RadBall throughout the U.S. Department of Energy Complex have led to the NNL partnering with the Savannah River National Laboratory (SRNL) to further test, underpin, and strengthen the technical performance of the technology.

The study completed at SRNL addresses key aspects of the testing of the RadBall technology. The first set of tests was performed at Savannah River Nuclear Solutions' Health Physics Instrument Calibration Laboratory (HPICL) using various gamma-ray sources and an $\mathrm{x}$-ray machine with known radiological characteristics. The objective of these preliminary tests was to identify the optimal dose and collimator thickness. The second set of tests involved a highly contaminated hot cell. The objective of this testing was to characterize a hot cell with unknown radiation sources. The RadBall calibration experiments and hot cell deployment were successful in that for each trial radiation tracks were visible.

The deployment of RadBall can be accomplished in different ways depending on the size and characteristics of the contaminated area (e.g., a hot cell that already has a crane/manipulator available or highly contaminated room that requires the use of a remote control device with sensor and video equipment to position RadBall). This report also presents SRNL-designed RadBall accessories for future RadBall deployment (a harness, PODS, and robot). 
This Page Intentionally Left Blank 


\section{TABLE OF CONTENTS}

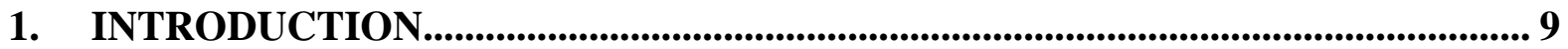

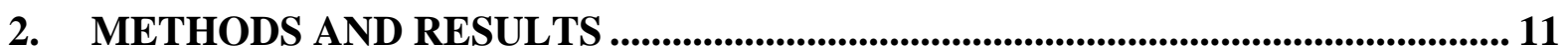

2.1. EXPERIMENTS AT SRS HEALTH PHYSICS INSTRUMENT CALIBRATION LABORATORY

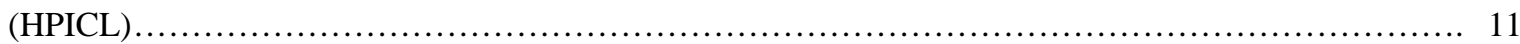

2.1.1. A selection of RadBall irradiations from HPICL .................................................................14

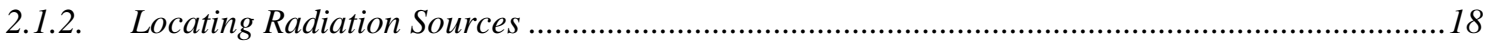

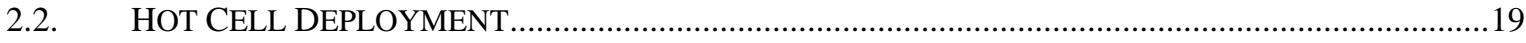

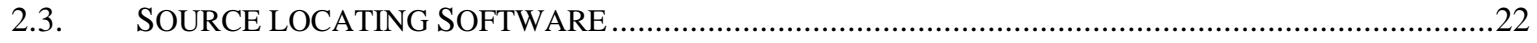

2.4. CURRENT DEVELOPMENT OF RADBALL ACCESSORIES FOR FUTURE HOT CELL DEPLOYMENT

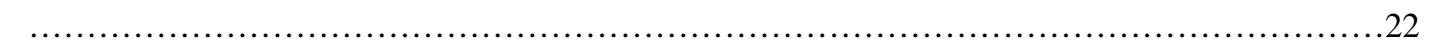

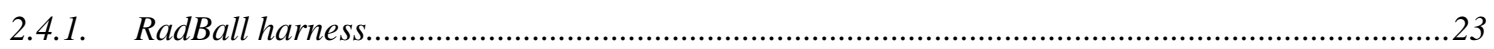

2.4.2. SRNL's Position and Orientation Determination System (PODS) ............................................23

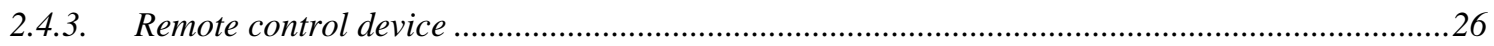

3. DISCUSSION AND CONCLUSIONS …...................................................................... 29

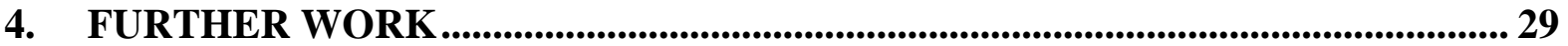

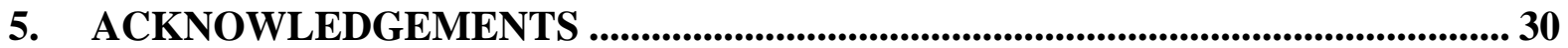

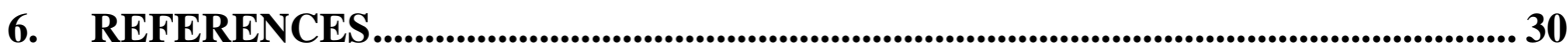

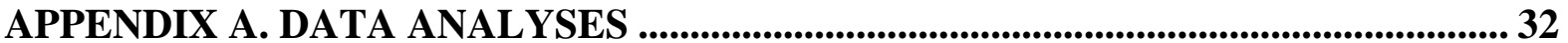




\section{LIST OF TABLES}

Table 1. Phase 1 Calibration Facility Experiments........................................................... 13

Table 2. Phase 2 Calibration Facility Experiments......................................................... 13

Table 3. Phase 3 Calibration Facility Experiments.......................................................... 15

\section{LIST OF FIGURES}

Figure 1. Two components of a RadBall device: the outer collimation shell and inner

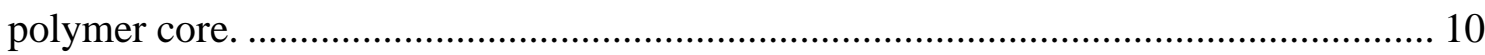

Figure 2. Schematic representation of the optical scanner developed at Duke University. ... 11

Figure 3. RadBall positioned in front of an automated irradiator system at HPICL.............. 12

Figure 4. Example of optical scan images of RadBall N-2-4 (Images provided by NNL).... 14

Figure 5. Images of (a) Pre and (b) Post contrast enhanced slices of RadBall N-2-4 …......... 16

Figure 6. Images of (a) Pre and (b) Post contrast enhanced slices of RadBall N-4-5. ........... 16

Figure 7. Images of (a) Pre and (b) Post contrast enhanced slices of RadBall N-8-4 ........... 17

Figure 8. Images of (a) Pre and (b) Post contrast enhanced slices of RadBall N-10-2. ......... 17

Figure 9. RadBall predicted radiation source locations at HPICL: Point sources in.............. 18

Figure 10. Photographs of (a) SRNL shielded cells facility, (b) RadBall deployed in hot cell.

Figure 11. 3D Visualization of the hot cell in the SRNL shielded cells facility .................... 20

Figure 12. (a) Photograph of hot cell floor. (b) CAD drawing with located radiation sources 21

Figure 13. Hot cell floor with located radiation sources (visualization background). ........... 21

Figure 14. Harness for RadBall deployment into hot cells using a crane or manipulator ...... 23

Figure 15. Placing RadBall into PODS ............................................................................ 24

Figure 16. PODS measuring distances - scanning surrounding walls.................................... 25

Figure 17. Placing RadBall into PODS placed on top of a remote controlled device............ 27

Figure 18. Whole System: RadBall, PODS, and robot.......................................................... 27

Figure 19. Possible design of a complete RadBall deployment system .................................. 28 


\section{INTRODUCTION}

The consequences of radiological operations at various U.S. Department of Energy (DOE) sites have resulted in substantially contaminated facilities (e.g., reactors, fuel and isotope processing facilities, laboratories, hot cells, gloveboxes, etc.). These facilities are usually associated with extremely high dose rates and, therefore, it is imperative to use remote technologies for characterization and decommissioning to keep worker exposures as low as reasonably achievable (ALARA) in these highly contaminated environments. Although technologies might exist in other industry applications that could be tested, modified, and deployed for characterization and decommissioning efforts throughout the DOE complex, development of new and innovative technologies is also needed. In addition, even though it might be possible to complete these tasks without remote/robotic systems, the benefits of remote systems to safety/ALARA and cost/schedule are expected to be substantial. A critical initial step in planning and implementing decontamination and decommissioning of contaminated facilities involves the development of an accurate assessment of the radiological, chemical, and structural conditions inside of the facilities. These conditions are often unknown for many of these facilities. Radiological and chemical contamination, as well as structural deterioration of such facilities presents risks to workers, which must be mitigated. To the extent that information can be collected to describe facility conditions using remote technologies, the conservatism associated with planning initial worker entry (and associated cost) can be reduced. For facilities confirmed to be high hazard, remote and robotic technologies for characterization, decontamination and decommissioning can further reduce the costs to mitigate worker risks.

Various national and international organizations (e.g., the U.S. DOE, Department of Defense, Department of Homeland Security, Nuclear Regulatory Commission, Environmental Protection Agency, and the International Atomic Energy Agency) deal with radioactive contamination on a regular basis. These organizations have expressed the need for better radiation detector systems to characterize and locate unidentified sources of radiation such as hot spots within glove boxes, hot cells, and other confined spaces where elevated radiation levels exist. These systems should provide 3D characterizations of the affected areas while having valuable properties that include low cost, robustness, and stability against falls, impacts, and extreme temperatures. In addition, the systems should be remotely deployable during the measurement/characterization process (no connecting power, communication cords or electronics) to ensure a high degree of deployability that may open up new possibilities for radiation measurement and mapping in areas of a facility, which were previously considered physically inaccessible with traditional electrical-based radiation detection systems. A suitable technology should also offer an inexpensive and safer means to perform initial radiological characterizations, in-process surveys, and final status surveys to enable effective decontamination while minimizing exposures to workers.

This study completed at Savannah River National Laboratory (SRNL) addresses key aspects of the testing of an innovative technology, RadBall; currently being developed by the National Nuclear Laboratory (NNL) in the United Kingdom. RadBall technology presents a significant opportunity to expedite initial characterization of radiologically contaminated facilities with respect to ALARA concerns, initial decontamination strategies, and costs associated with the decontamination efforts. RadBall will make radiation mapping safer and potentially more accurate and convenient than conventional detection devices, which are often much bigger and 
cumbersome due to their electrical components and accessories. A single RadBall can be positioned in a highly contaminated area, glove box, or hot cell and left alone to collect data instead of personnel spending valuable time carrying out manual scanning and surveying.

The device consists of a colander-like outer shell that houses a radiation-sensitive polymer sphere (Figure 1). The outer shell works to collimate radiation sources and those areas of the polymer sphere that are exposed react, becoming increasingly less transparent, in proportion to the absorbed dose. The polymer sphere is imaged in an optical-CT scanner developed at Duke University (Figure 2), which produces a high resolution 3D map of optical attenuation coefficients that are proportional to absorbed dose.

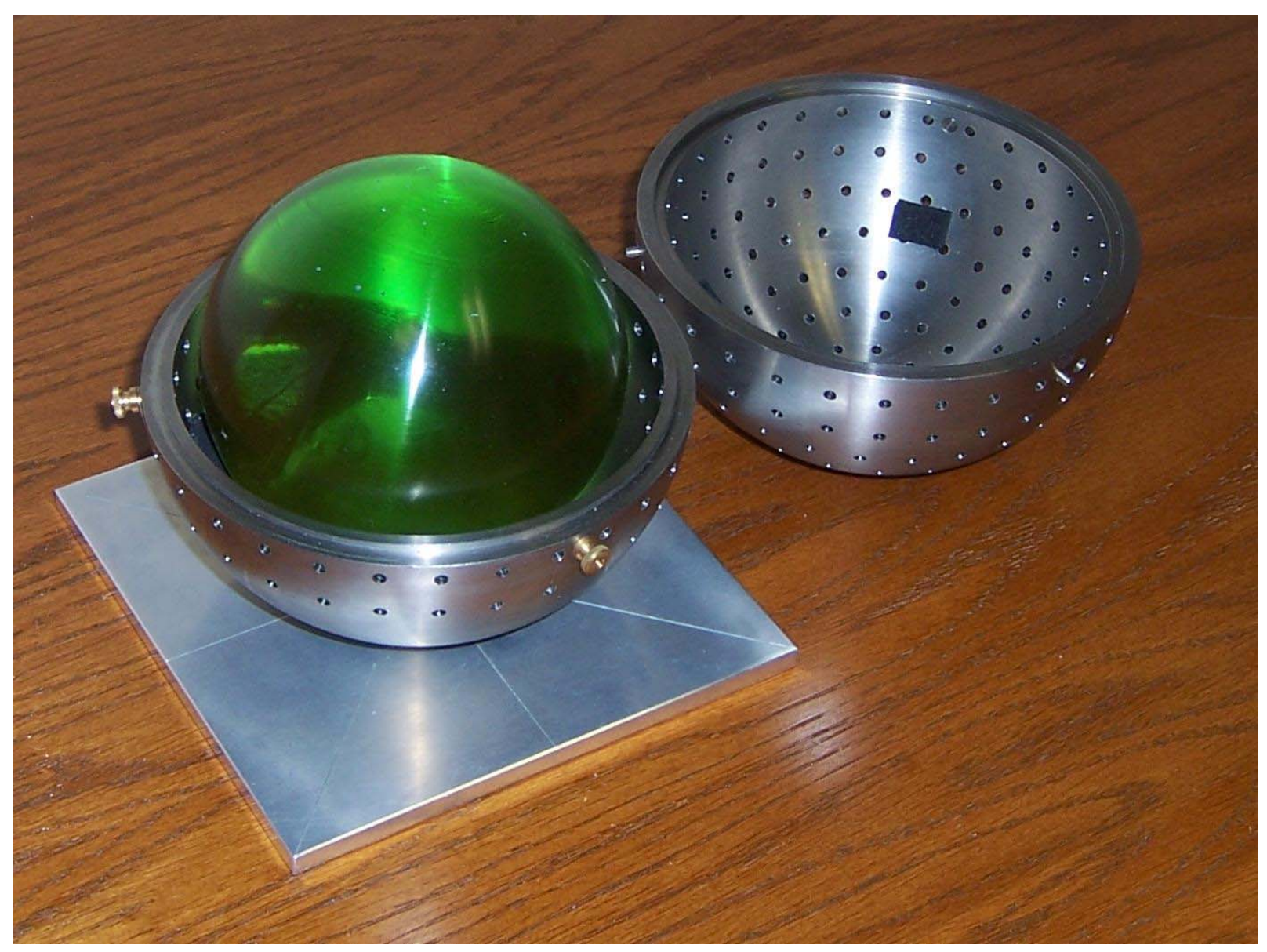

Figure 1. Two components of a RadBall device: the outer collimation shell and inner polymer core.

The orientation of the opacity track provides the positional information regarding the source (achieved by using a reverse ray tracing technique). The activity of the detected source is assessed by quantifying the magnitude of the opacity change (which follows a linear relationship with respect to absorbed dose). There is the potential to characterize radiation sources by studying the depth of the opacity track (the measured opacity in the track over the depth of the track will follow a function that can be interpreted to estimate the characteristic energy or 
energies of the incident radiation source). NNL has published information regarding RadBall development [1-3] and Duke University has published material on the characterization and optical-CT scanning of the radiation sensitive polymer, PRESAGE ${ }^{\mathrm{TM}}$ [4-7].

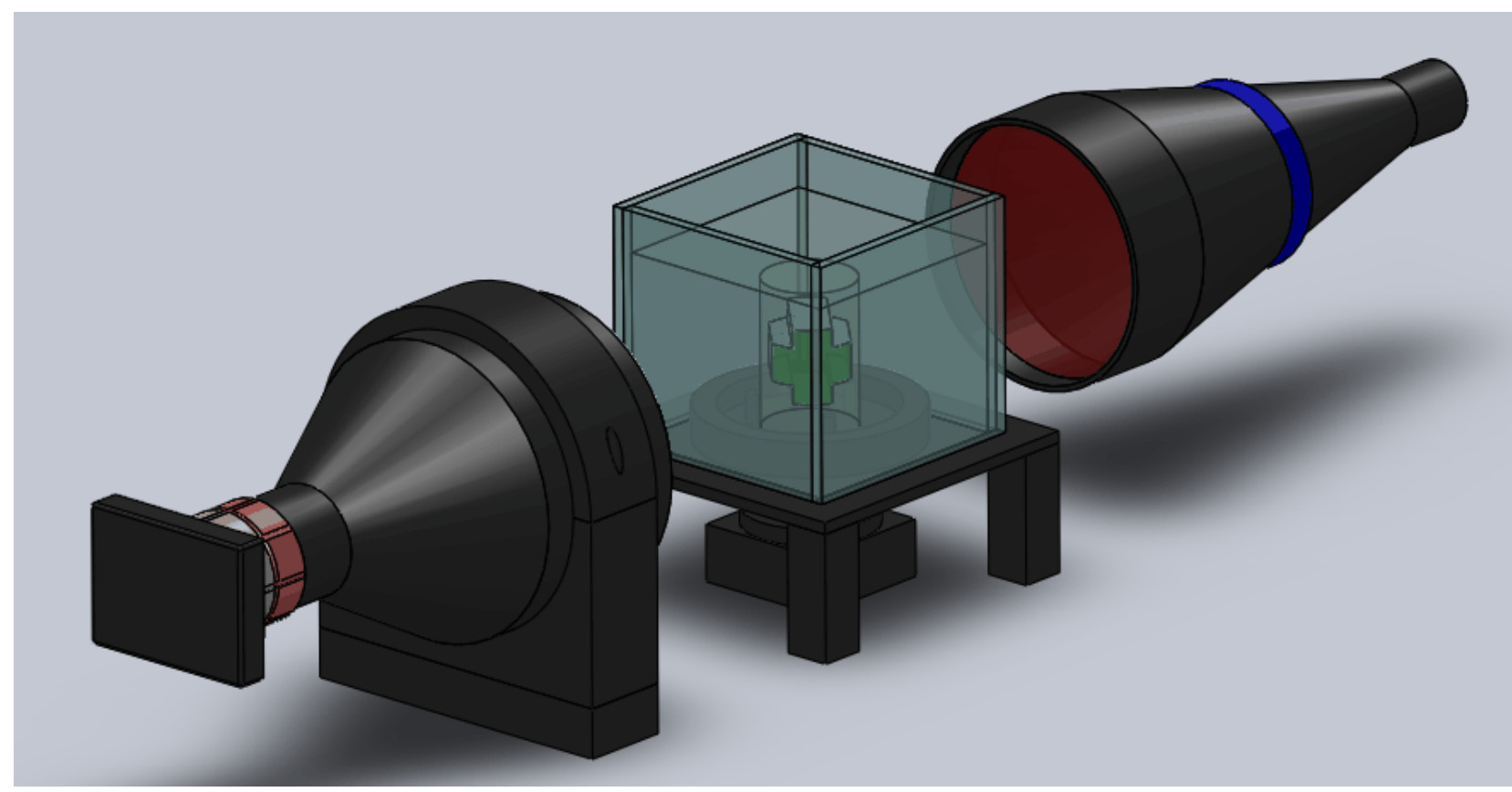

Figure 2. Schematic representation of the optical scanner developed at Duke University.

The first set of tests was performed at the Savannah River Site (SRS) Health Physics Instrument Calibration Laboratory (HPICL) using various gamma-ray sources and an x-ray machine with known radiological characteristics. The objective of these preliminary tests was to identify the optimal dose and collimator thickness of the RadBall. The second set of tests involved a highly contaminated operational hot cell. The objective of this part of the testing was to characterize a hot cell with unknown sources. The RadBall testing in the hot cell involved the characterization of the hot cell by using common methods such as teledetectors and smears to determine the dose rates and radionuclides present. Once this characterization was complete, RadBalls were deployed in the hot cell to obtain a comprehensive 3D characterization. Subsequently, the results from both characterization methods were compared and analyzed.

\section{METHODS AND RESULTS}

\subsection{Experiments at SRS Health Physics Instrument Calibration Laboratory (HPICL)}

The HPICL at SRS contains nine Automated Irradiator Systems (Figure 3). All of the irradiators were designed or refurbished by Hopewell Designs Incorporated to provide radiation beams of various types (beta particles, gamma rays, neutrons, and x-rays). The primary purpose of the equipment is to calibrate radiation detection instruments and test and verify personnel dosimeters. The sources and the exposures are therefore known with a high degree of certainty. The higher activity sources were ideal for the RadBall experiments since these sources provided shortened periods of exposure time. The highest ${ }^{137} \mathrm{Cs}$ and ${ }^{60} \mathrm{Co}$ sources were used for the 
majority of the experiments currently around 45.9 and $178 \mathrm{TBq}(1,240$ and 4,756 Ci), respectively.

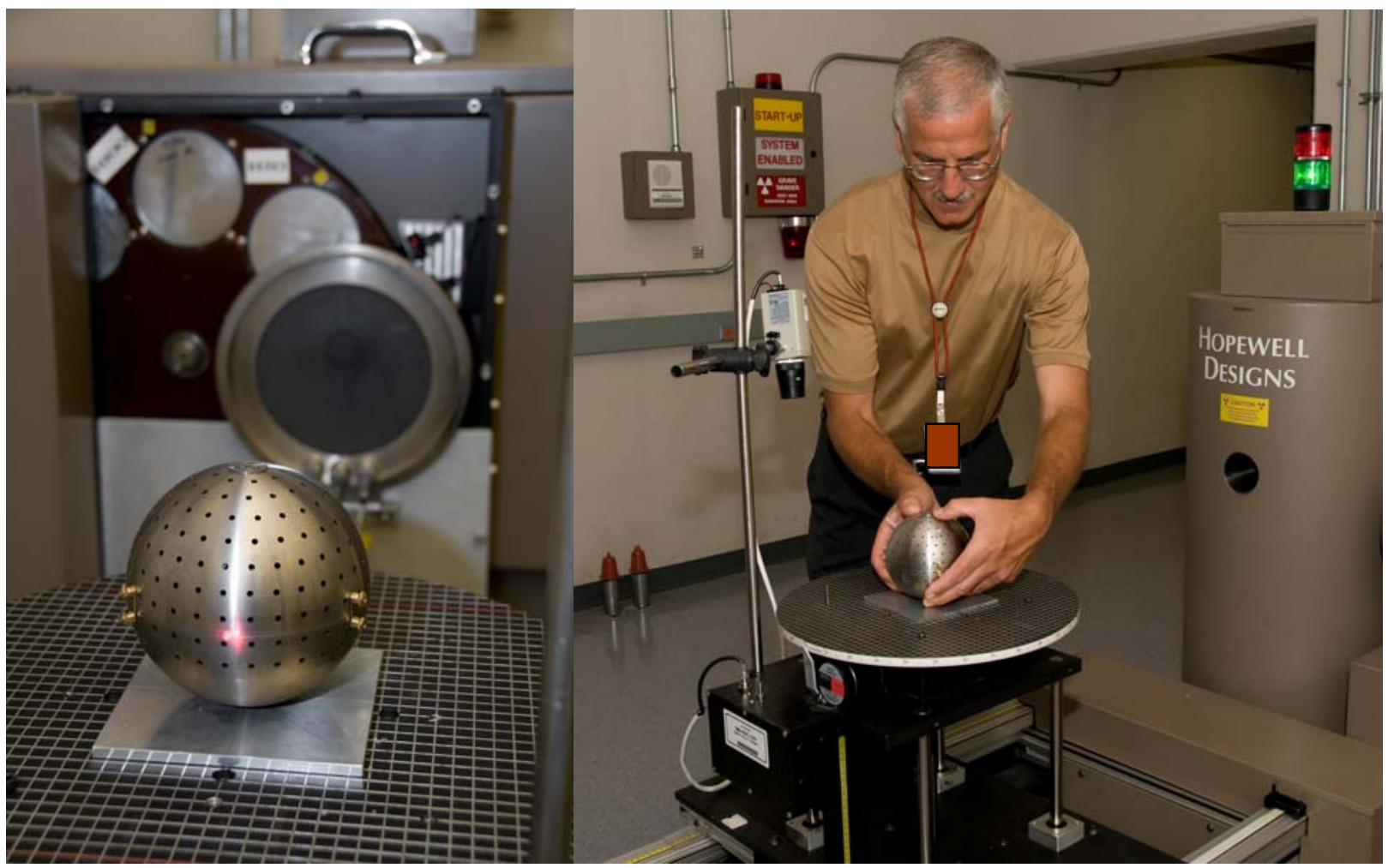

Figure 3. RadBall positioned in front of an automated irradiator system at HPICL.

Three experimental phases were completed at the HPICL which included the exposure of 45 RadBalls. Table 1-3 detail all of the experiments completed at the HPICL:

- Phase 1 experiments were primarily used to obtain information on the target dose for RadBall. Experiments were completed with a ${ }^{137}$ Cs source with irradiations from 0.5 to $5 \mathrm{~Gy}$ and with a ${ }^{60} \mathrm{Co}$ source also with irradiations over the range of 0.5 to $5 \mathrm{~Gy}$.

- Phase 2 experiments investigated the RadBall performance with different radiation sources and different collimator thicknesses.

- Phase 3 experiments investigated the ability of the RadBall technology to perform with high background levels of radiation. Un-collimated RadBall polymers were given a background radiation dose and then a second irradiation was performed with the collimator fitted.

The ${ }^{241} \mathrm{Am}$ source was used for one exposure; however, due to its low activity and therefore long exposure times, it was not used in any other test. With the exception of experiment $28\left({ }^{241} \mathrm{Am}\right.$ exposed at a distance of $30 \mathrm{~cm}$ as shown in Table 2) all experiments were completed with the RadBall positioned $100 \mathrm{~cm}$ away from the radiation source. At $30 \mathrm{~cm}$, the ${ }^{241} \mathrm{Am}$ source could not be considered a point source because it is large (consisting of seven separate sources and resembling an area source at $30 \mathrm{~cm}$ ). An x-ray source was used, which generated various photon 
energies with peaks at $166 \mathrm{keV}, 120 \mathrm{keV}$, and $38 \mathrm{keV}$. The x-ray source was not ideal since it generated a distribution of photon energies; however, the peaks available were near the $60 \mathrm{keV}$ gamma ray energy emitted from ${ }^{241} \mathrm{Am}$. The $\mathrm{x}$-ray machine offered a much higher rate of exposure than the ${ }^{241} \mathrm{Am}$ source and was therefore much more convenient in terms of exposure times.

Table 1. Phase 1 Calibration Facility Experiments.

\begin{tabular}{ccccc}
\hline Test & $\begin{array}{c}\text { Total } \\
\text { Dose } \\
\text { (Gy) }\end{array}$ & Radiation Source(s) & RadBall & $\begin{array}{c}\text { Collimator } \\
\text { Thickness } \\
\text { (mm) }\end{array}$ \\
\hline 1 & 0.5 & ${ }^{137} \mathrm{Cs}$ & $\mathrm{N}-1-2$ & 5.0 \\
2 & 1.0 & ${ }^{137} \mathrm{Cs}$ & $\mathrm{N}-1-3$ & 5.0 \\
3 & 1.5 & ${ }^{137} \mathrm{Cs}$ & $\mathrm{N}-1-4$ & 5.0 \\
4 & 2.0 & ${ }^{137} \mathrm{Cs}$ & $\mathrm{N}-1-5$ & 5.0 \\
5 & 3.0 & ${ }^{137} \mathrm{Cs}$ & $\mathrm{N}-1-6$ & 5.0 \\
6 & 5.0 & ${ }^{137} \mathrm{Cs}$ & $\mathrm{N}-2-4$ & 5.0 \\
7 & 0.5 & ${ }^{60} \mathrm{Co}$ & $\mathrm{N}-2-1$ & 5.0 \\
8 & 1.0 & ${ }^{60} \mathrm{Co}$ & $\mathrm{N}-2-2$ & 5.0 \\
9 & 1.5 & ${ }^{60} \mathrm{Co}$ & $\mathrm{N}-2-3$ & 5.0 \\
10 & 2.0 & ${ }^{60} \mathrm{Co}$ & $\mathrm{N}-2-5$ & 5.0 \\
11 & 3.0 & ${ }^{60} \mathrm{Co}$ & $\mathrm{N}-2-6$ & 5.0 \\
12 & 5.0 & ${ }^{60} \mathrm{Co}$ & $\mathrm{N}-1-1$ & 5.0 \\
13 & 3.0 & $\mathrm{~N}-3-2$ & 5.0 \\
14 & 6.0 & $1.5 \mathrm{~Gy}{ }^{137} \mathrm{Cs}+1.5 \mathrm{~Gy}{ }^{60} \mathrm{Co} \mathrm{(collinear)}$ & $\mathrm{N}-3-3$ & 5.0 \\
15 & 6.0 & $3 \mathrm{~Gy}{ }^{60} \mathrm{Co} \mathrm{(no} \mathrm{collimator)}+3$ Gy ${ }^{60} \mathrm{Co}$ & $\mathrm{N}-3-1$ & 7.5 \\
\hline
\end{tabular}

Table 2. Phase 2 Calibration Facility Experiments.

\begin{tabular}{ccccc}
\hline Test & $\begin{array}{c}\text { Total } \\
\text { Dose } \\
\text { (Gy) }\end{array}$ & Radiation Source(s) & RadBall & $\begin{array}{c}\text { Collimator } \\
\text { Thickness } \\
\text { (mm) }\end{array}$ \\
\hline 16 & 2.0 & $1 \mathrm{~Gy}{ }^{60} \mathrm{Co}$ (no collimator) $+1 \mathrm{~Gy}{ }^{60} \mathrm{Co}$ & $\mathrm{N}-3-4$ & 5.0 \\
17 & 4.0 & $2 \mathrm{~Gy}{ }^{60} \mathrm{Co}$ (no collimator) $+2 \mathrm{~Gy}{ }^{60} \mathrm{Co}$ & $\mathrm{N}-3-5$ & 5.0 \\
18 & 8.0 & $4 \mathrm{~Gy}{ }^{60} \mathrm{Co}$ (no collimator) $+4 \mathrm{~Gy}{ }^{60} \mathrm{Co}$ & $\mathrm{N}-3-6$ & 5.0 \\
19 & 3.0 & $166 \mathrm{keV}$ X-ray & $\mathrm{N}-5-5$ & 5.0 \\
20 & 3.0 & $2 \mathrm{~Gy}{ }^{137} \mathrm{Cs}+1 \mathrm{~Gy}{ }^{60} \mathrm{Co}$ (collinear) & $\mathrm{N}-4-3$ & 5.0 \\
21 & 3.0 & $1 \mathrm{~Gy}{ }^{137} \mathrm{Cs}+2 \mathrm{~Gy}{ }^{60} \mathrm{Co}$ (collinear) & $\mathrm{N}-5-6$ & 5.0 \\
22 & 3.0 & $3 \mathrm{~Gy}{ }^{137} \mathrm{Cs}+1 \mathrm{~Gy}{ }^{60} \mathrm{Co}$ (collinear) & $\mathrm{N}-4-2$ & 5.0 \\
23 & 3.0 & $1 \mathrm{~Gy}{ }^{137} \mathrm{Cs}+3 \mathrm{~Gy}{ }^{60} \mathrm{Co}$ (collinear) & $\mathrm{N}-4-1$ & 5.0 \\
24 & 3.0 & ${ }^{60} \mathrm{Co}$ & $\mathrm{N}-5-1$ & 7.5 \\
25 & 3.0 & ${ }^{60} \mathrm{Co}$ & $\mathrm{N}-5-3$ & 10.0 \\
26 & 3.0 & ${ }^{137} \mathrm{Cs}$ & $\mathrm{N}-5-2$ & 7.5 \\
27 & 3.0 & ${ }^{137} \mathrm{Cs}$ & $\mathrm{N}-5-4$ & 10.0 \\
28 & 0.5 & ${ }^{241} \mathrm{Am}$ & $\mathrm{N}-4-4$ & 5.0 \\
29 & 3.0 & $1.5 \mathrm{~Gy} 120 \mathrm{keV}$ x-ray, rotated $90^{\circ} \& 1.5 \mathrm{~Gy} 38 \mathrm{keV}$ & $\mathrm{N}-4-5$ & 5.0 \\
\hline
\end{tabular}


After irradiation at the HPICL, the RadBall polymers were sent to Duke University Medical Center for optical CT scanning using the device represented in Figure 2. The data results from the optical CT scan were subsequently analysed at NNL, using the Image Processing and Analysis in Java (ImageJ) software (ImageJ website: http://rsbweb.nih.gov/ij/)

\subsubsection{A selection of RadBall irradiations from HPICL}

Figure 4 shows two side view images (left) and a montage of horizontal slices moving through the RadBall top to bottom (right) produced in ImageJ from the optical CT scan data for RadBall $\mathrm{N}-2-4$, which was irradiated with a $5.0 \mathrm{~Gy}{ }^{137} \mathrm{Cs}$ source from a distance of $100 \mathrm{~cm}$ with a collimation thickness of $5.0 \mathrm{~mm}$ (Table 1). The top left image is a vertical slice taken from the middle of the RadBall. It shows the radiation tracks entering from the left of the RadBall at a slight angle above the horizontal. The bottom left image shows the radiation tracks penetrating into the polymer through the holes of the collimation device. The set of montage images shows radiation tracks appearing in the polymer as you move up through the stack of horizontal slices with the middle of the RadBall showing the largest number and highest intensity radiation tracks. This is consistent with aligning the radiation source to deliver the radiation dose to the middle of the RadBall.
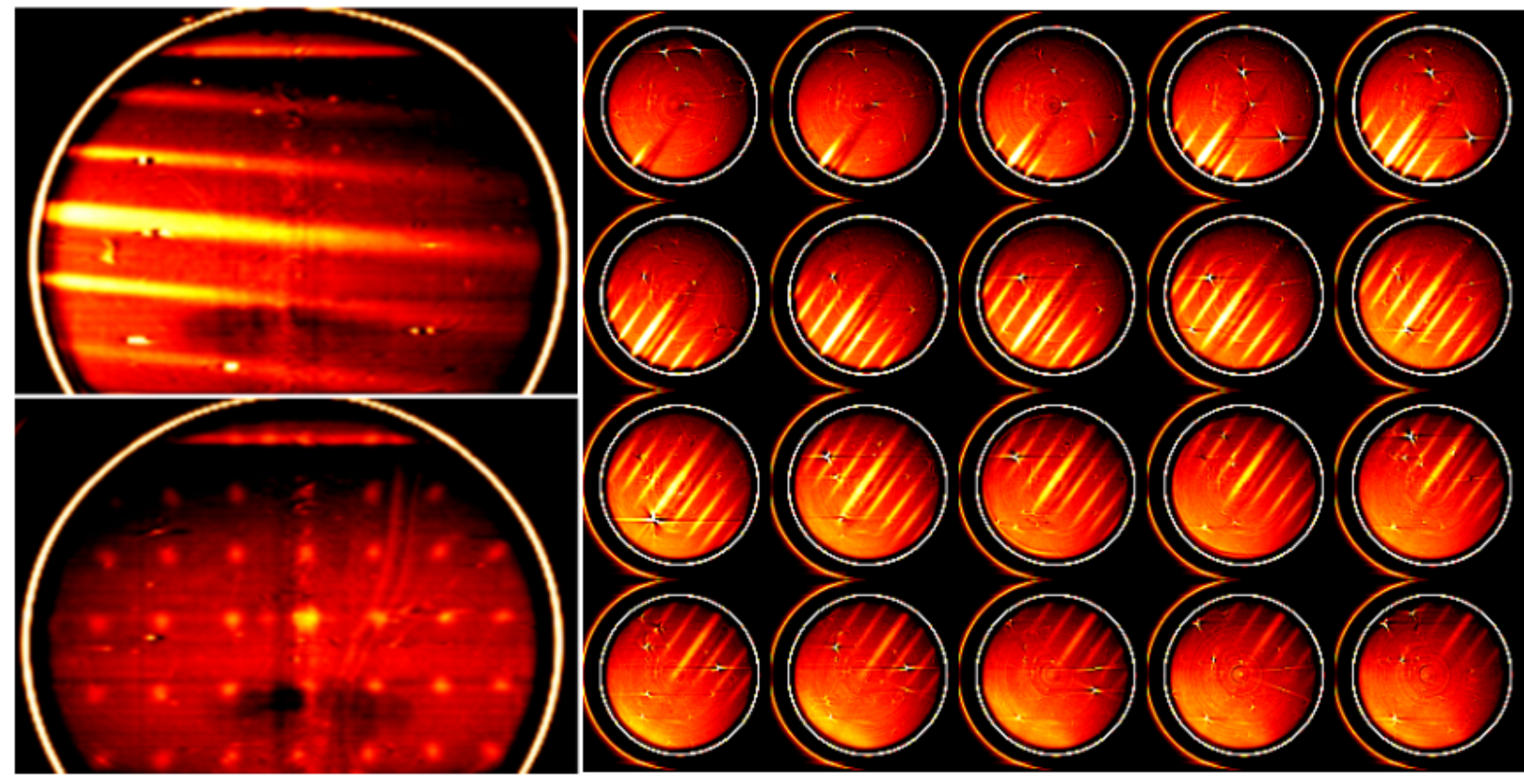

Figure 4. Example of optical scan images of RadBall N-2-4 (Images provided by NNL).

Phase 1 experiments 1-12, produced results similar to that displayed in Figure 5, which shows images of a horizontal slice of a RadBall (N-2-4) with (a) pre and (b) post contrast enhancement applied (a feature within the ImageJ software, which allows the contrast between the radiation tracks and the background to be enhanced). For both the ${ }^{137} \mathrm{Cs}$ and ${ }^{60} \mathrm{Co}$ radiation sources, the experiments demonstrated a linear response between the opacity change of the PRESAGE ${ }^{\mathrm{TM}}$ polymer and the radiation dose delivered. 
Table 3. Phase 3 Calibration Facility Experiments.

\begin{tabular}{|c|c|c|c|c|}
\hline Test & $\begin{array}{l}\text { Total } \\
\text { Dose } \\
\text { (Gy) }\end{array}$ & Radiation Source(s) & RadBall & $\begin{array}{l}\text { Collimator } \\
\text { Thickness } \\
\text { (mm) }\end{array}$ \\
\hline 30 & 3.0 & $1.5 \mathrm{~Gy}{ }^{137} \mathrm{Cs}$ (no collimator) + $1.5 \mathrm{~Gy}{ }^{137} \mathrm{Cs}$ (with collimator) & $\mathrm{N}-7-2$ & 7.5 \\
\hline 31 & 3.0 & $2.0 \mathrm{~Gy}{ }^{137} \mathrm{Cs}$ (no collimator) $+1.0 \mathrm{~Gy}{ }^{137} \mathrm{Cs}$ (with collimator) & $\mathrm{N}-8-2$ & 7.5 \\
\hline 32 & 3.0 & $2.5 \mathrm{~Gy}{ }^{137} \mathrm{Cs}$ (no collimator) + $0.5 \mathrm{~Gy}{ }^{137} \mathrm{Cs}$ (with collimator) & $\mathrm{N}-7-4$ & 7.5 \\
\hline 33 & 3.0 & $\begin{array}{c}2.75 \mathrm{~Gy}{ }^{137} \mathrm{Cs} \text { (no collimator) + } 0.25 \text { Gy }{ }^{137} \mathrm{Cs} \text { (with } \\
\text { collimator) }\end{array}$ & $\mathrm{N}-8-5$ & 7.5 \\
\hline 34 & 3.0 & $\begin{array}{c}2.85 \mathrm{~Gy}{ }^{137} \mathrm{Cs} \text { (no collimator) }+0.15 \mathrm{~Gy}{ }^{137} \mathrm{Cs} \text { (with } \\
\text { collimator) }\end{array}$ & $\mathrm{N}-8-3$ & 7.5 \\
\hline 35 & 3.0 & $1.5 \mathrm{~Gy}{ }^{137} \mathrm{Cs}$ (no collimator) + $1.5 \mathrm{~Gy}{ }^{137} \mathrm{Cs}$ (with collimator) & $\mathrm{N}-7-1$ & 10.0 \\
\hline 36 & 3.0 & $2.0 \mathrm{~Gy}{ }^{137} \mathrm{Cs}$ (no collimator) $+1.0 \mathrm{~Gy}{ }^{137} \mathrm{Cs}$ (with collimator) & $\mathrm{N}-8-1$ & 10.0 \\
\hline 37 & 3.0 & $2.5 \mathrm{~Gy}{ }^{137} \mathrm{Cs}$ (no collimator) + $0.5 \mathrm{~Gy}{ }^{137} \mathrm{Cs}$ (with collimator) & N-10-3 & 10.0 \\
\hline 38 & 3.0 & $\begin{array}{c}2.75 \mathrm{~Gy}{ }^{60} \mathrm{Co} \text { (no collimator) }+0.25 \mathrm{~Gy}{ }^{137} \mathrm{Cs} \text { (with } \\
\text { collimator) }\end{array}$ & $\mathrm{N}-9-1$ & 10.0 \\
\hline 39 & 3.0 & $\begin{array}{c}2.85 \mathrm{~Gy}{ }^{137} \mathrm{Cs} \text { (no collimator) }+0.15 \mathrm{~Gy}{ }^{137} \mathrm{Cs} \text { (with } \\
\text { collimator) }\end{array}$ & $\mathrm{N}-7-3$ & 10.0 \\
\hline 40 & 3.0 & $\begin{array}{l}{ }^{60} \mathrm{Co} \text { : Mimic a distributed source by moving the RadBall in a } \\
\text { direction perpendicular to the line between the source and the } \\
\text { RadBall initial position (i.e. irradiate using a }{ }^{60} \mathrm{Co} \text { source to } \\
\text { deliver } 0.5 \mathrm{~Gy} \text {. Then, move the RadBall by } 0.5 \mathrm{~cm} \text { and repeat } \\
\text { a } 0.5 \text { Gy exposure until a total dose of } 3.0 \mathrm{~Gy} \text { is delivered.) }\end{array}$ & $\mathrm{N}-9-2$ & 7.5 \\
\hline 41 & 3.0 & $\begin{array}{l}{ }^{60} \text { Co: Repeat exp. } 40 \text { moving the RadBall by } 1.0 \mathrm{~cm} \text { in each } \\
\text { step. }\end{array}$ & N-9-3 & 7.5 \\
\hline 42 & 3.0 & $\begin{array}{l}{ }^{60} \mathrm{Co:} \text { Mimic multiple sources that are close to each other by } \\
\text { rotating the RadBall between each irradiation. I.e. irradiate } \\
\text { using }{ }^{60} \mathrm{Co} \text { to deliver } 0.5 \mathrm{~Gy} \text {. Then, rotate the RadBall by } 5^{\circ} \\
\text { and repeat exposure }(0.5 \mathrm{~Gy}) \text {. Repeat this sequence until a } \\
\text { total dose of } 3.0 \mathrm{~Gy} \text { is delivered. }\end{array}$ & $\mathrm{N}-8-6$ & 7.5 \\
\hline 43 & 3.0 & ${ }^{60} \mathrm{Co}$ : Repeat experiment 42 using an angle of rotation of $10^{\circ}$. & $\mathrm{N}-8-4$ & 7.5 \\
\hline 44 & 6.0 & $\begin{array}{l}{ }^{60} \mathrm{Co} \text { : Irradiate RadBall with an initial dose of } 1 \mathrm{~Gy} \text {, then } \\
\text { rotate the RadBall by } 60^{\circ} \text { and give another } 1 \mathrm{~Gy} \text { dose. Repeat } \\
\text { sequence until } 6 \text { irradiations have been completed and the } \\
\text { RadBall has received a total dose of } 6.0 \mathrm{~Gy} \text {. }\end{array}$ & $\mathrm{N}-10-2$ & 10.0 \\
\hline 45 & 6.0 & $\begin{array}{l}{ }^{60} \text { Co: Repeat exp. } 44 \text { with the RadBall tilted at a } 45 \text { degree } \\
\text { angle. }\end{array}$ & N-10-1 & 10.0 \\
\hline
\end{tabular}




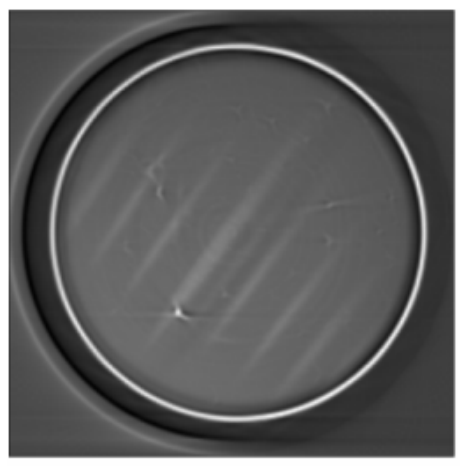

(a)

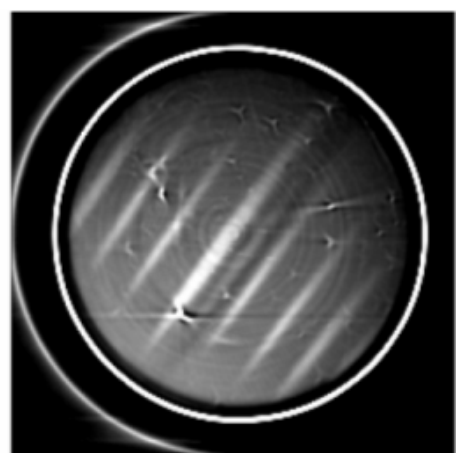

(b)

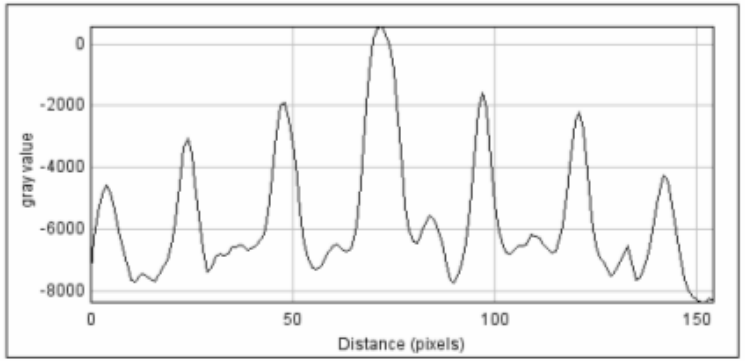

(c)

Figure 5. Images of (a) Pre and (b) Post contrast enhanced slices of RadBall N-2-4

(c) Plot profile of tracks.

Figure 5(c) is a plot profile taken from across the radiation tracks shown in Figure 5(b) of RadBall N-2-4 (Table 1) and highlights the ability to be able to pick out the radiation tracks from against areas of the un-irradiated polymer. Seven tracks are visible in the plot profile with a wider diameter radiation track in the middle of the RadBall. This is to be as expected as the middle collimation hole was slighter larger than the other holes on the collimation device. The diminishing intensity of the peaks to the left and right of the middle peak is due to the curvature of the collimator geometry. Figure 6 shows the scan images of RadBall N-4-5 (Table 2) irradiated with two sources (1.5 Gy $120 \mathrm{keV}$ x-ray and $1.5 \mathrm{~Gy} 38 \mathrm{keV}$ at $90^{\circ}$ to the first irradiation). The scans show 4 radiation tracks entering from the top left and 3 radiation tracks entering from the top right which cross-over in the middle of the RadBall.

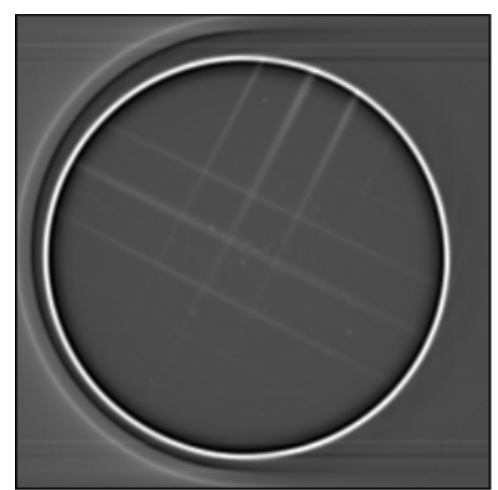

(a)

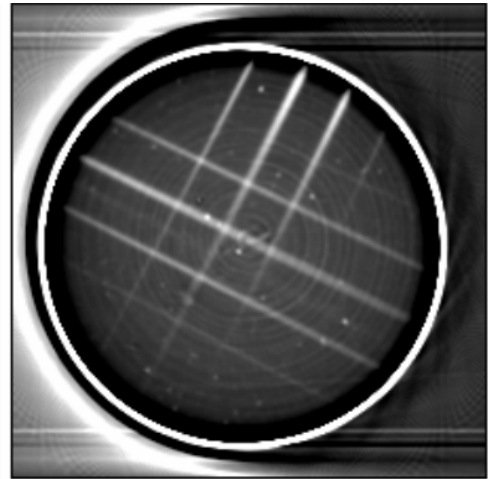

(b)

Figure 6. Images of (a) Pre and (b) Post contrast enhanced slices of RadBall N-4-5.

Figure 7 shows optical scan images for RadBall N-8-4 (Table 3). The aim of this experiment was 
to simulate multiple sources that are close to each other. The RadBall was delivered a ${ }^{137} \mathrm{Cs}$ dose of $0.5 \mathrm{~Gy}$, rotated by 10 degrees and then delivered another ${ }^{137} \mathrm{Cs}$ dose of $0.5 \mathrm{~Gy}$. This exercise was repeated until a total dose of 3.0 Gy was delivered. The scan images from RadBall N-8-4 highlight an interesting infringement pattern effect, where the radiation tracks are closer together at the bottom left of the image and become more dispersed and spread out towards the top right of the image. Brighter spots appear where radiation tracks are overlaid over one another.

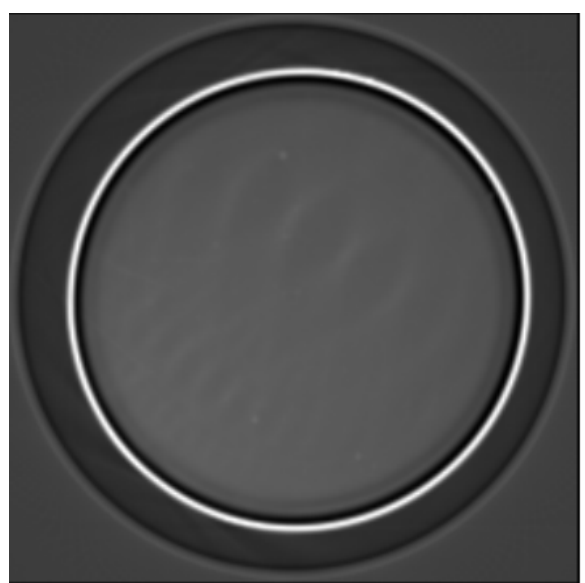

(a)

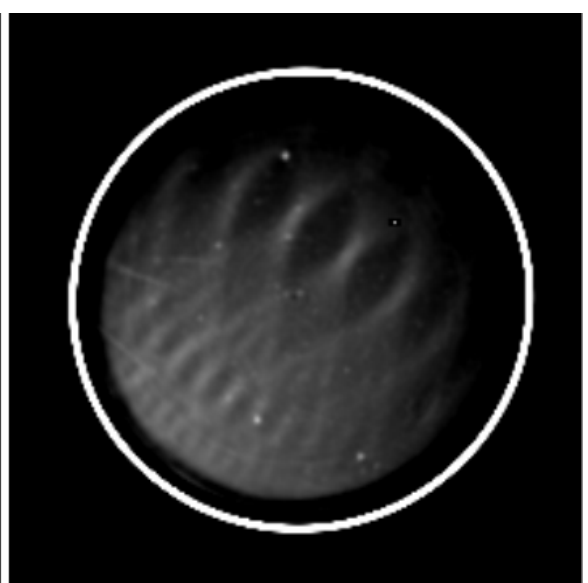

(b)

Figure 7. Images of (a) Pre and (b) Post contrast enhanced slices of RadBall N-8-4.

Figure 8 shows optical scan images for RadBall N-10-2 (Table 3). In this experiment the RadBall was given an initial dose of $1 \mathrm{~Gy}$, rotated by 60 degrees and another 1 Gy dose delivered. This exercise was repeated until six irradiations had been completed. The pattern appearing in the polymer is similar to isometric graph paper. Higher intensity bright spots appear where one or more radiation tracks have been overlaid increasing the radiation dose delivered to that area.

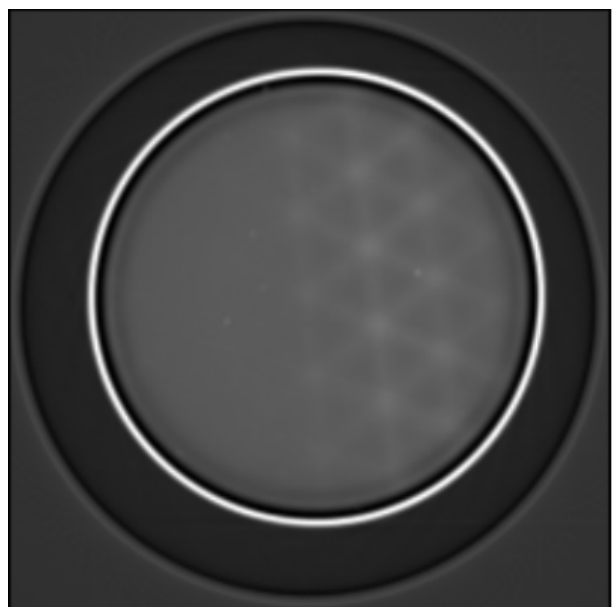

(a)

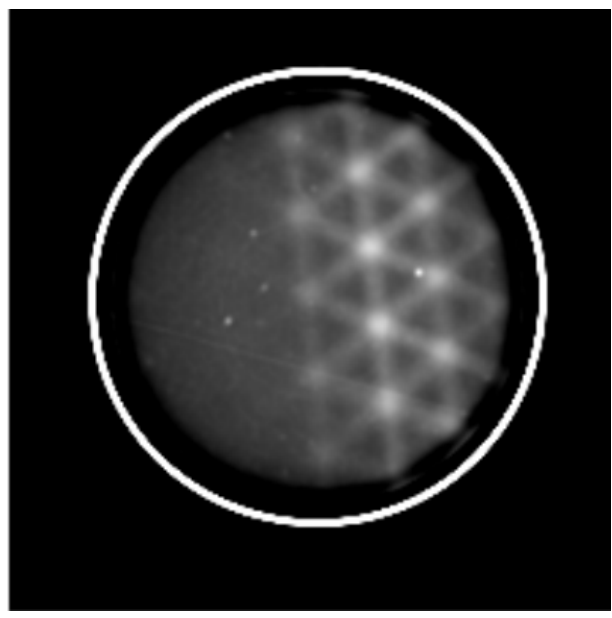

(b)

Figure 8. Images of (a) Pre and (b) Post contrast enhanced slices of RadBall N-10-2. 
All 45 RadBall irradiations completed at the HPICL resulted in radiation tracks that were visible in the optical CT scans and have demonstrated the effective performance of the RadBall against the selected radiation sources and doses. Analysis of the RadBall optical CT scans from the HPICL experiments has indicated that for optimum contrast and thus ability to accurately locate radiation tracks in the PRESAGE ${ }^{\mathrm{TM}}$ polymer, a target dose of between $3-5 \mathrm{~Gy}$ is required. At these target doses, the contrast of optical CT scans is improved by increasing the collimator thickness. Experiments completed with the $10 \mathrm{~mm}$ collimator provided the optimum contrast for data analysis. The ability of the RadBall technology to characterize the different radiation sources is currently being investigated.

\subsubsection{Locating Radiation Sources}

Using software developed in-house by NNL (based on a reverse ray tracing technique), the ability of the RadBall technology to accurately locate radiation sources was tested on the data from the calibration experiments. In this example, Figure 9 shows the predicted locations of the HPICL radiation source from 9 radiation tracks that had developed in RadBall N-2-4 (Table 2). The software predicts a point source in 3D space, to demonstrate this 3D position on a 2D graph, three sets of data have been plotted to denote the position of the predicted radiation source in the $\mathrm{XZ}, \mathrm{XY}$ and YZ spatial positions. For a RadBall to radiation source distance of $100 \mathrm{~cm}$, the RadBall predicts the position of the radiation source to within $10 \mathrm{~mm}$ (within $1 \%$ accuracy).

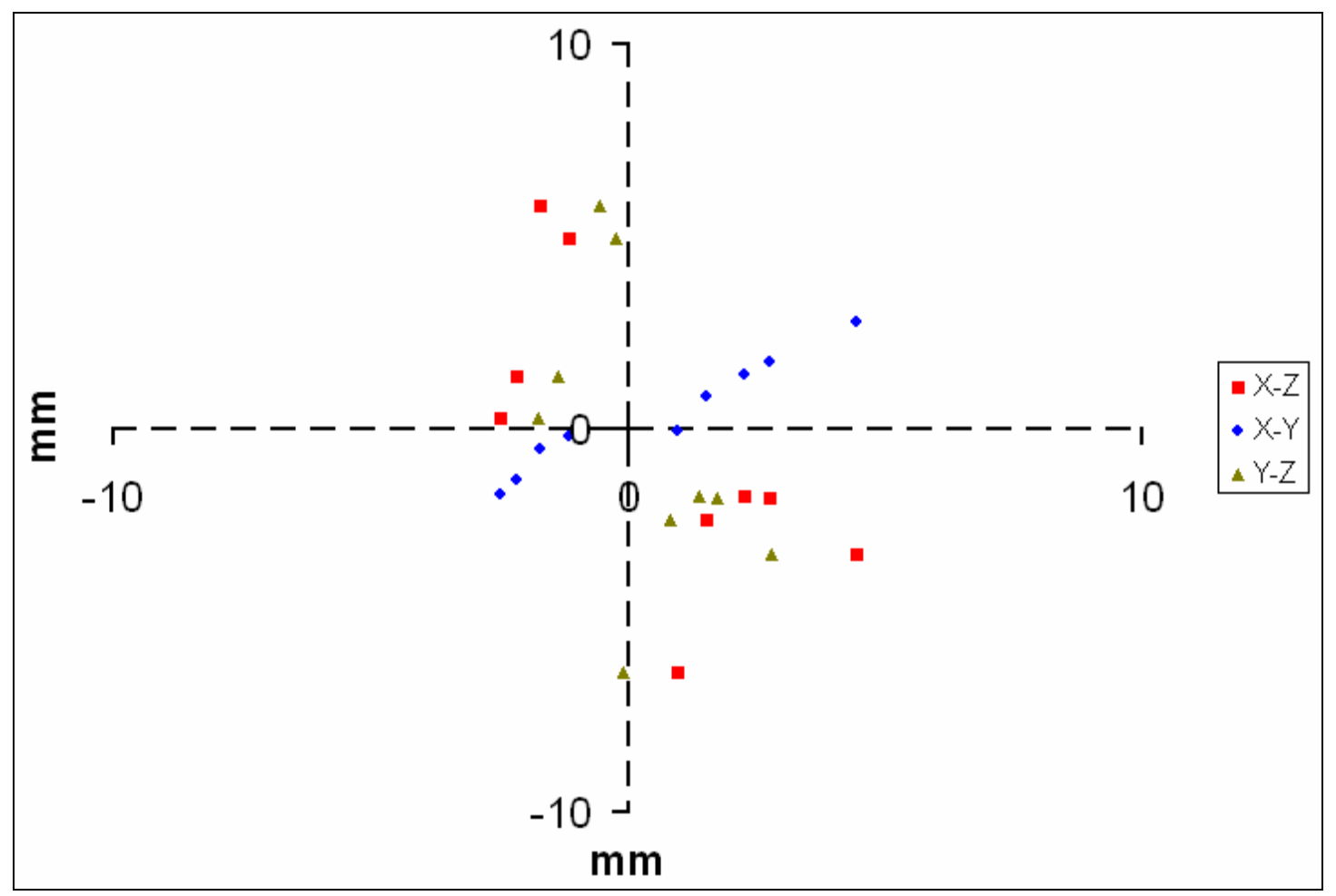

Figure 9. RadBall predicted radiation source locations at HPICL: Point sources in 3D space plotted on a 2D graph (i.e., with XZ, XY and YZ spatial positions) 


\subsection{Hot Cell Deployment}

The Savannah River National Laboratory Shielded Cells Facility has been utilized to work with a wide variety of highly radioactive samples. These cells offered an area to test RadBall as over the years, their use has resulted in the build-up of contamination on the walls and floor. Another benefit of testing the RadBall is there is already infrastructure to move the RadBall around in the cell with the manipulator arms and crane. The shielded cell can also be viewed during exposure, which is beneficial for knowing where the RadBall is in the cell and how it is orientated. Figure 10 shows photographs of the Shielded Cells Facility and the Hot Cell in which RadBall was deployed.

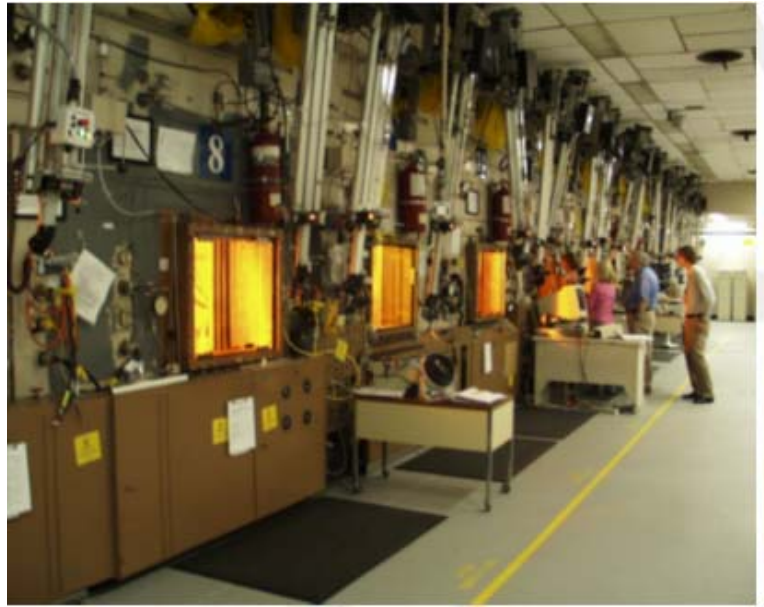

(a)

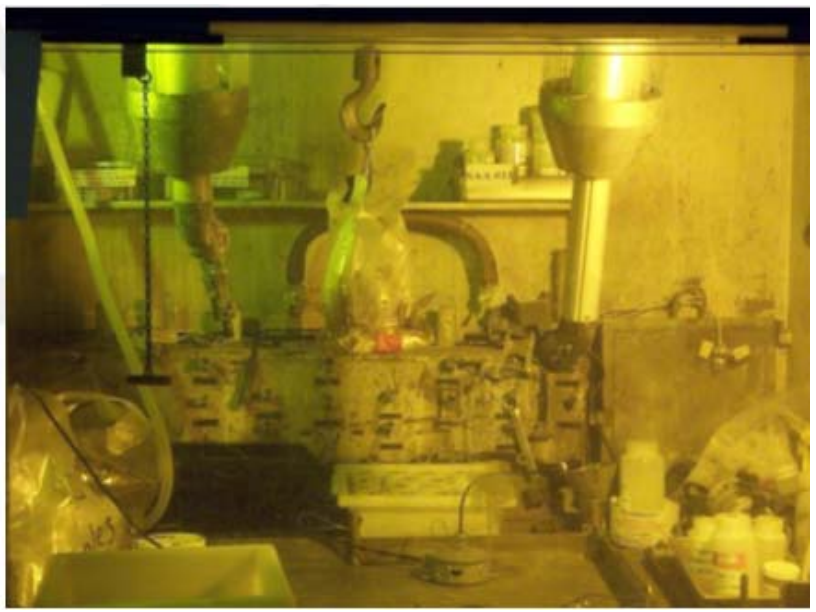

(b)

Figure 10. Photographs of (a) SRNL shielded cells facility, (b) RadBall deployed in hot cell.

An electronic personal dosimeter (EPD) was placed in various shielded cells to gain an estimate of dose rates. The shielded cell with the highest EPD reading was chosen to minimize the amount of time RadBall would need to be exposed in the cell. Figure 11 is a 3D visualization of the chosen hot cell created in Autodesk Inventor ${ }^{\mathrm{TM}}$ (weblink: http://usa.autodesk.com) and is used in conjunction with the radiation results from the deployed RadBall to effectively visualize the origins of the detected radiation.

Swipes were taken in the selected hot cell and ${ }^{60} \mathrm{Co},{ }^{137} \mathrm{Cs},{ }^{154} \mathrm{Eu}$, and ${ }^{241} \mathrm{Am}$ sources were found on the floor and walls. Other isotopes may be present in containers in the cell. The EPD was used to estimate exposure rates at various locations in the selected shielded cell. The center of the floor gave a reading of $0.18 \mathrm{~Gy} \mathrm{hr}^{-1}\left(18 \mathrm{rad} \mathrm{hr}^{-1}\right)$ on the EPD. The EPD read $0.02 \mathrm{~Gy} \mathrm{hr}^{-1}$ (2.0 rad $\left.\mathrm{hr}^{-1}\right)$ at $145 \mathrm{~cm}$ and $0.039 \mathrm{~Gy} \mathrm{hr}^{-1}\left(3.9 \mathrm{rad} \mathrm{hr}^{-1}\right)$ at $91.4 \mathrm{~cm}$ above the floor. It was estimated that at $107 \mathrm{~cm}$ there would be $0.0326 \mathrm{~Gy} \mathrm{hr}^{-1}\left(3.26 \mathrm{rad} \mathrm{hr}^{-1}\right)$.

RadBall N-7-5 was deployed in the hot cell at a raised height of $107 \mathrm{~cm}$ above the floor and left for a 72 hour time period with a $10 \mathrm{~mm}$ collimator. The optical CT scans of N-7-5 showed 21 faint radiation tracks in the RadBall polymer. The coordinates of these tracks were imported into the NNL's in-house software along with the geometry of the hot cell. These combined data sets predicted the location of the radiation sources in the hot cell. The majority of the radiation was deemed to be originating from the floor. These predicted radiation location results are overlaid in Figure 12 on a CAD drawing of the floor and in Figure 13 on a floor view from the 3D 
visualization of the hot cell. RadBall has located 12 closely distributed radiation sources originating from the floor and the bottles located on the right hand side of the tray shown in Figure 12(a). This analysis is consistent with the RadBall pre-deployment EPD investigations which confirmed that the highest radiation doses were on the floor of the hot cell. Although not knowing the isotopes in the bottles to the right of the tray, it is reasonable to assume that the tray on the hot cell floor would have the highest radiological contamination in the hot cell from bottle spills etc. This contamination would be concentrated at the lowest point in the cell.

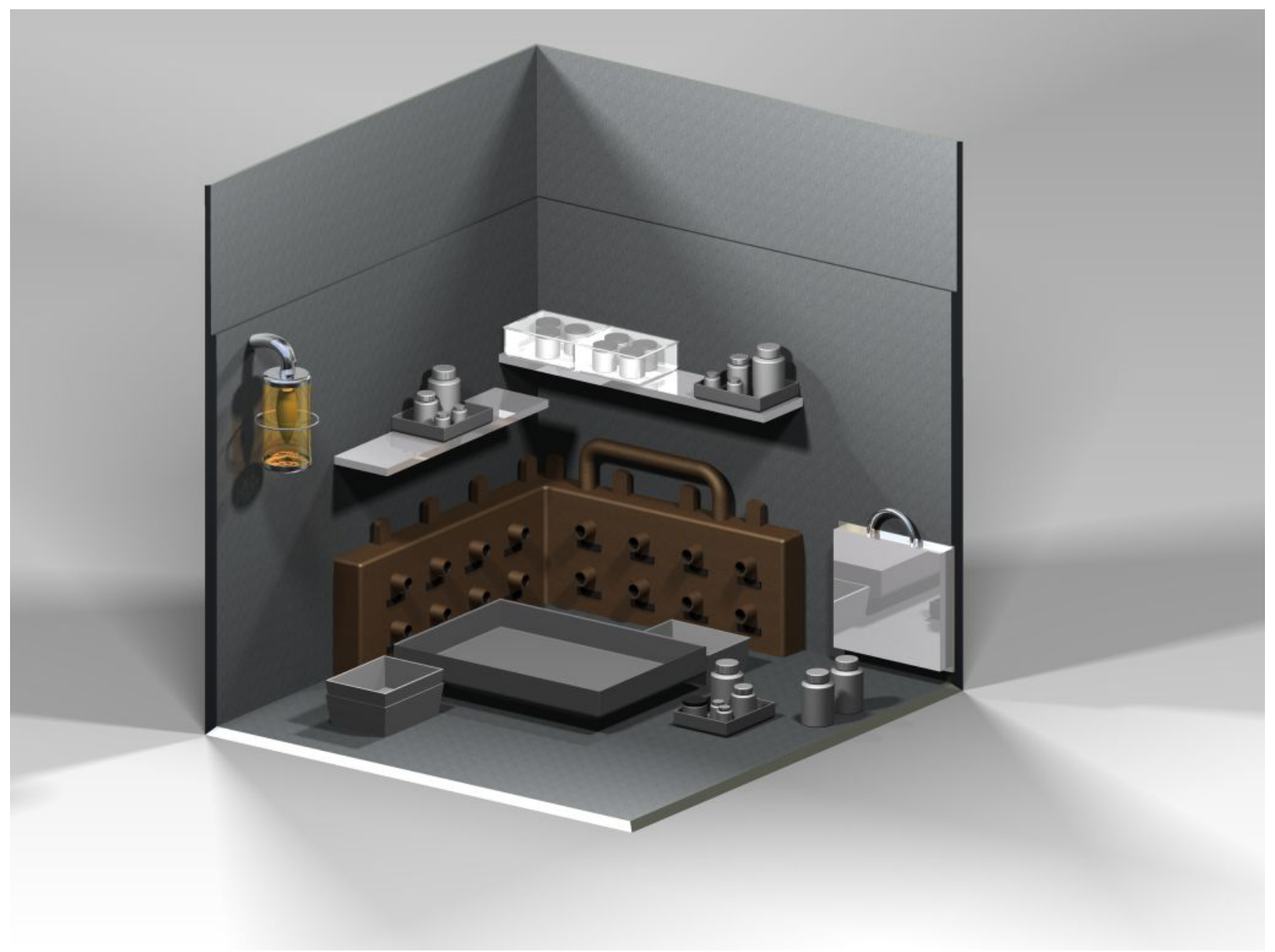

Figure 11. 3D Visualization of the hot cell in the SRNL shielded cells facility (Visualization provided by NNL). 


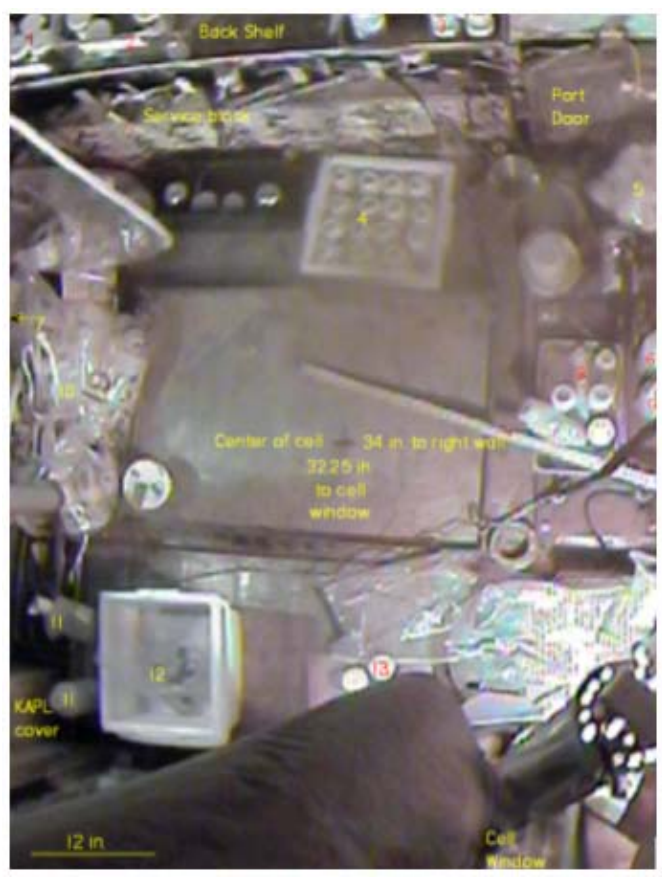

(a)

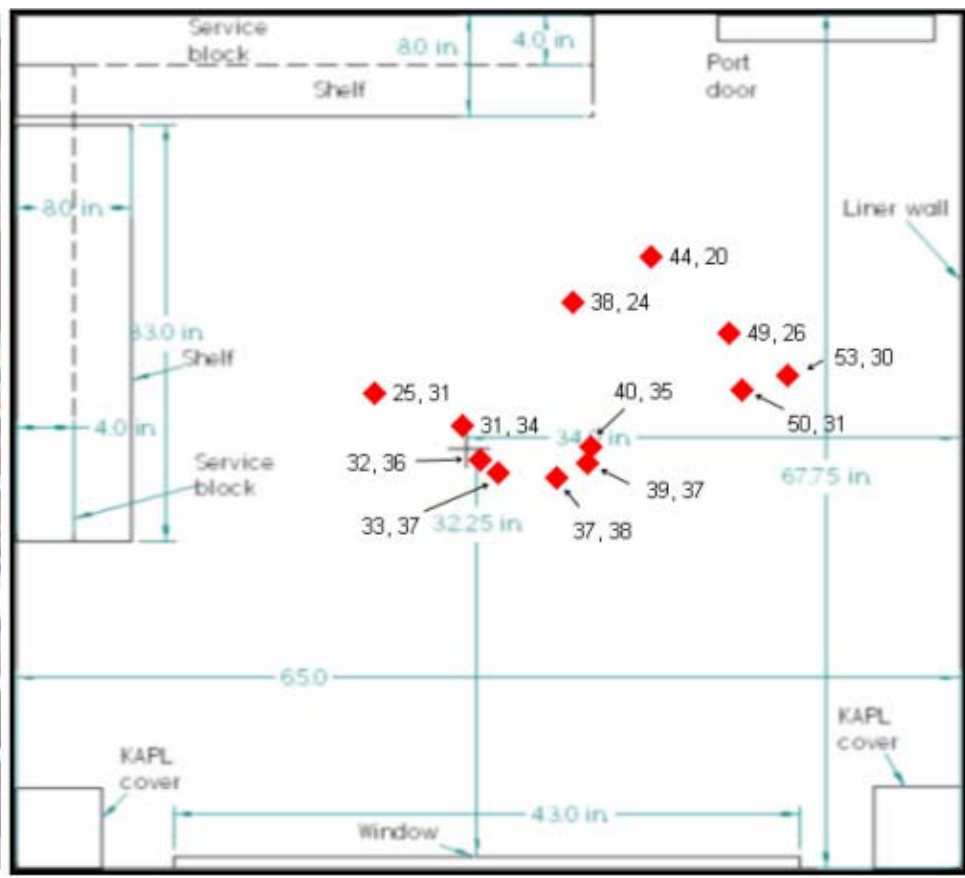

(b)

Figure 12. (a) Photograph of hot cell floor. (b) CAD drawing with located radiation sources (The numbers represent $\mathrm{X}, \mathrm{Y}$ coordinates in inches. The left upper corner represents the origin 0,0 )

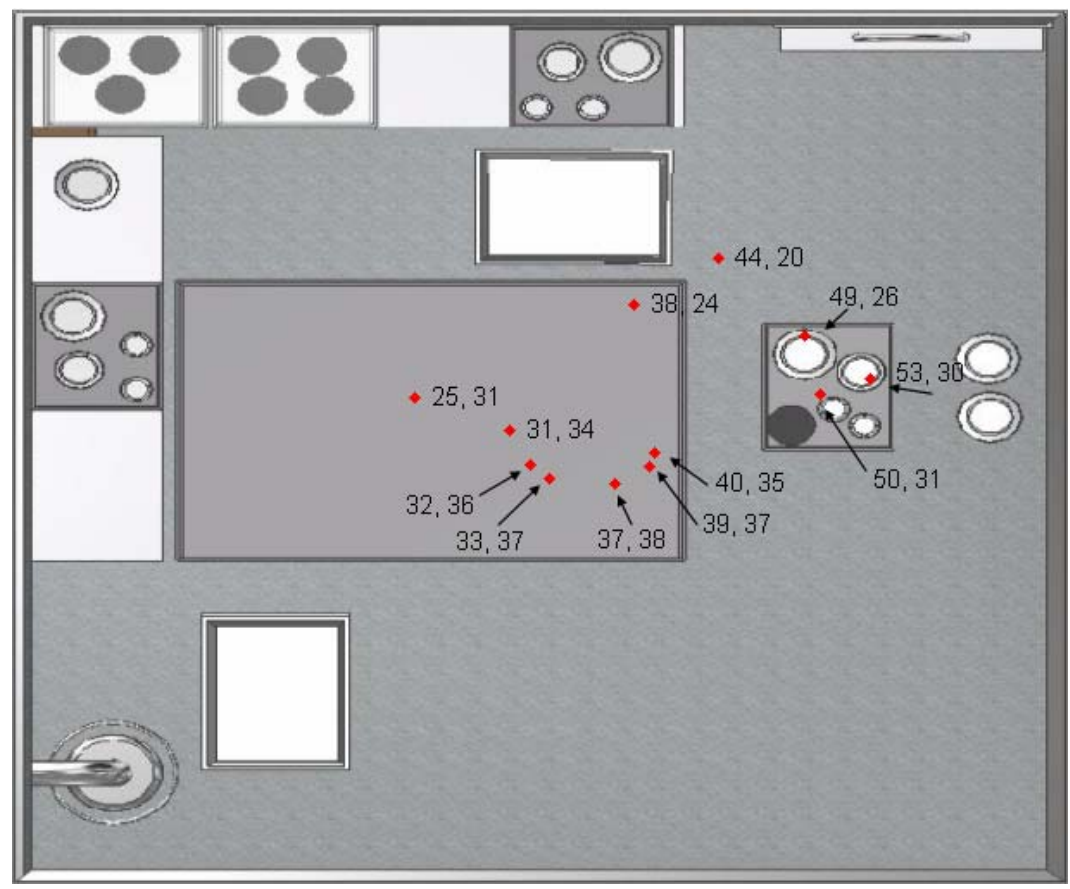

Figure 13. Hot cell floor with located radiation sources (visualization background). (The numbers represent X, Y coordinates in inches. The left upper corner represents the origin 0, 0) 


\subsection{Source locating Software}

When a RadBall is irradiated in its collimator, $\mathrm{x}$ - or gamma- ray photons streaming through the holes in the collimator leave tracks of opacity in the RadBall. Using optical scanning techniques it is possible to digitize the RadBall opacity into 3D scans, which can be supplied as 16-bit signed data cubes consisting of the opacity in each voxel. This opacity is related to the dose deposited in each voxel. In addition to tracks from direct photons entering the collimator holes, there is also opacity from photons passing through the collimator, photons scattered within the collimator shell, and irregularities in the polymer produced during manufacturing. Where the tracks from the collimator holes are more opaque than the background, it is possible to identify tracks in the 3D scans. Using image display software such as ImageJ (website: http://rsbweb.nih.gov/ij/), it is possible to determine coordinates of points on the tracks, which can be used to determine possible source locations of the radiation. To obtain the best resolution these tracks are recorded as coordinate pairs at the start and end of the observable tracks.

The coordinates of tracks in the RadBall scans can be used to determine possible locations of the radiation source using a prototype RadBall imager FORTRAN code that takes these coordinates and back projects the path of the track on to a set of arbitrary quadrilateral surfaces representing the contaminated area surfaces (e.g., walls, floor, ceiling etc.). In this work each surface is defined by four corner points on the same geometric plane. The code consists of three procedures. First, the track coordinate pairs are converted from the RadBall scan frame of reference to that of the contaminated area. This requires two different points on or in the RadBall for which the coordinates are known in both the RadBall and contaminated area frames of reference. This allows any position and rotation of the RadBall to be modeled. Second, for each path defined by a track's coordinate pairs, the intercept points on all the planes given by the modeled surfaces are determined. Third, those points of interception outside of the defined quadrilateral surfaces are rejected.

The code has several limitations in its use that are planned to be removed in a future version based upon a more appropriate development platform than the current FORTRAN. Firstly, the code does not consider which of the track points is closest to the source and thus two possible intercept points are calculated on diametrically opposing surfaces and it is up to the user to determine which are possible. However, by storing the track width at the coordinate points and the location of the collimator hole through which the track enters, it would be possible to select which of these intercepts are the source and give an estimate of the source distribution. Secondly, by estimating the attenuation of the track across the RadBall it should be possible to determine the track's characteristic energies and thus potentially determine the possible radioactive source material. Thirdly, FORTRAN is not easy to couple to $2 \mathrm{D}$ and $3 \mathrm{D}$ imaging resources. It is hoped that the planned development platform will be able to produce a Graphical User Interface that an analyst can use to both display the original 3D scans to simplify track digitization and display the results of its calculations to simplify interpretation.

\subsection{Current development of RadBall accessories for future hot cell deployment}

The deployment of RadBall can be accomplished in different ways depending on the size and characteristics of the contaminated area (e.g., a hot cell that already has a crane available or highly contaminated room that requires the use of a remote control device with sensor and video equipment to position RadBall). SRNL has designed a harness, locator system, and robot for 
RadBall deployment.

\subsubsection{RadBall harness}

A harness has been designed at SRNL for future RadBall deployments into hot cells when a crane or manipulator is available (Figure 14). The harness has been certified, tested and approved to lift $100 \mathrm{~kg}$. It can hold RadBall right-side-up or upside-down depending on the deployment scenario.

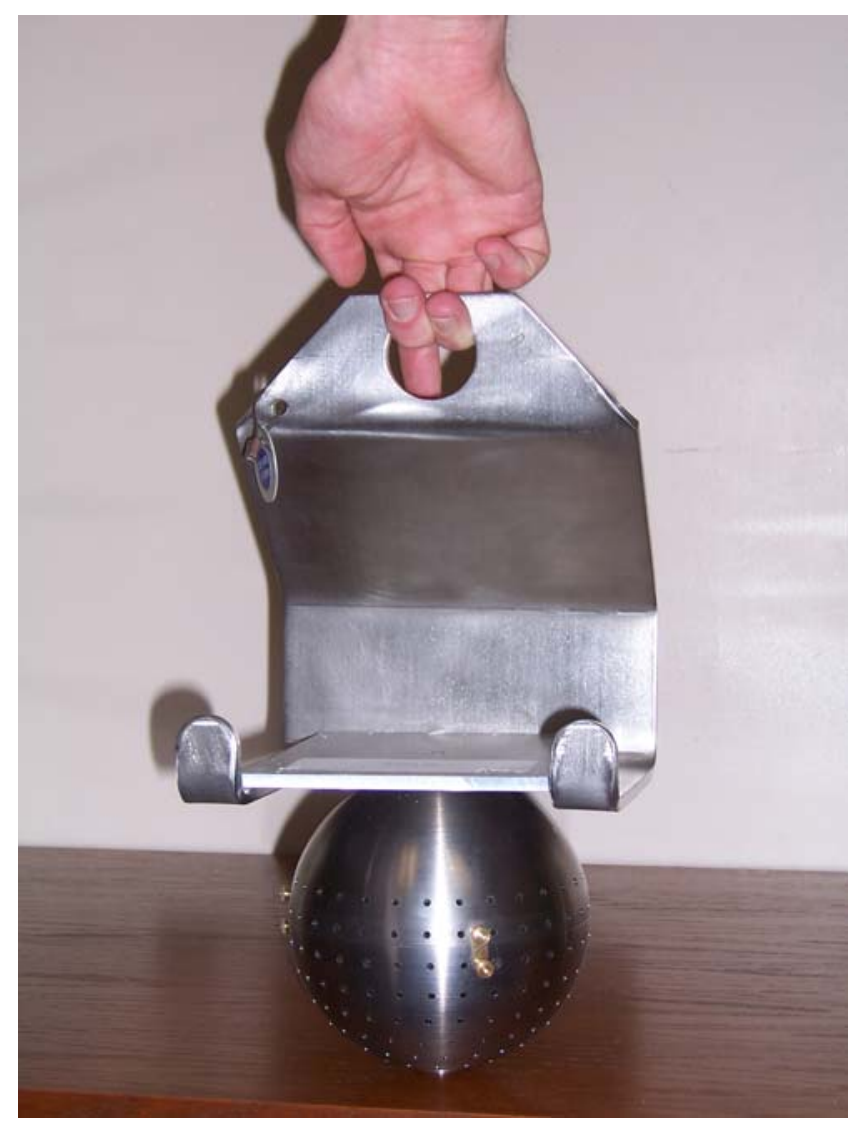

Figure 14. Harness for RadBall deployment into hot cells using a crane or manipulator

(The harness was designed by Ronald W. Blessing).

\subsubsection{SRNL's Position and Orientation Determination System (PODS)}

Since RadBall is a passive 3-D radiation detection device and contains no electronics, it cannot determine its location or orientation within a contaminated room. SRNL has been developing a proof of concept device that will determine the RadBall's location and orientation within a room [Position and Orientation Determination System (PODS-patent pending)]. For the proof of concept, the working parameters are a nine meter cube room with no obstructions, and flat floors. PODS must run on batteries long enough to determine the location and orientation and then save the data to nonvolatile memory. The electronic portion of the system has been designed. Major PODS components include an embedded computer, stepper motor, ultrasonic 
sensor, digital compass, power supply and battery (Figure 15 and Figure 16).

The concept of operation is as follows. After a predetermined delay, the PODS computer system takes ultrasonic distance readings as the stepper motor moves in very small steps. These data indicate the distance from the wall to the RadBall and therefore locates it within the room. In addition, a reading from the digital compass determines which wall the RadBall orientation line is pointing toward. This information is used along with the RadBall data in order to map the detected radiation spots onto the walls, floor and ceiling. The mechanical structure holds all of the parts including the RadBall, stepper motor, ultrasonic sensor, and digital compass. The challenge for this structure was to provide, as much as possible, an unobstructed view for the ultrasonic sensor and the RadBall. SRNL has developed software to communicate with the stepper motor, ultrasonic sensor and digital compass in order to produce the desired results.

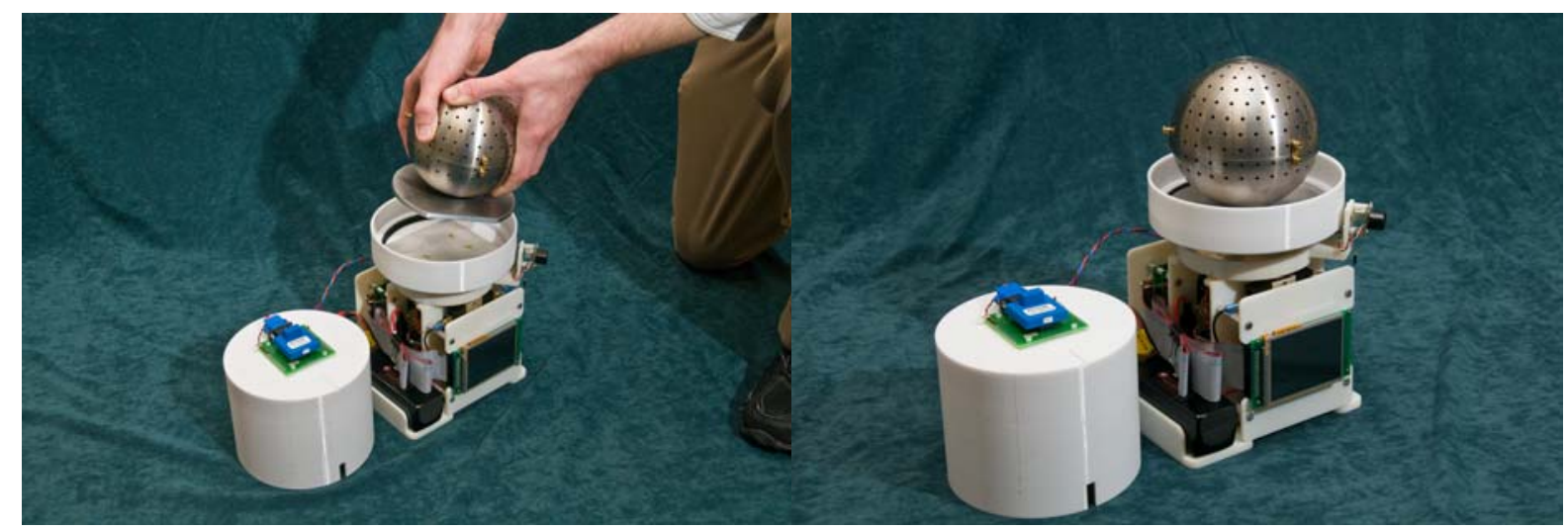

Figure 15. Placing RadBall into PODS

(PODS was designed by John R. Gordon and Larry J. Harpring; patent pending) 


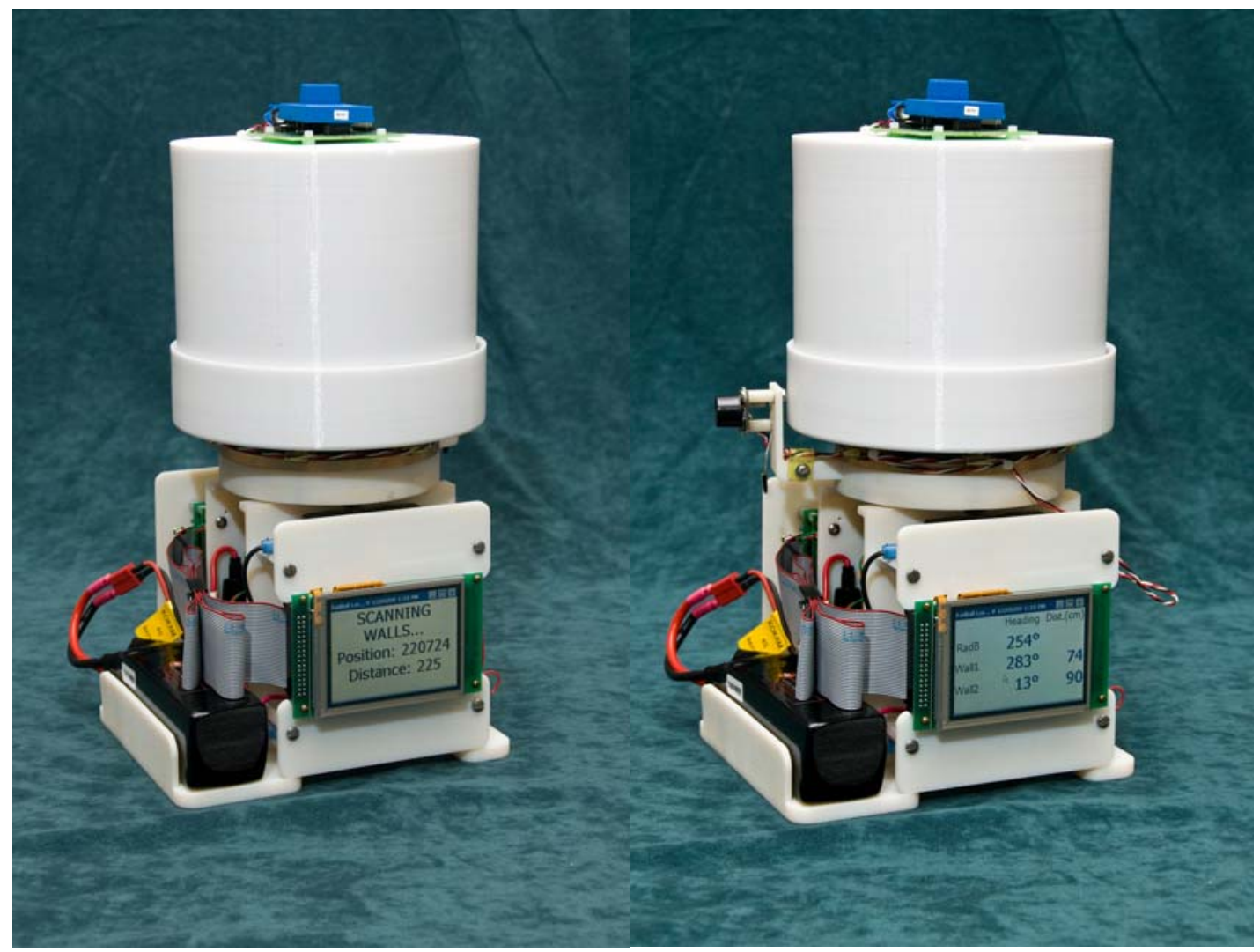

Figure 16. PODS measuring distances - scanning surrounding walls.

\subsubsection{RadBall PODS current operational sequence}

- Upon turning on the power switch, the device software automatically runs and begins the count down. Currently, the count down time is hard coded.

- Once the count down finishes, the device moves the ultrasonic sensor (US) to the home position.

- From the home position, the US is stepped one degree and then takes a distance measurement. The US must send three consecutive identical readings before the number is accepted as valid.

- $\quad$ The stepping is continued for 360 degrees.

- During the 360 steps, the software is constantly monitoring the distance data to determine the angle to the closest wall. The US range is $20-765 \mathrm{~cm}$ or 0.65 to 25 feet.

- The US uses a cone shaped sound wave to search for objects. The leading edge of this cone is what will first find the closest wall, and the trailing edge of the cone is the last part to see the closest wall. As the cone passes by the closest wall, it moves a specific angle. The point on the wall perpendicular to the sensor is simply half of this angle. This is the distance reported by the software.

- After the scan, the US is moved to point to the closest wall and its compass angle and distance are displayed on the LCD display along with the compass angle of RadBall orientation line. The US then moves to a wall 90 degrees from this angle, reads its 
distance and display the compass angle and distance. Finally, the US returns to point at the closest wall.

\subsubsection{RadBall PODS - Path forward}

The list below consists of items that need to be completed:

- Add the offset, from the center of the RadBall to the face of the ultrasonic sensor, to all distance measurements

- Determine the angle difference where identical closest points cannot be part of the same wall (i.e., RadBall was deployed equidistant from two walls)

- Save all data to flash memory (SD Card)

- Test accuracy of ultrasonic sensor at its maximum range (765 cm or 25 feet)

- Increase count down delay to the desired hard coded value or add a feature to select one of several hard coded options (i.e., 30 min, 15 min, 10 min, 5 min, 1 min, 30 sec, 15 sec,, etc.)

- Develop an algorithm to detect if the home sensor is pointed toward the closest wall (i.e., the distance at the start of the scan is equal to the distance at the end of the scan and equal to the closest wall). This is necessary to more accurately determine the angle of the closest wall in the scenario.

\subsection{3. $\quad$ Remote control device}

The RadBall and PODS could be used in conjunction with a robot as shown in Figure 17 and Figure 18. The robot recommended at SRNL is relatively simple and uses a set of self-contained tracks for locomotion produced by Inuktun Services Limited (website: http://www.inuktun.com/). These tracks have the following characteristics:

- Weight: 70 lbs

- Payload: $200 \mathrm{lbs}$

- Max Speed: 30 feet/min

- Tethered Range: 300 feet

- Water Proof: 100 foot depth

These tracks are quickly adaptable into numerous configurations for deployment into buildings, tanks, pipes, and other locations. Robots utilizing these tracks are generally low center of gravity, highly maneuverable, skid steer type vehicles that are controlled via a tethered connection to a custom control interface. These robots can be configured to carry lights and cameras for navigation or inspection along with their other payload, which is normally some type of instrumentation package. Various designs of a system composed of a RadBall, PODS, and robot are being considered at SRNL for RadBall deployment as illustrated in Figure 19. 


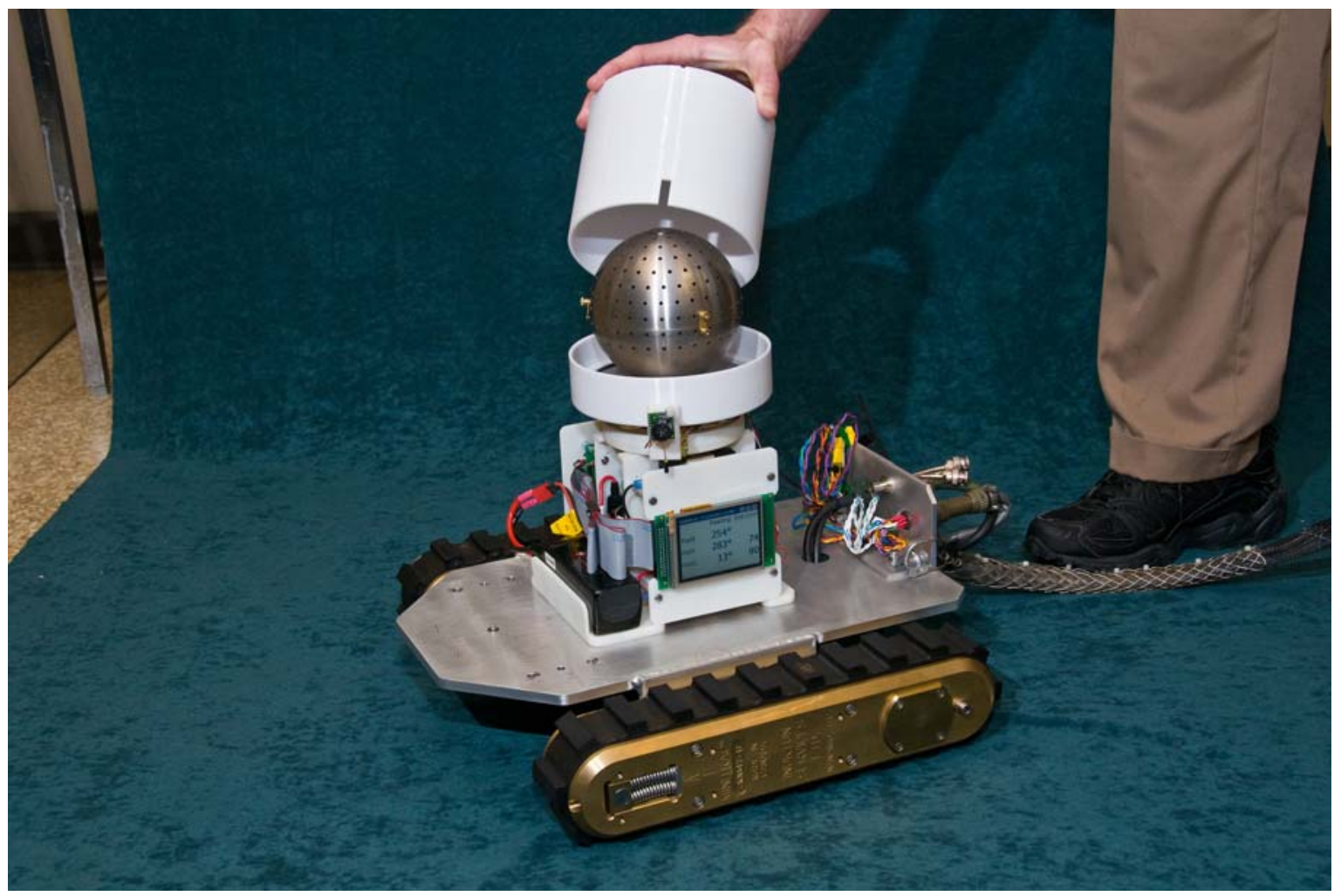

Figure 17. Placing RadBall into PODS placed on top of a remote controlled device.

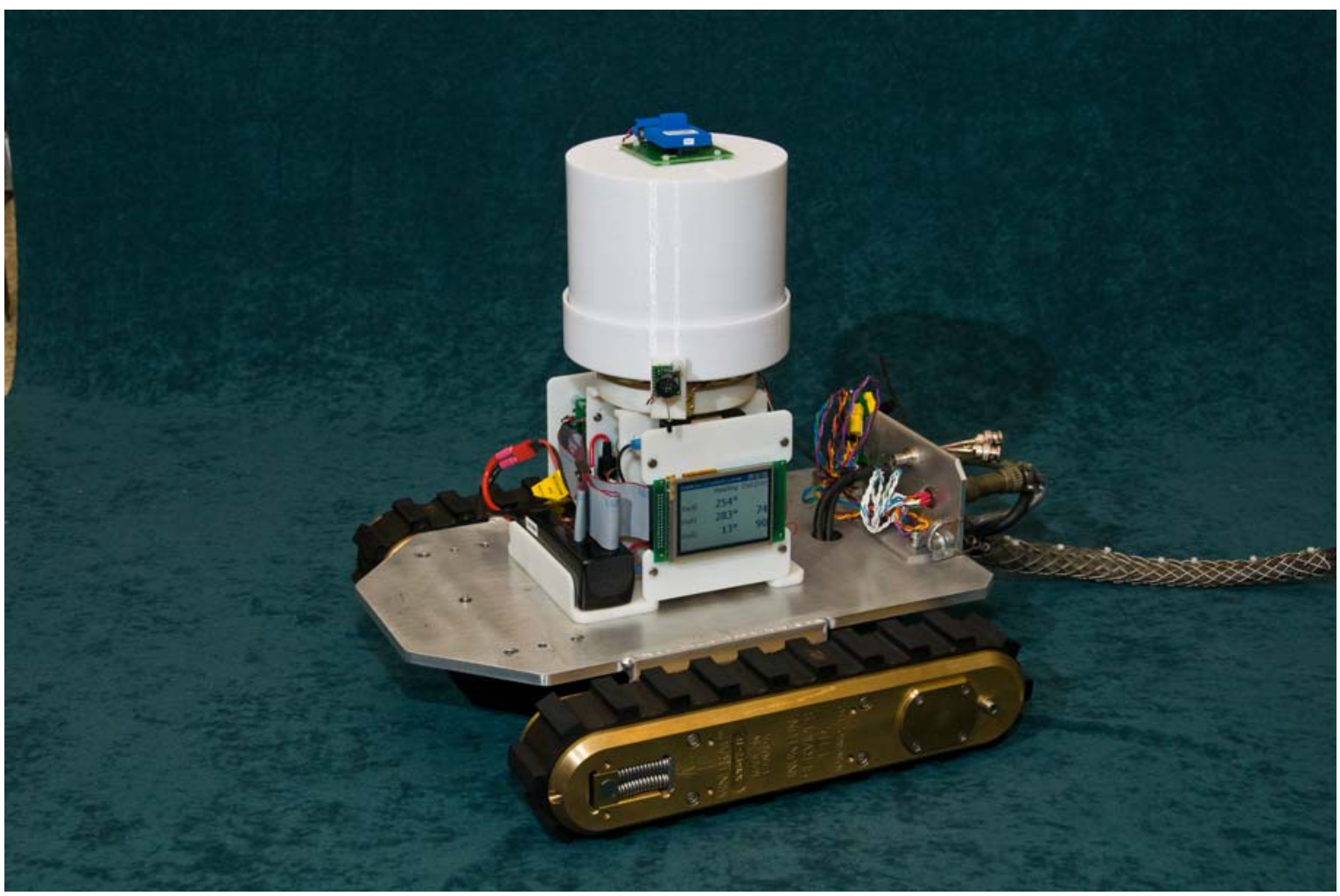

Figure 18. Whole System: RadBall, PODS, and robot. 


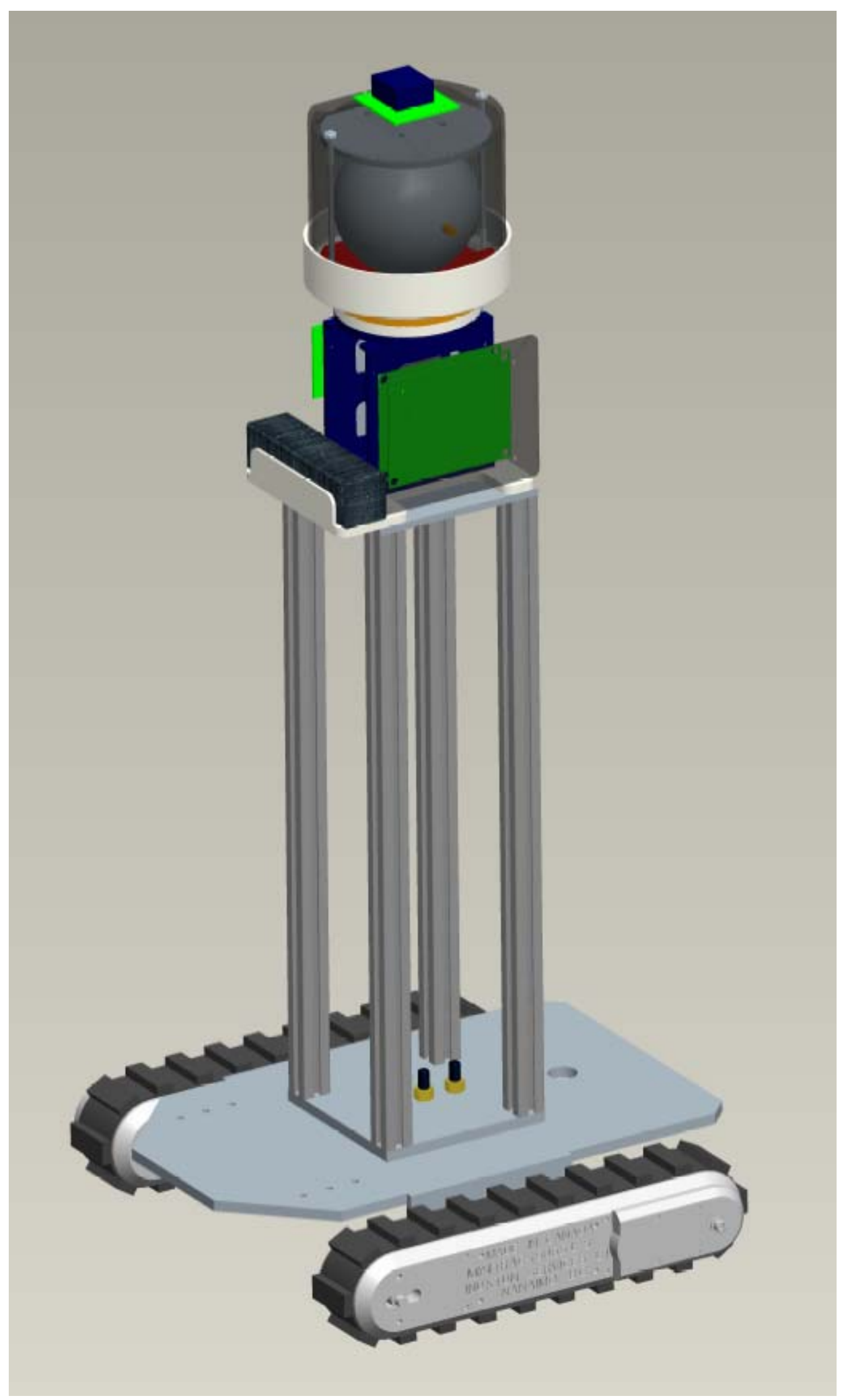

Figure 19. Possible design of a complete RadBall deployment system (Designed by John R. Gordon) 


\section{DISCUSSION AND CONCLUSIONS}

The RadBall technology has responded well during the HPICL calibration facility experiments. Radiation tracks were visible in all of the 45 experiments and demonstrated that the RadBall technology is sensitive to ${ }^{60} \mathrm{Co},{ }^{137} \mathrm{Cs}$ and ${ }^{241} \mathrm{Am}$ sources over the radiation range of 0.5 to $8 \mathrm{~Gy}$ (Appendix $\mathrm{A}^{1,2}$ ). Based on the ability to produce scan data with a suitable contrast between radiation tracks and the background of the RadBall polymer, the target dose for the RadBall is 1.5 - 3.0 Gy and the optimum collimation thickness is $10 \mathrm{~mm}$.

The HPICL Calibration experiments have demonstrated that the RadBall has the ability to locate radiation point sources with an accuracy of $1 \%$ over a distance of $100 \mathrm{~cm}$. Further work is ongoing to investigate whether the RadBall technology is able to characterize more complex radiation sources.

Upon completion of the calibration facility testing, the RadBall technology was deployed in a hot cell in the SRNL Shielded Cells Facility. RadBall located the strongest radiation doses originating from the floor of the hot cell and the location of these radiation sources has been displayed on a 3D visualization of the hot cell. This represents the first successful hot cell deployment of the RadBall and a further step in demonstrating NNL's unique radiation mapping service with the ability to be remotely deployed with no electrical supplies into difficult to access areas and locate and quantify radiation hazards.

RadBall can be deployed in different ways depending on the size and characteristics of the contaminated area. Some deployments might involve a crane and/or hand manipulators. Other deployments might include highly contaminated rooms with limited access and/or visibility; thus, using remote control devices with sensor and video equipment might be required. SRNL has been designing RadBall accessories for these types of deployments (a harness, PODS, and robot).

\section{FURTHER WORK}

Future milestones involve the testing of a robot for remote RadBall deployment into highly contaminated facilities, portable optical CT scanner development for field deployment, and

\footnotetext{
1 Some of the images shown in Appendix A contain artifacts (e.g., N2-1) that may be the result of a defect in the PRESAGE polymer.

2 The dates indicated the time when the output was analyzed in the Image J Software.
} 
RadBall deployment at another DOE facility using the robot and portable scanner to promptly obtain visualizations of the contaminated hot cell or glove box. Further software and visualization development will also take place to provide an enhanced, texturized output image to better visually interpret the sources of radiation in the deployed environment (e.g., similar to map contours).

\section{ACKNOWLEDGEMENTS}

The authors of this report would like to thank the US DOE, Office of Environmental Management, Technology Innovation and Development (EM-30) for the funding associated with the testing and development of the RadBall technology (Contract No. DE-AC09-08SR22470). The authors would also like to thank staff members of Savannah River Nuclear Solutions' Health Physics Instrument Calibration Laboratory, Shielded Cells, and Robotics, Remote \& Specialty Equipment for their assistance with this project.

\section{REFERENCES}

1 Stanley SJ, RadBall: A small deployable polymer based radiation mapping device for locating, quantifying and characterising contamination in a given cell/glovebox/room, Nuclear Future, 4(6), pp 302-308, 2008.

2 Doran SJ, Stanley SJ, Jenneson PM, Prott E, Adamovics J, RADBALLTM: a new field for 3D dosimetry, DOSGEL: The 5th International Conference on Radiotherapy Gel Dosimetry, University of Heraklion, Crete, 2008.

3 Stanley SJ, RadBall ready to roll, World Nuclear News (www.world-nuclearnews.org), June, 2008.

4 Guo P, Adamovics J and Oldham 2006 M Simple 3D validation experiments for PRESAGE ${ }^{\mathrm{TM}}$ /optical-CT dosimetry Institute of Physics Publishing Journal of Physics: Conference Series 56187-190.

5 Guo P, Adamovics J and Oldham M 2006 Quality assurance in 3D dosimetry by optical-CT Institute of Physics Publishing Journal of Physics: Conference Series 56 191-194.

6 Guo P, Adamovics J and Oldham M 2006 Investigation of the dosimetric characteristics of PRESAGE ${ }^{\mathrm{TM}}$ Institute of Physics Publishing Journal of Physics: Conference Series 56 207-210.

7 Oldham M 2006 3D dosimetry by optical-CT scanning Institute of Physics Publishing Journal of Physics: Conference Series 56 58-71. 
This Page Intentionally Left Blank 
APPENDIX A. DATA ANALYSES 


\section{RadBall data analysis sheet}

Experiment Number

Data Number:

Source:

Total Dose:

Collimation thickness:

Distance to source:

Completed by:

Date:

Visible Tracks:
Phase 1 Exp 1 Calibration Facility

N1-2

Cs-137

$0.5 \mathrm{~Gy}$

$5 \mathrm{~mm}$

$1000 \mathrm{~mm}$

Steve Stanley (NNL)

October $28^{\text {th }} 2009$

Yes

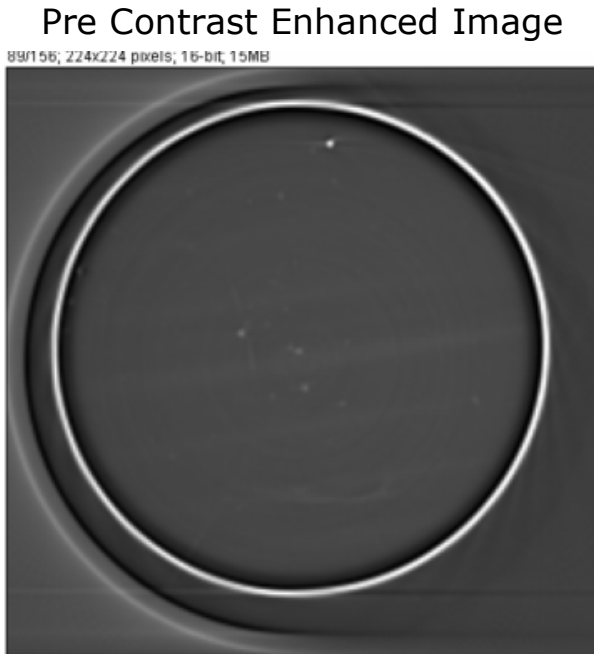

Pre Contrast Enhanced Pixel Histogram

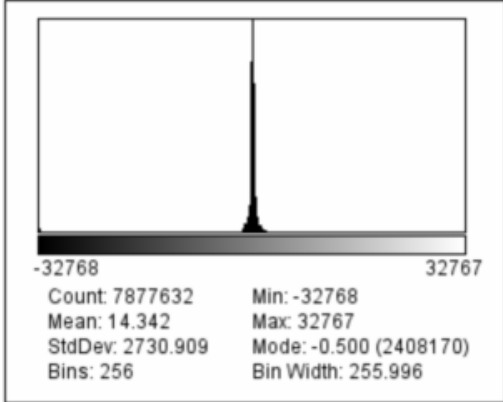

Post Contrast Enhanced Image

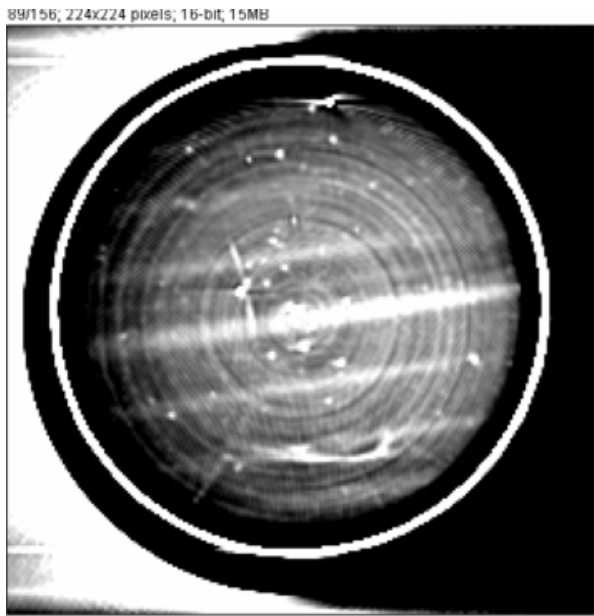

Post Contrast Enhanced Pixel Histogram

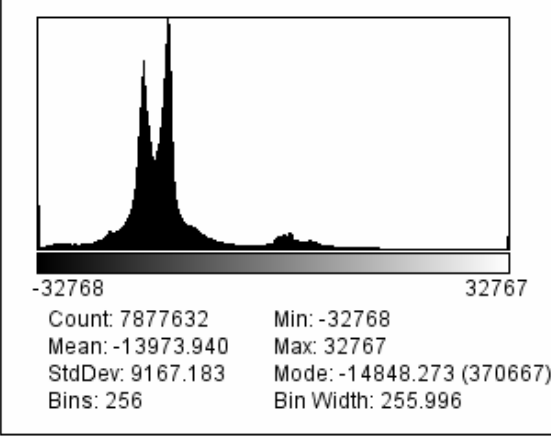

Plot Through Radiation Tracks

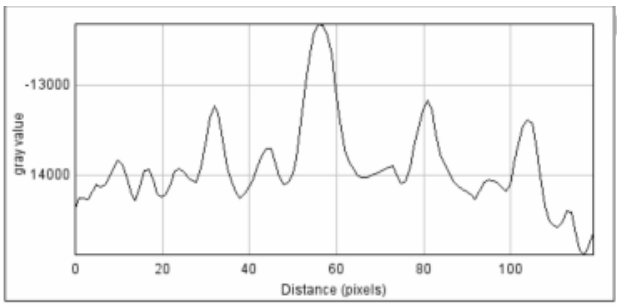




\section{RadBall data analysis sheet}

Experiment Number

Data Number:

Source:

Total Dose:

Collimation thickness:

Distance to source:

Completed by:

Date:

Visible Tracks:
Phase 1 Exp 2 Calibration Facility

N1-3

Cs-137

$1.0 \mathrm{~Gy}$

$5 \mathrm{~mm}$

$1000 \mathrm{~mm}$

Steve Stanley (NNL)

October $28^{\text {th }} 2009$

Yes
Pre Contrast Enhanced Image

93/157; $224 \times 224$ pixels; 16 -bit; $15 \mathrm{MB}$

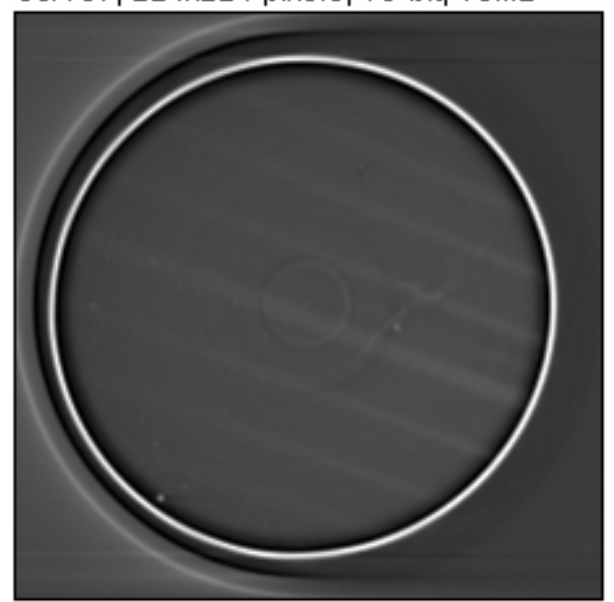

Pre Contrast Enhanced Pixel Histogram

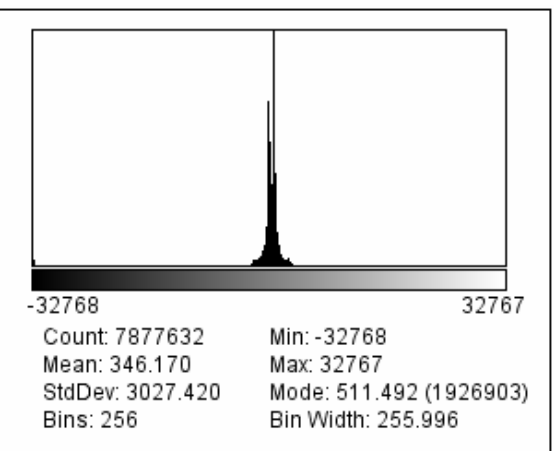

Post Contrast Enhanced Image 224×224 pixels; 16-bit; 98K

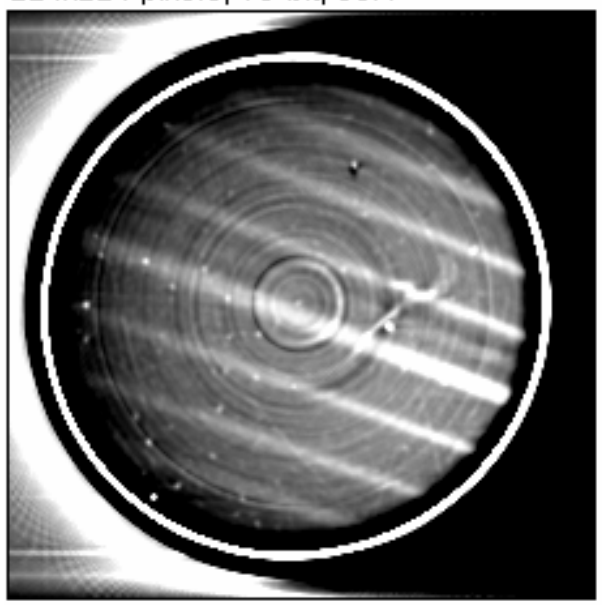

Post Contrast Enhanced Pixel Histogram

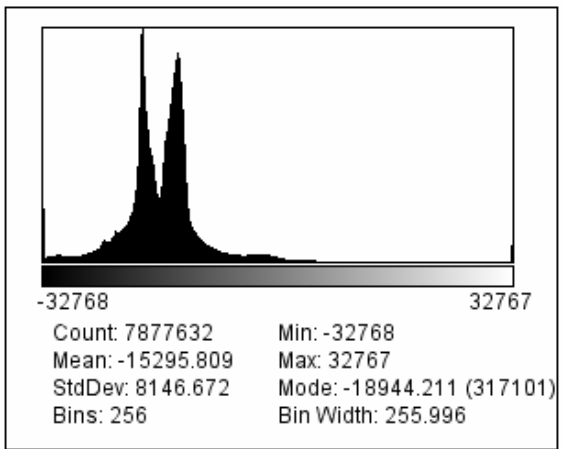

Plot Through Radiation Tracks

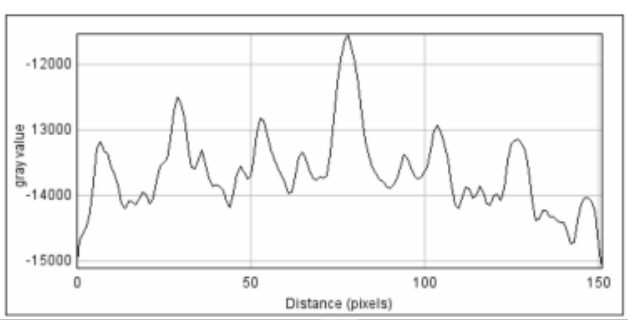




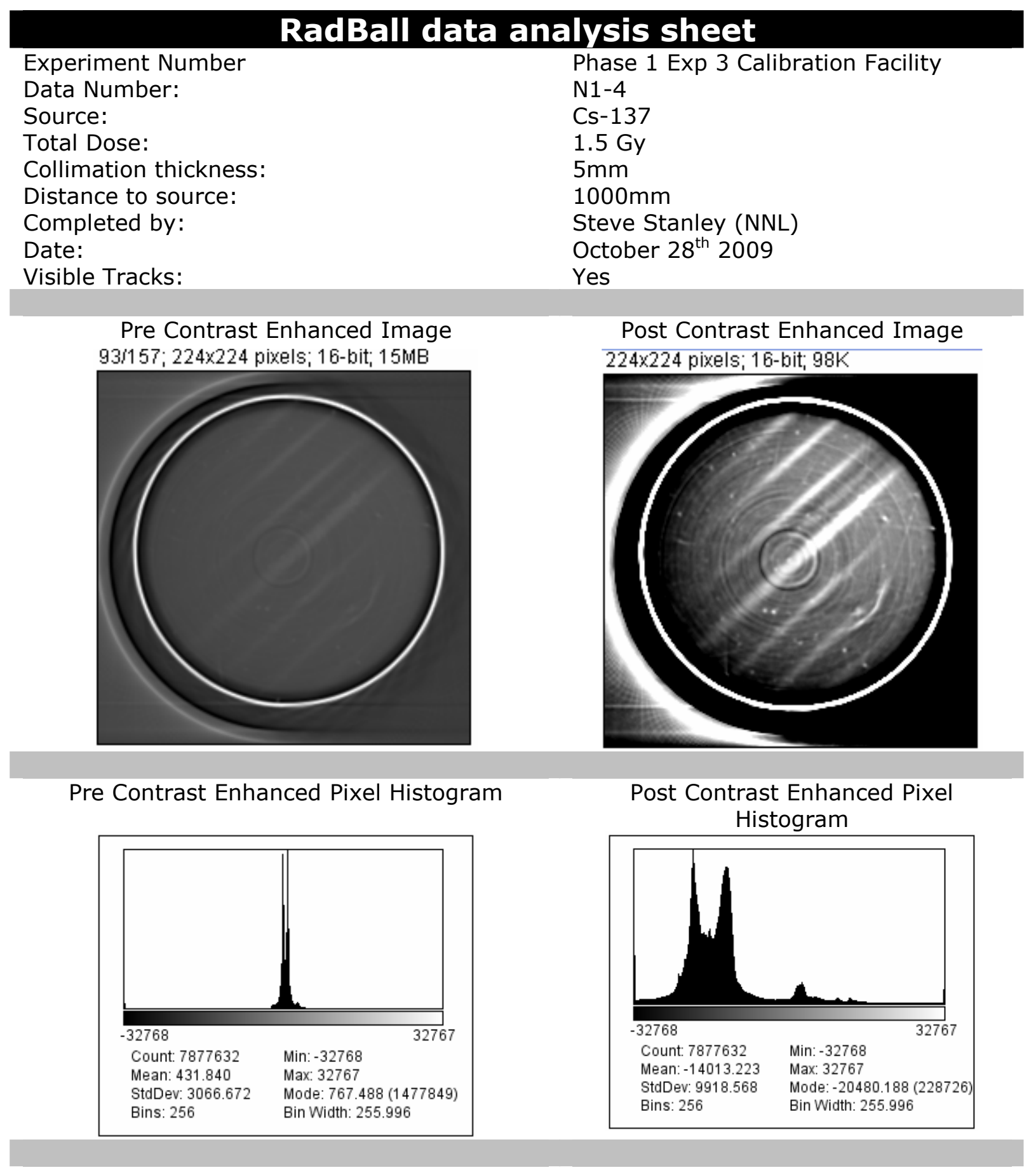

Plot Through Radiation Tracks

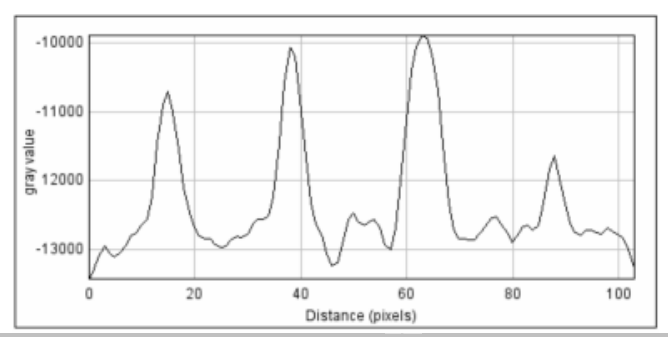




$\begin{array}{ll} & \text { RadBall data analysis sheet } \\ \text { Experiment Number } & \text { Phase } 1 \text { Exp } 4 \text { Calibration Facility } \\ \text { Data Number: } & \mathrm{N} 1-5 \\ \text { Source: } & \mathrm{Cs}-137 \\ \text { Total Dose: } & 2.0 \mathrm{~Gy} \\ \text { Collimation thickness: } & 5 \mathrm{~mm} \\ \text { Distance to source: } & 1000 \mathrm{~mm} \\ \text { Completed by: } & \text { Steve Stanley (NNL) } \\ \text { Date: } & \text { October } 28^{\text {th }} 2009 \\ \text { Visible Tracks: } & \text { Yes }\end{array}$

Pre Contrast Enhanced Image 900157; 224×224 pixels; 16-bit; $15 \mathrm{MB}$

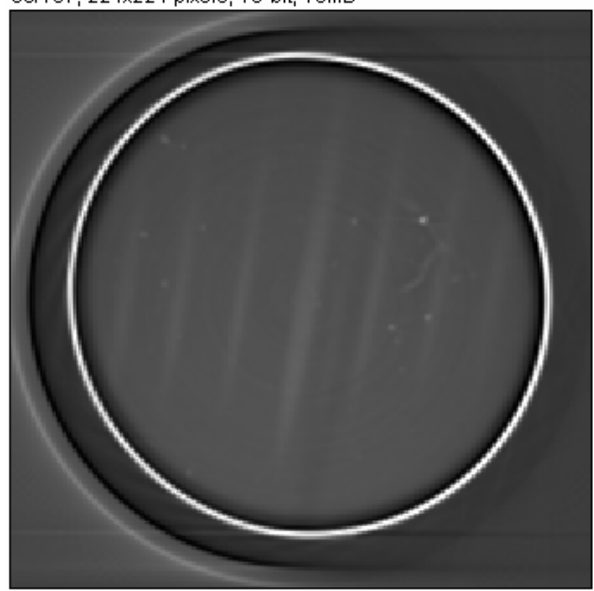

Pre Contrast Enhanced Pixel Histogram

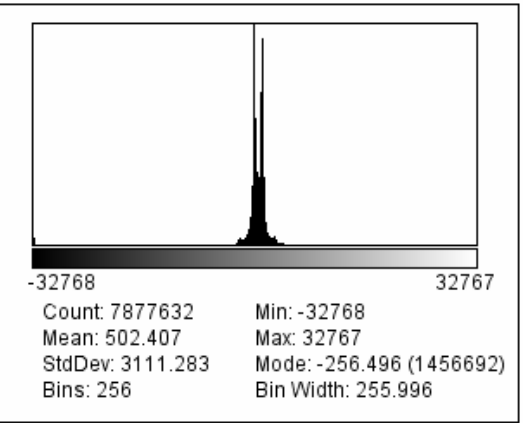

Post Contrast Enhanced Image 90:157: 224×224 pixels; 16-bit, 15MB

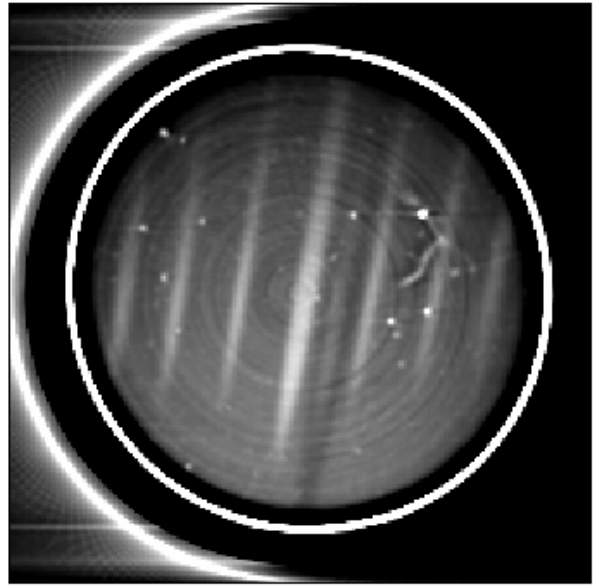

Post Contrast Enhanced Pixel Histogram

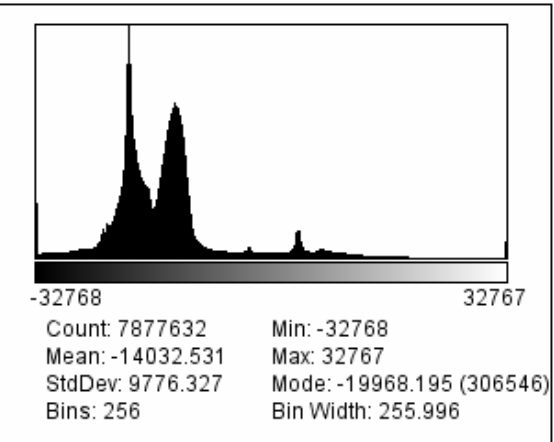

Plot Through Radiation Tracks

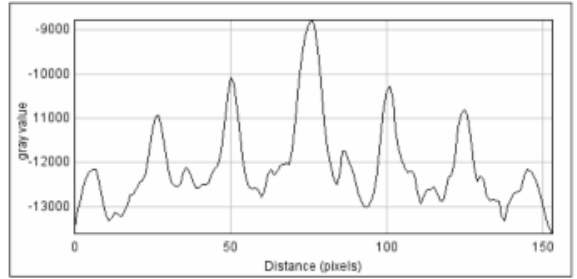




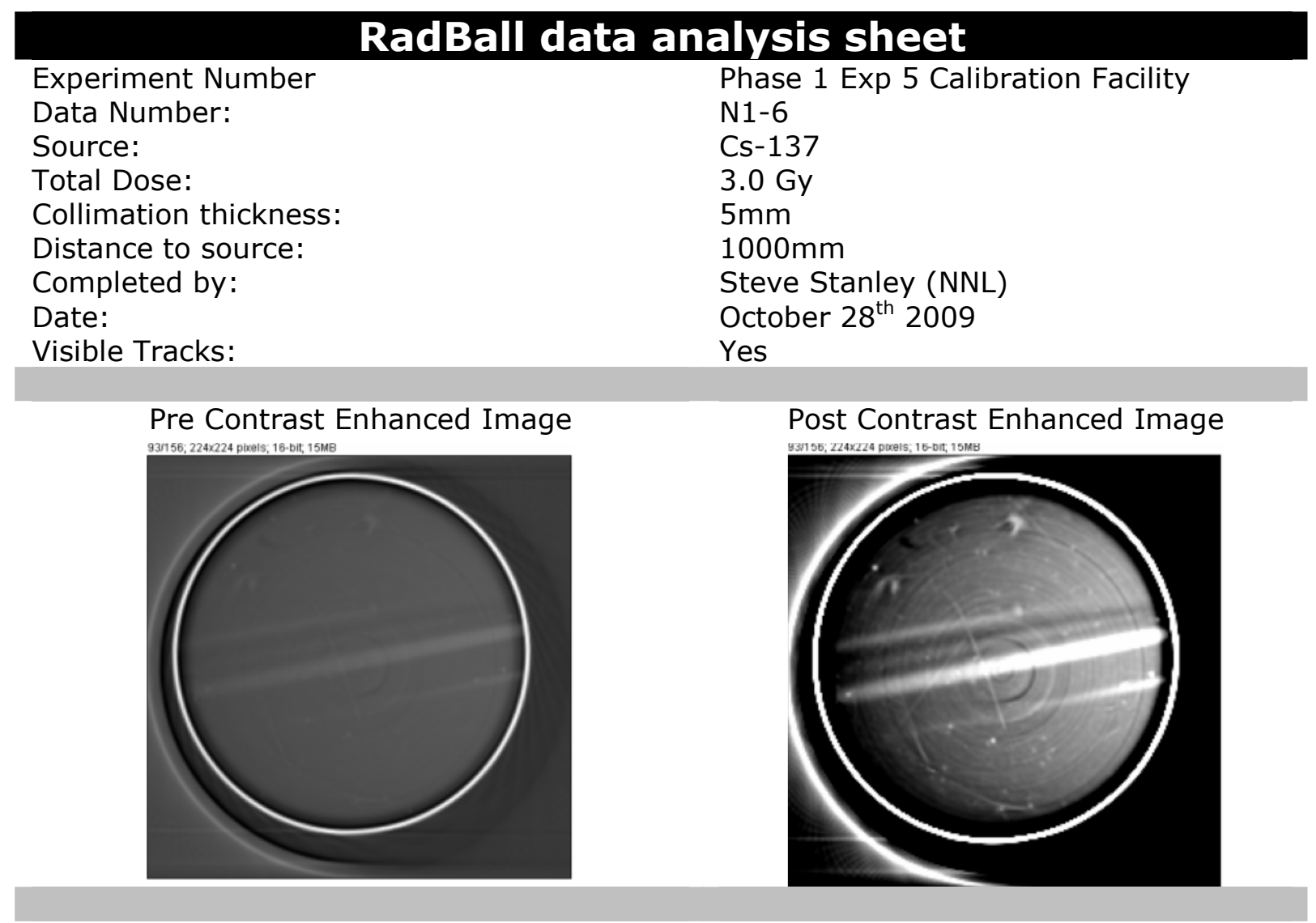

Pre Contrast Enhanced Pixel Histogram

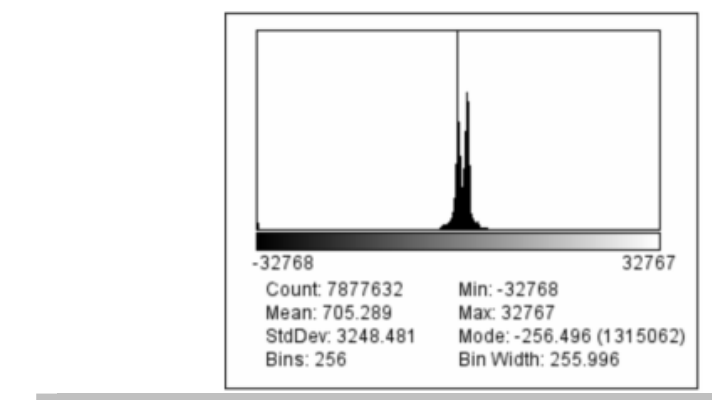

Post Contrast Enhanced Pixel Histogram

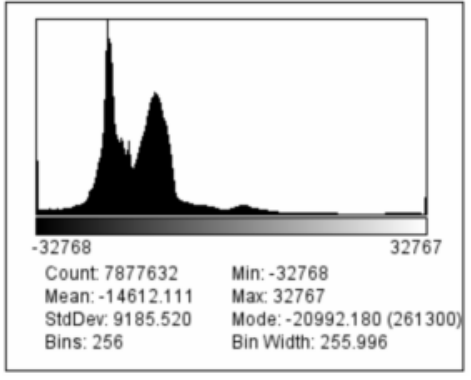

Plot Through Radiation Tracks

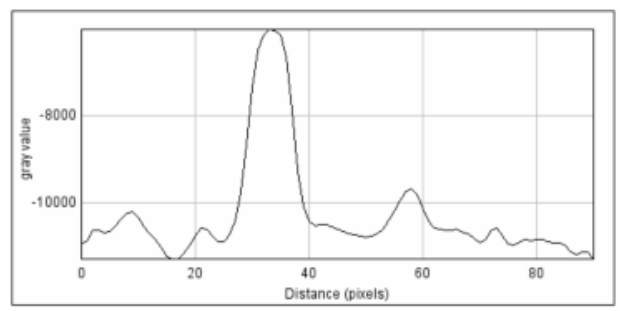




$\begin{array}{ll} & \text { RadBall data analysis sheet } \\ \text { Experiment Number } & \text { Phase } 1 \text { Exp } 6 \text { Calibration Facility } \\ \text { Data Number: } & \mathrm{N} 2-4 \\ \text { Source: } & \mathrm{Cs}-137 \\ \text { Total Dose: } & 5.0 \mathrm{~Gy} \\ \text { Collimation thickness: } & 5 \mathrm{~mm} \\ \text { Distance to source: } & 1000 \mathrm{~mm} \\ \text { Completed by: } & \text { Steve Stanley (NNL) } \\ \text { Date: } & \text { October } 28^{\text {th }} 2009 \\ \text { Visible Tracks: } & \text { Yes }\end{array}$
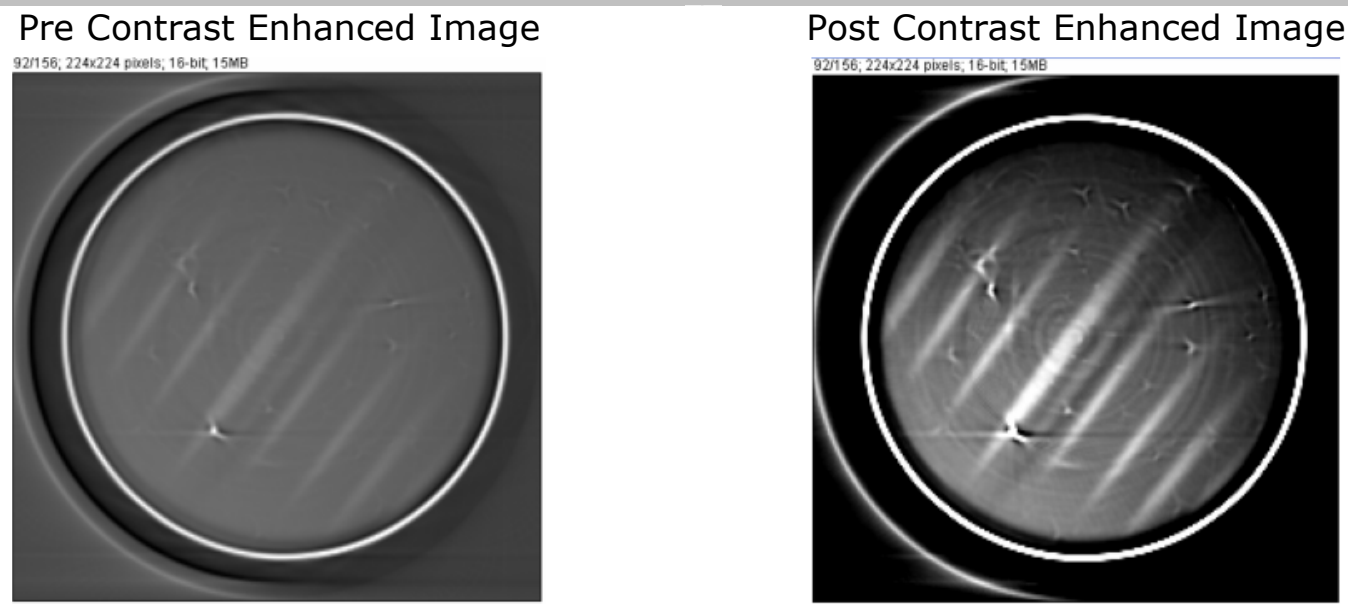

Pre Contrast Enhanced Pixel Histogram

Post Contrast Enhanced Pixel Histogram
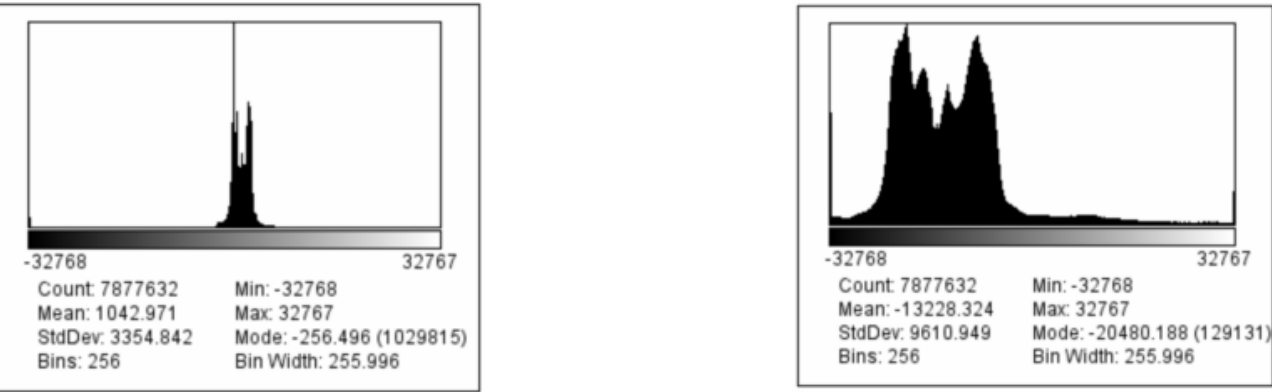

Plot Through Radiation Tracks

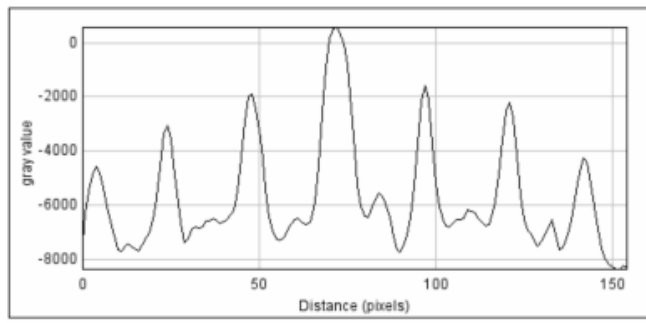




\section{RadBall data analysis sheet}

Experiment Number

Data Number:

Source:

Total Dose:

Collimation thickness:

Distance to source:

Completed by:

Date:

Visible Tracks:
Phase 1 Exp 7 Calibration Facility

N2-1

Co-60

$0.5 \mathrm{~Gy}$

$5 \mathrm{~mm}$

$1000 \mathrm{~mm}$

Steve Stanley (NNL)

October $28^{\text {th }} 2009$

Yes
Pre Contrast Enhanced Image

107/157; 224×224 pixels; 16 -bit; $15 \mathrm{MB}$

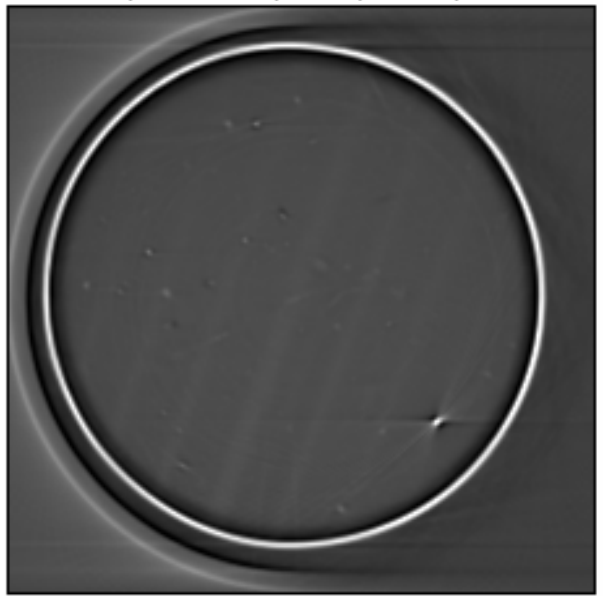

Pre Contrast Enhanced Pixel Histogram

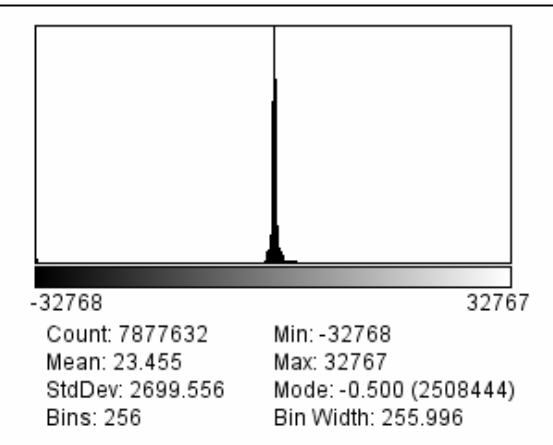

Post Contrast Enhanced Image

224×224 pixels; 16 -bit; $98 \mathrm{~K}$

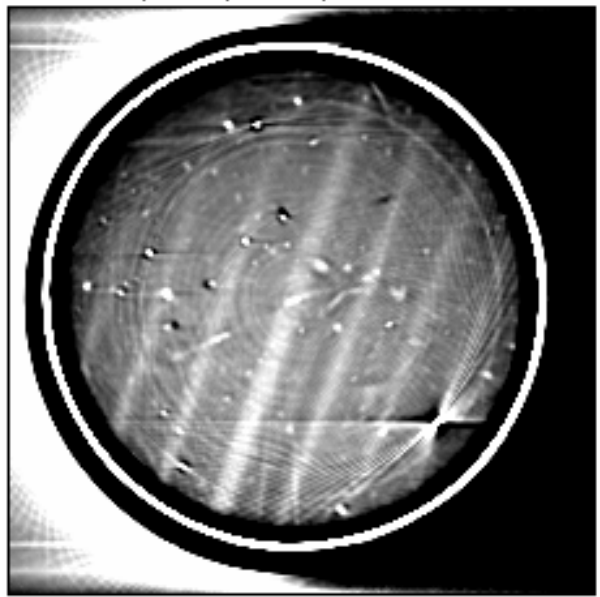

Post Contrast Enhanced Pixel Histogram

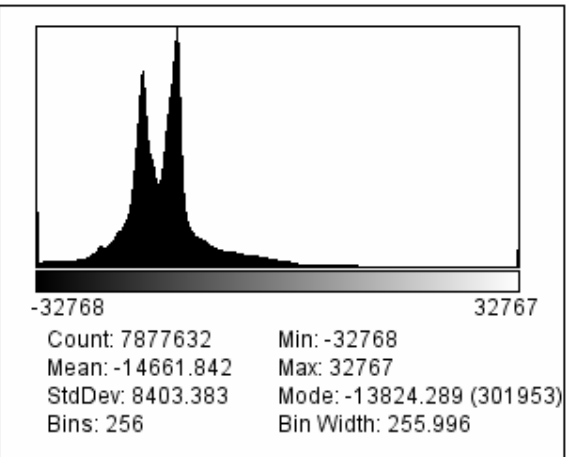

Plot Through Radiation Tracks

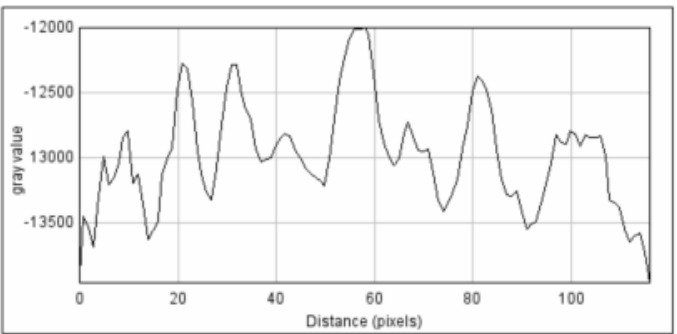




\section{RadBall data analysis sheet}

Experiment Number

Data Number:

Source:

Total Dose:

Collimation thickness:

Distance to source:

Completed by:

Date:

Visible Tracks:
Phase 1 Exp 8 Calibration Facility

N2-2

Co-60

$1.0 \mathrm{~Gy}$

$5 \mathrm{~mm}$

$1000 \mathrm{~mm}$

Steve Stanley (NNL)

October $28^{\text {th }} 2009$

Yes
Pre Contrast Enhanced Image

104/157; 224×224 pixels; 16 -bit; $15 \mathrm{MB}$

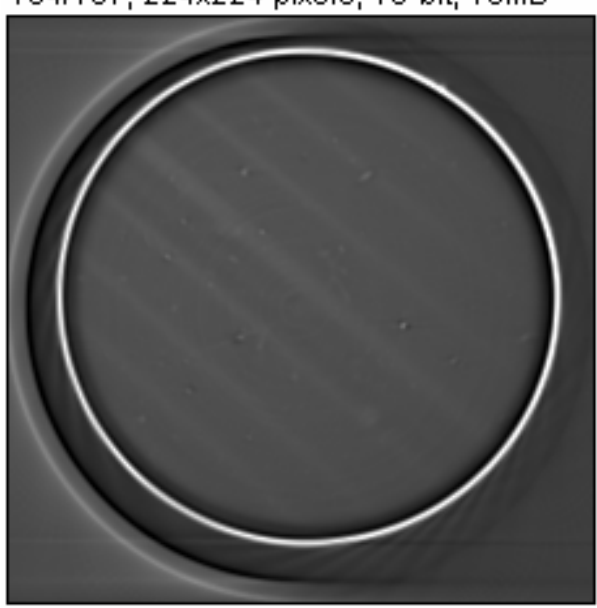

Pre Contrast Enhanced Pixel Histogram

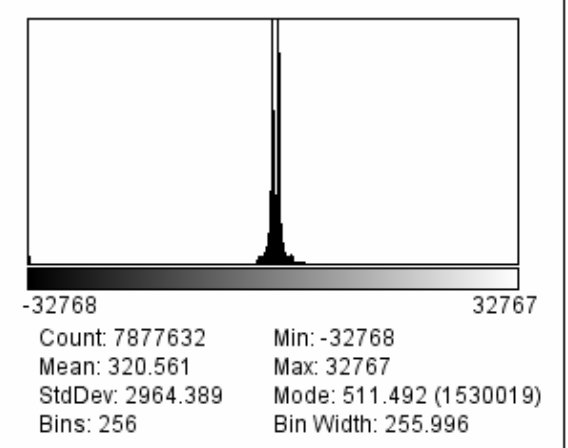

Post Contrast Enhanced Image 224×224 pixels; 16 -bit; $98 \mathrm{~K}$

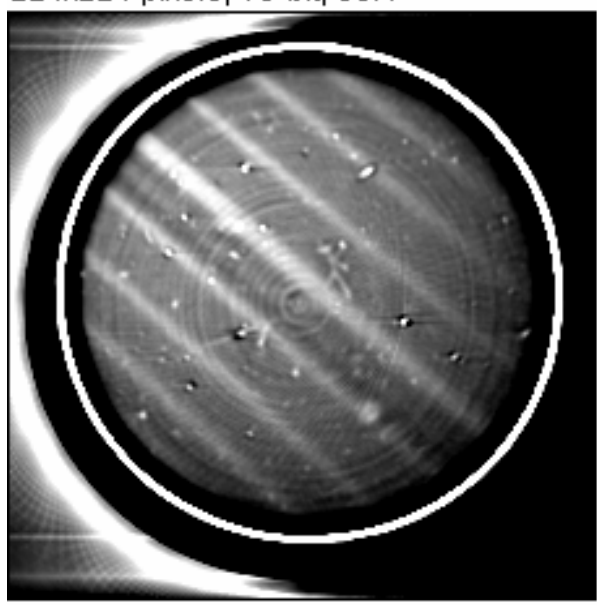

Post Contrast Enhanced Pixel Histogram

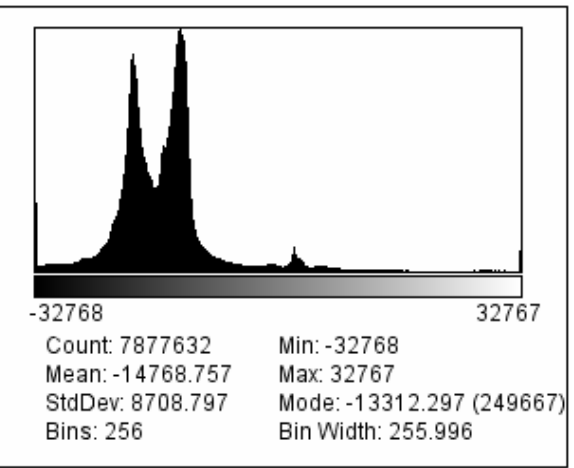

Plot Through Radiation Tracks

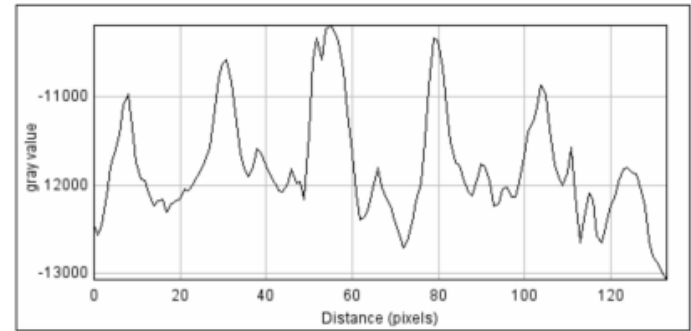



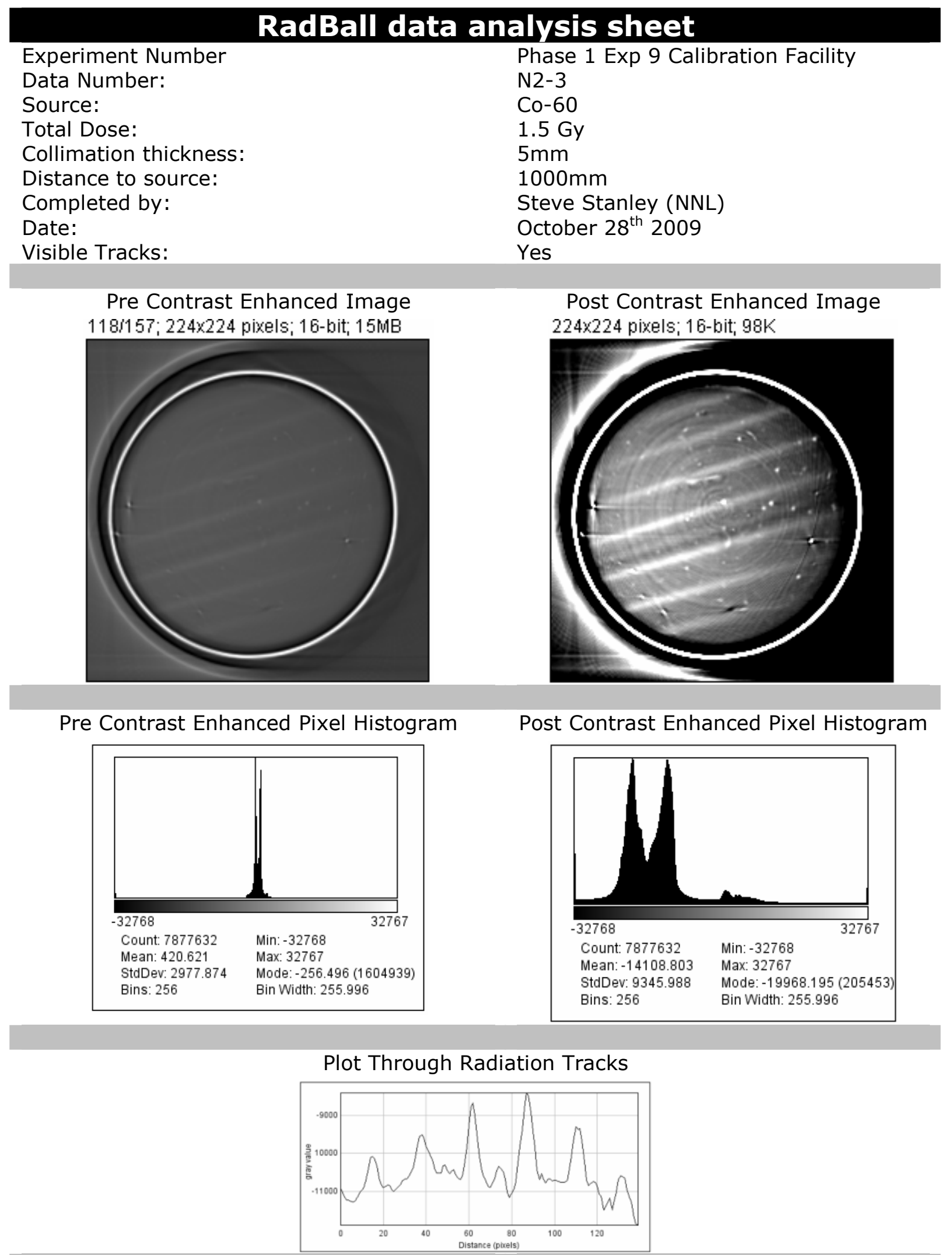


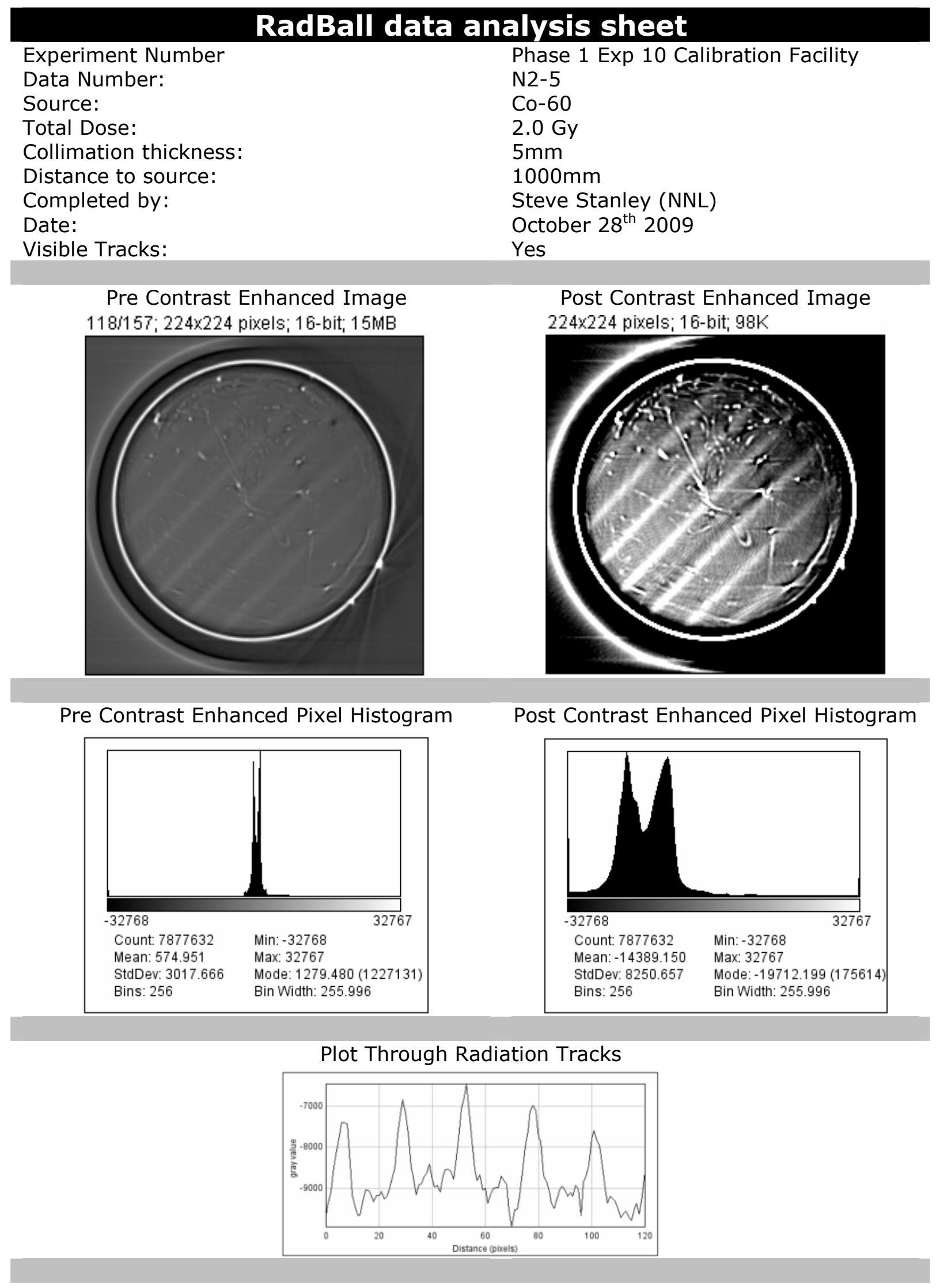




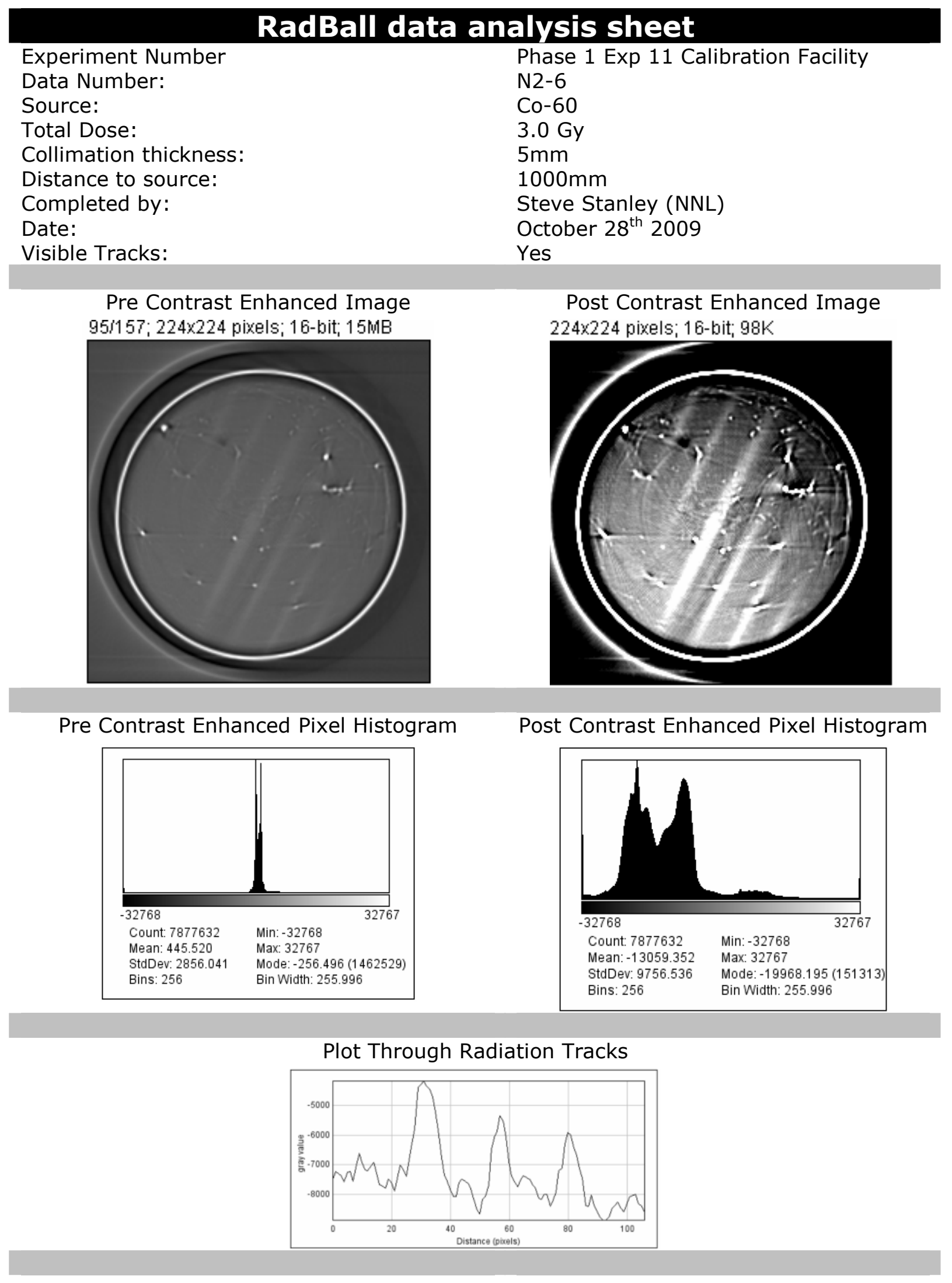




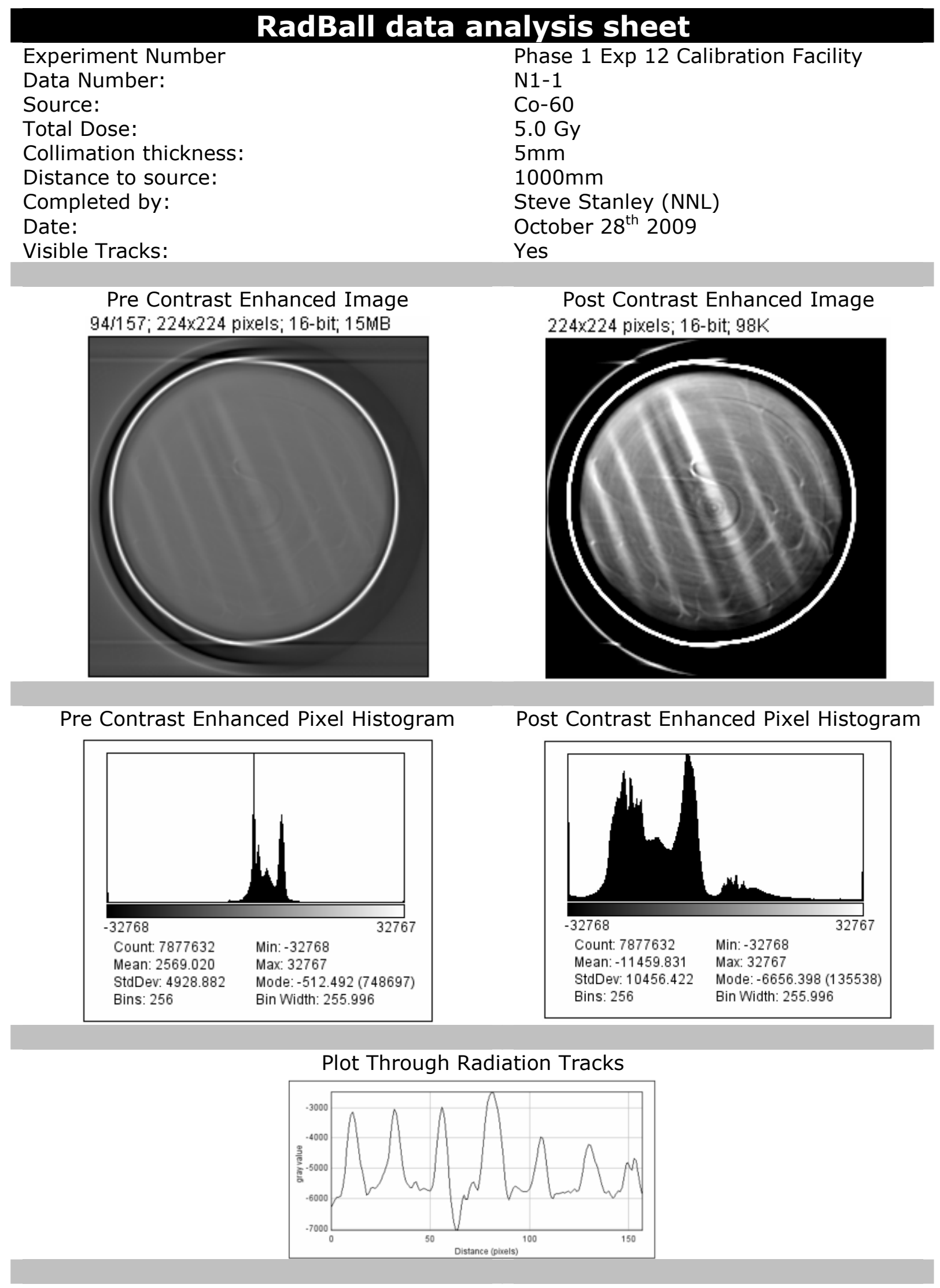




\section{RadBall data analysis sheet}

Experiment Number

Data Number:

Source:

Total Dose:

Collimation thickness:

Distance to source:

Completed by:

Date:

Visible Tracks:
Phase 1 Exp 13 Calibration Facility

N3-2

1.5 Gy Cs-137 + 1.5 Gy Co-60 co-linear

$3.0 \mathrm{~Gy}$

$5 \mathrm{~mm}$

$1000 \mathrm{~mm}$

Steve Stanley (NNL)

October $28^{\text {th }} 2009$

Yes
Pre Contrast Enhanced Image

91/157; $224 \times 224$ pixels; 16-bit; $15 \mathrm{MB}$

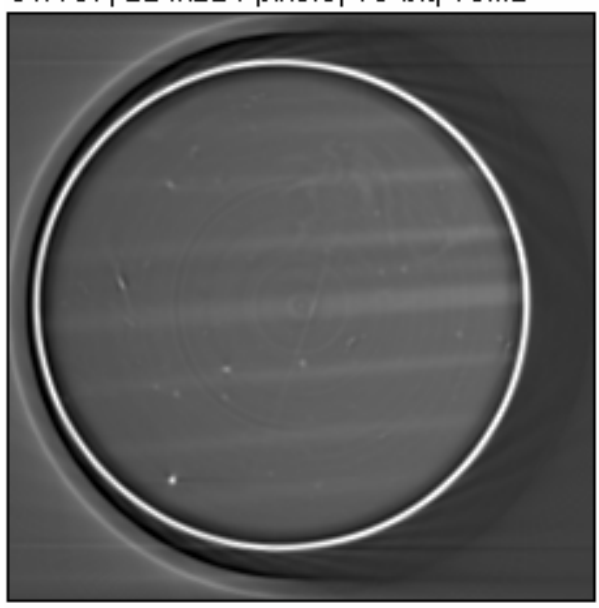

Pre Contrast Enhanced Pixel Histogram

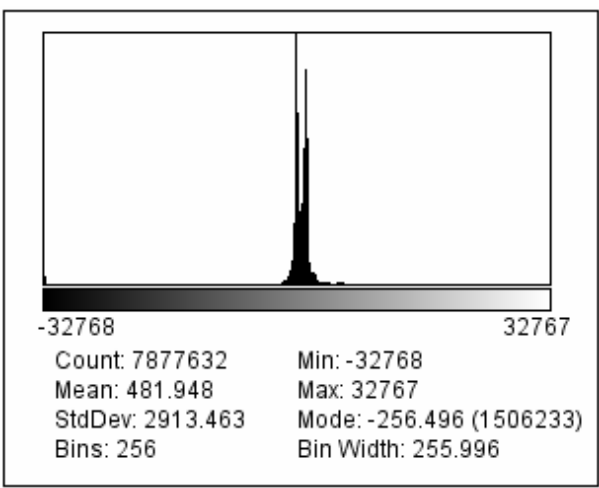

Post Contrast Enhanced Image

224×224 pixels; 16 -bit; $98 \mathrm{~K}$

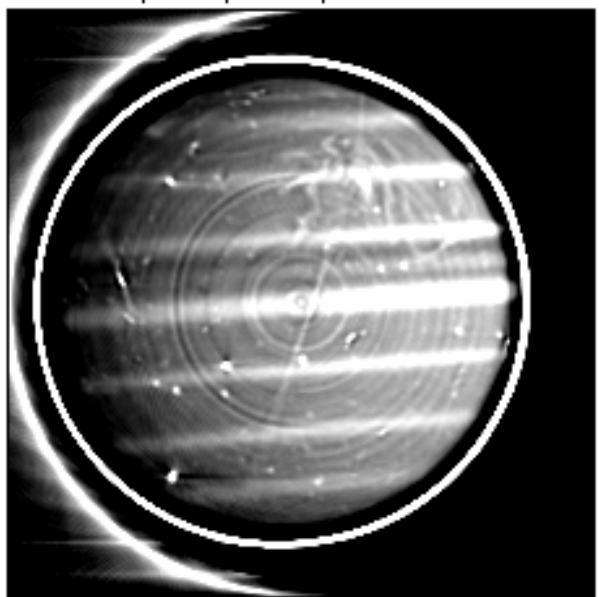

Post Contrast Enhanced Pixel Histogram

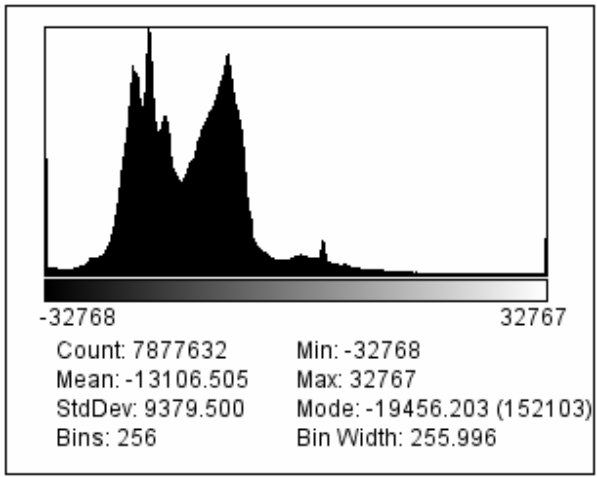

Plot Through Radiation Tracks

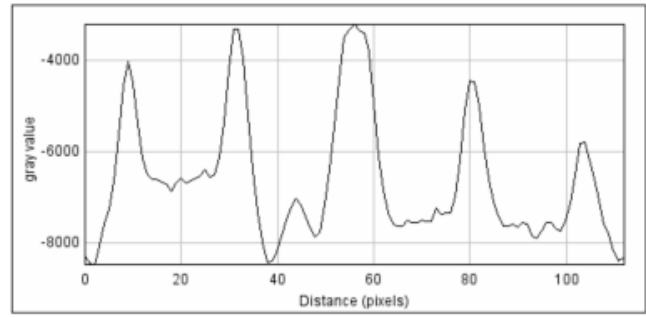




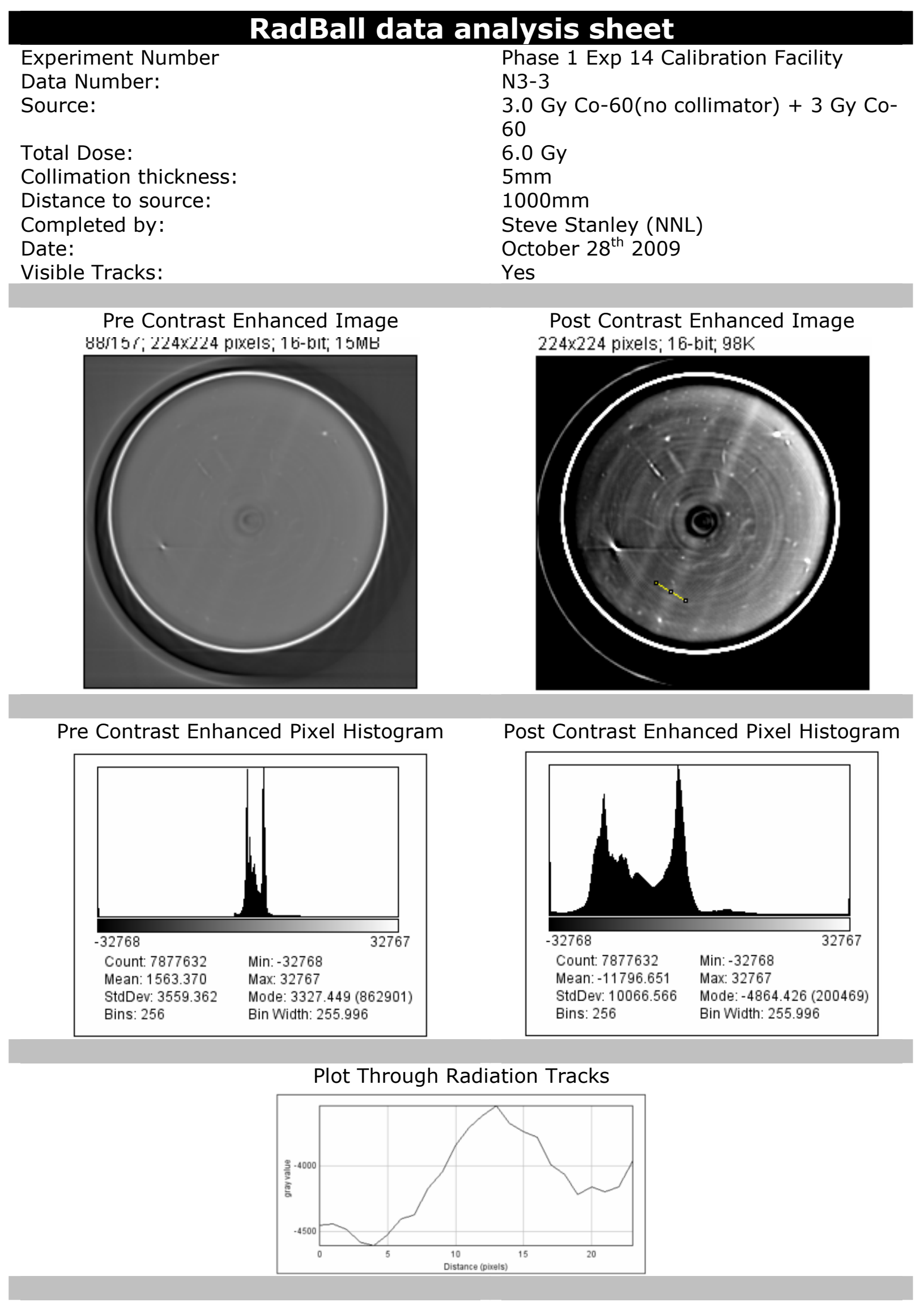




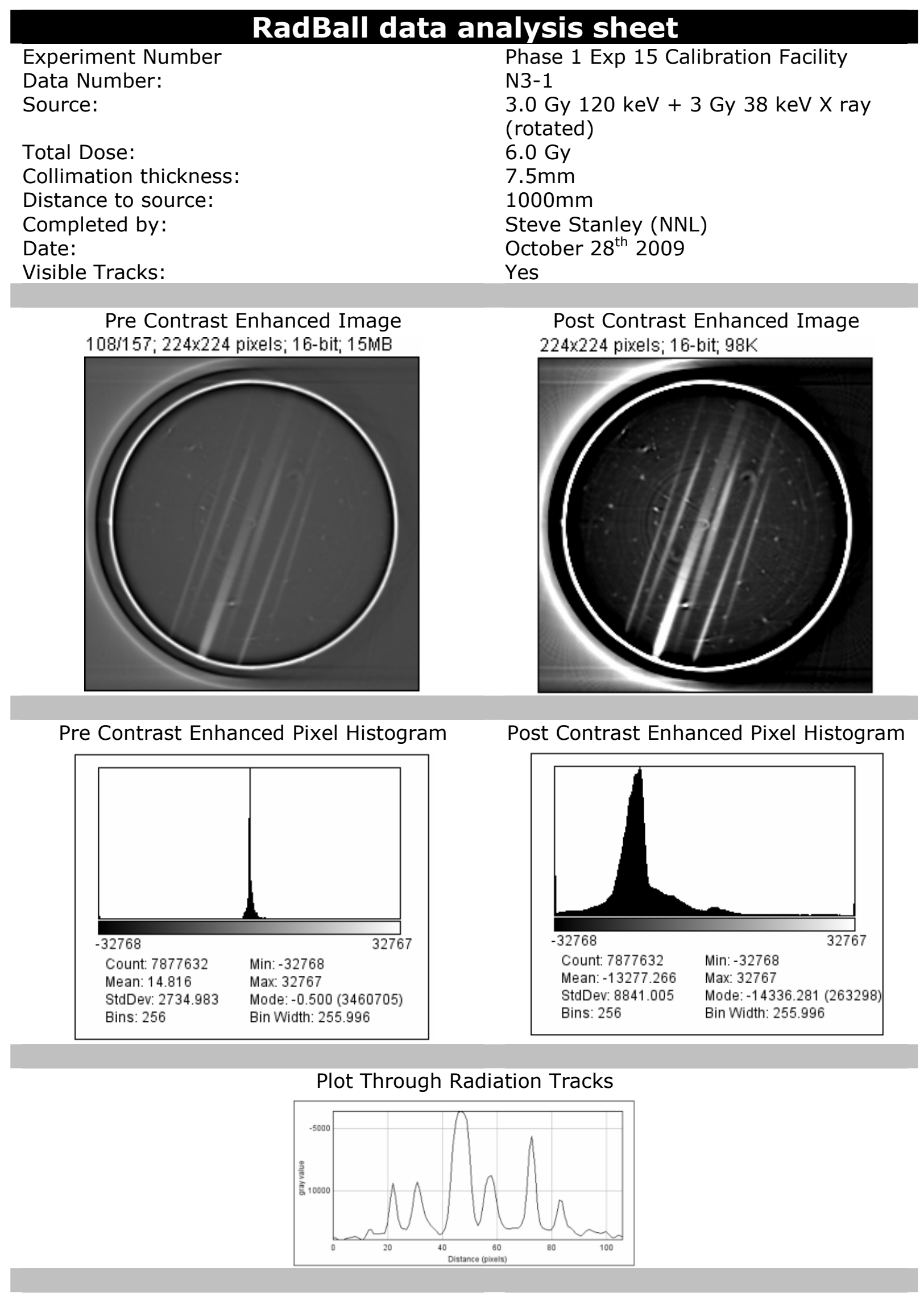




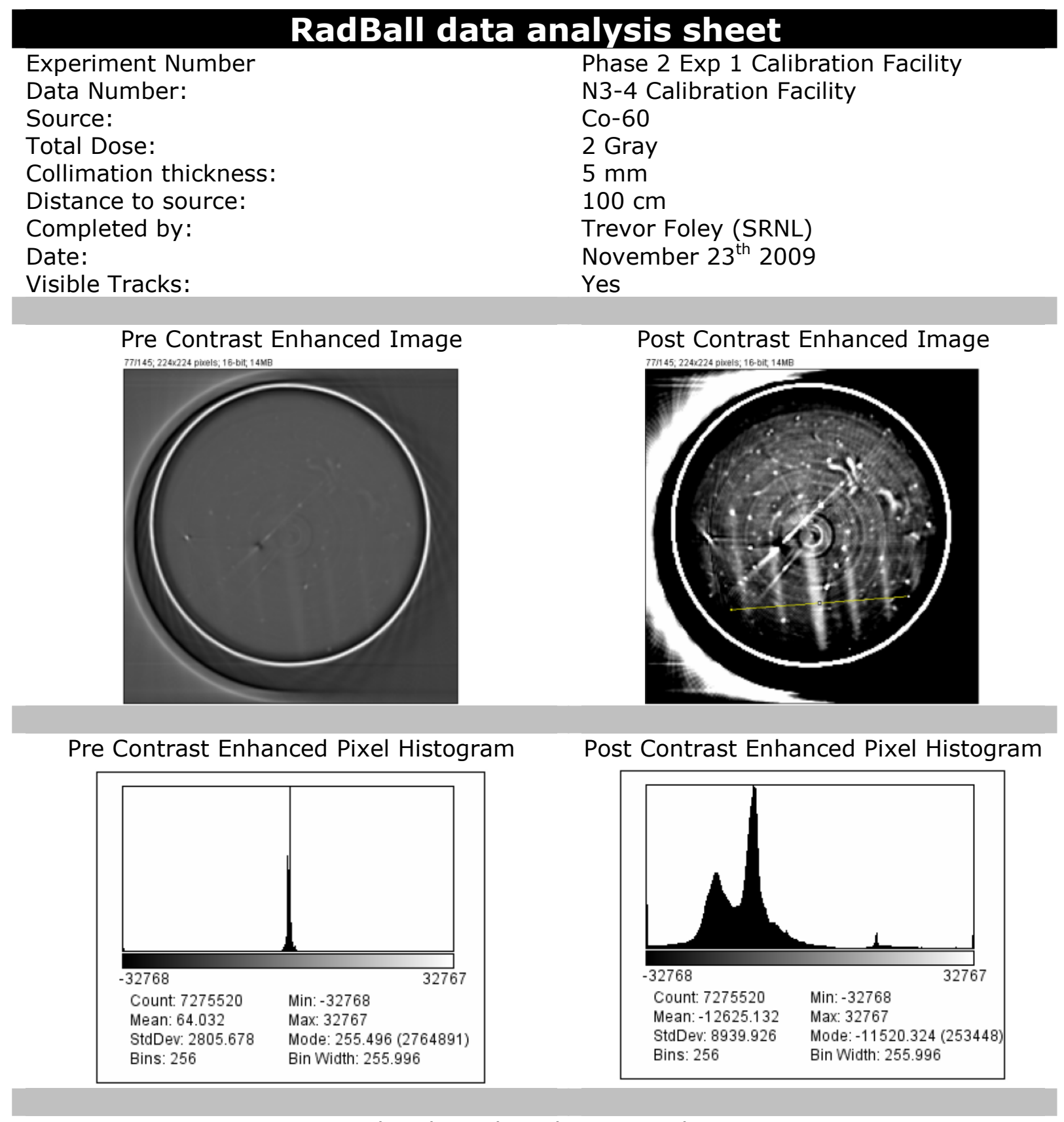

Plot Through Radiation Tracks

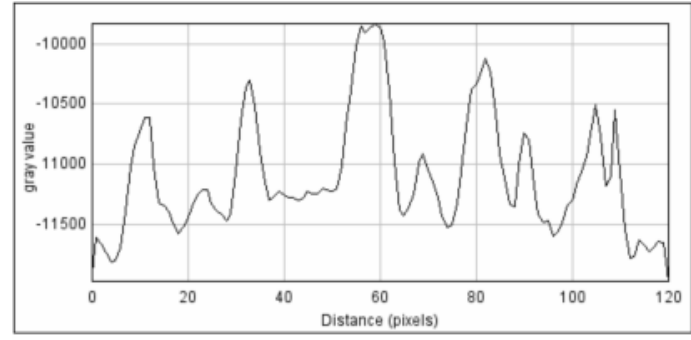




\section{RadBall data analysis sheet}

Experiment Number

Data Number:

Source:

Total Dose:

Collimation thickness:

Distance to source:

Completed by:

Date:

Visible Tracks:
Phase 2 Exp 2 Calibration Facility

N3-5 Calibration Facility

Co-60

4 Gray

$5 \mathrm{~mm}$

$100 \mathrm{~cm}$

Trevor Foley (SRNL)

November $23^{\text {th }} 2009$

Yes

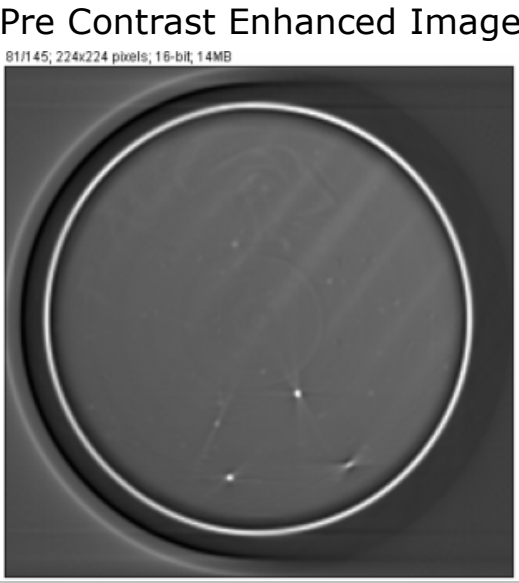

Pre Contrast Enhanced Pixel Histogram

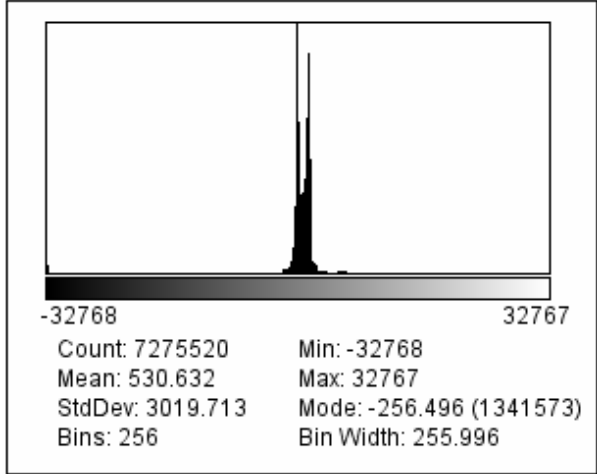

Post Contrast Enhanced Image

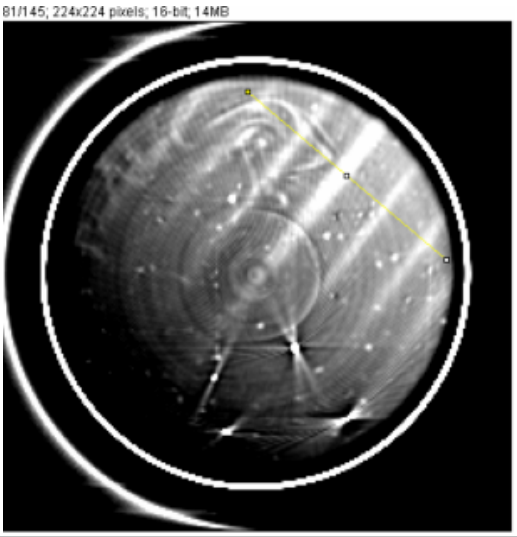

Post Contrast Enhanced Pixel Histogram

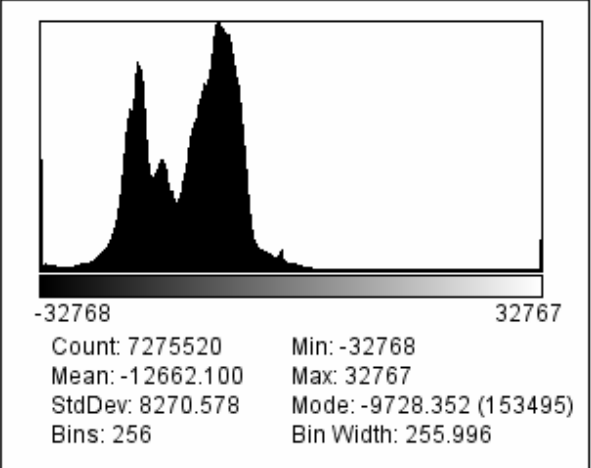

Plot Through Radiation Tracks

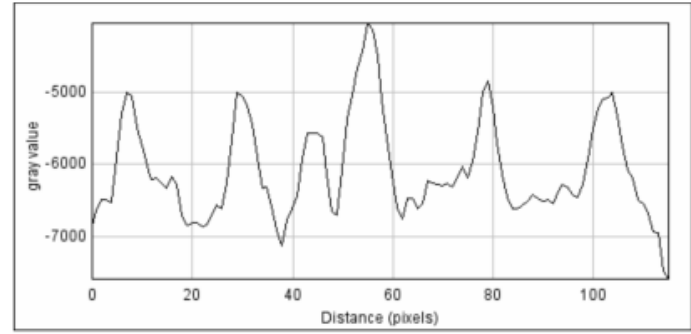




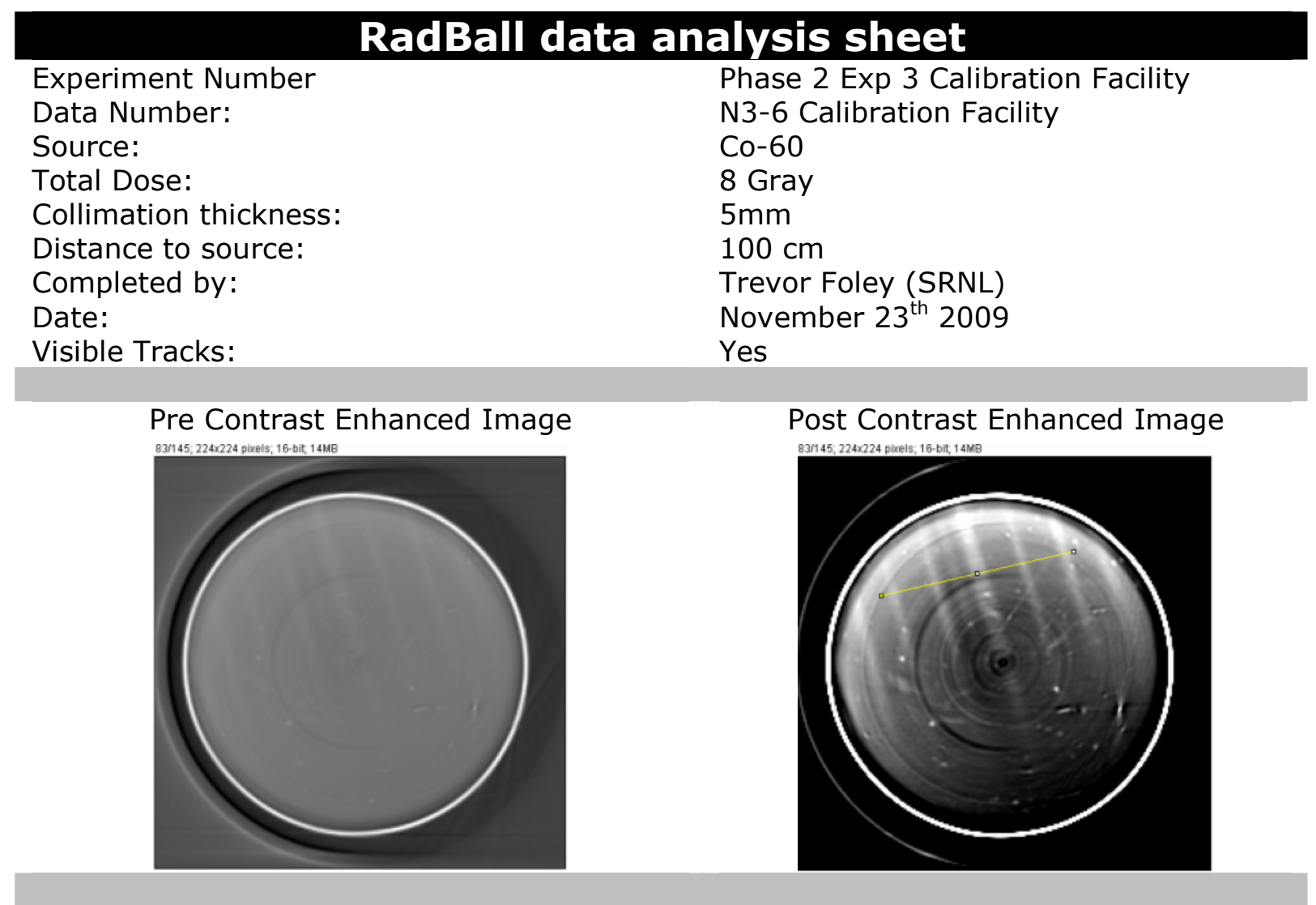

Pre Contrast Enhanced Pixel Histogram

Post Contrast Enhanced Pixel Histogram
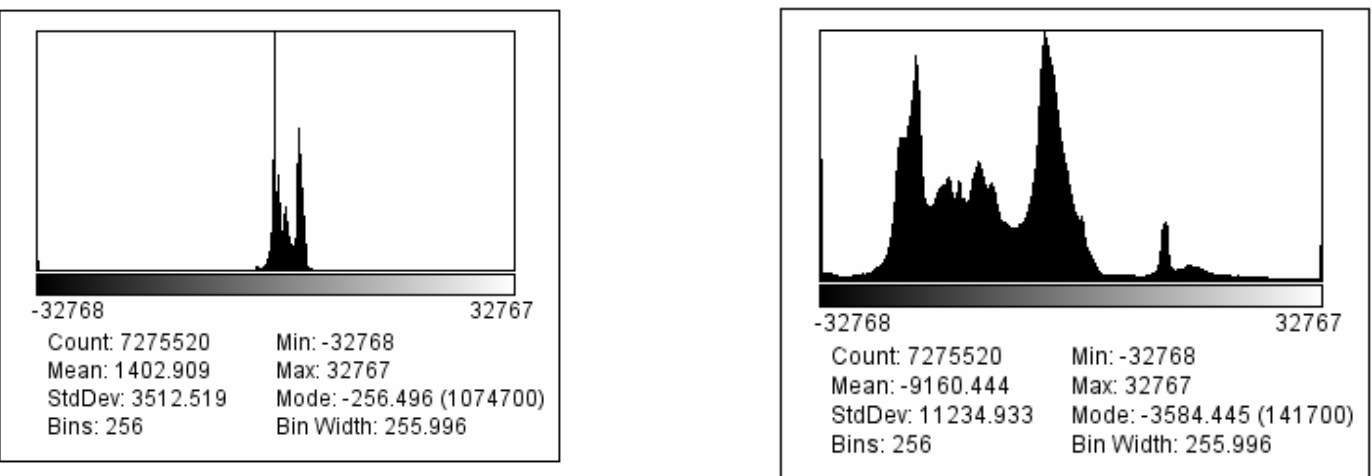

Plot Through Radiation Tracks

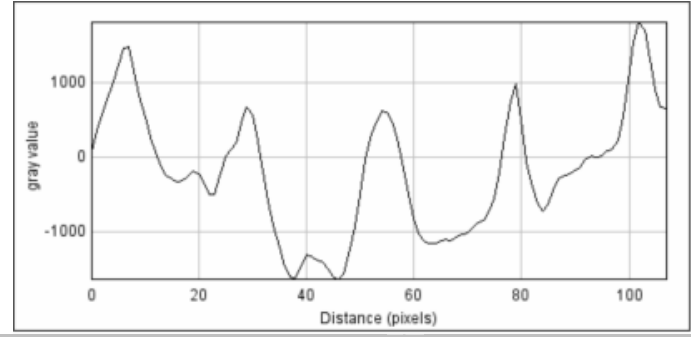




\section{RadBall data analysis sheet}

Experiment Number

Data Number:

Source:

Total Dose:

Collimation thickness:

Distance to source:

Completed by:

Date:

Visible Tracks:
Phase 2 Exp 4 Calibration Facility

N5-5 Calibration Facility

166 keV x-ray

3 Gray

$5 \mathrm{~mm}$

$100 \mathrm{~cm}$

Trevor Foley (SRNL)

November $23^{\text {th }} 2009$

Yes

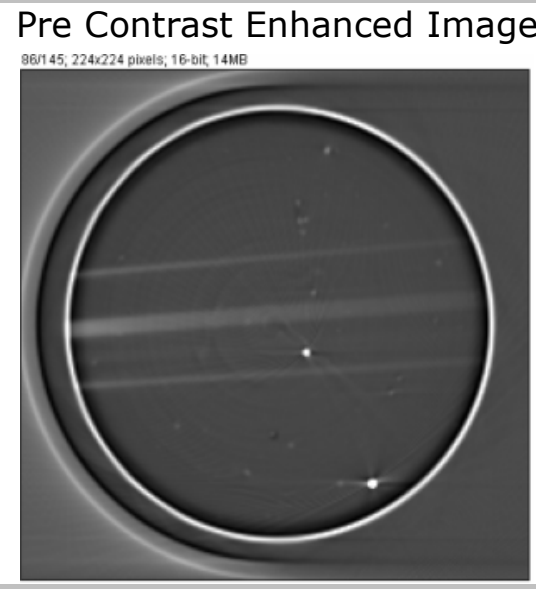

Pre Contrast Enhanced Pixel Histogram

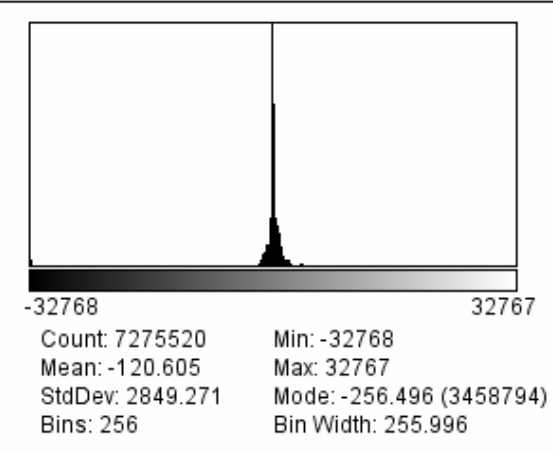

Post Contrast Enhanced Image

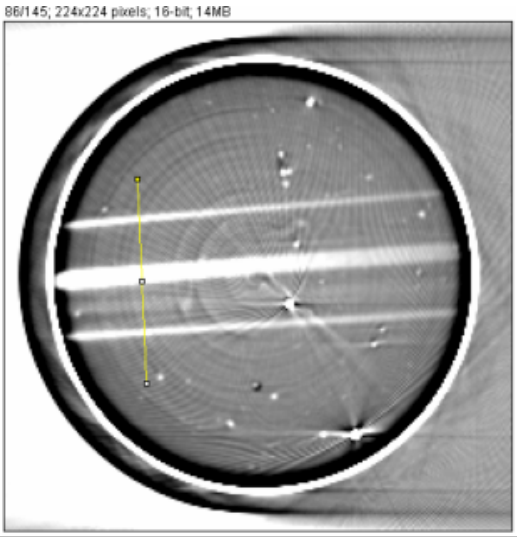

Post Contrast Enhanced Pixel Histogram

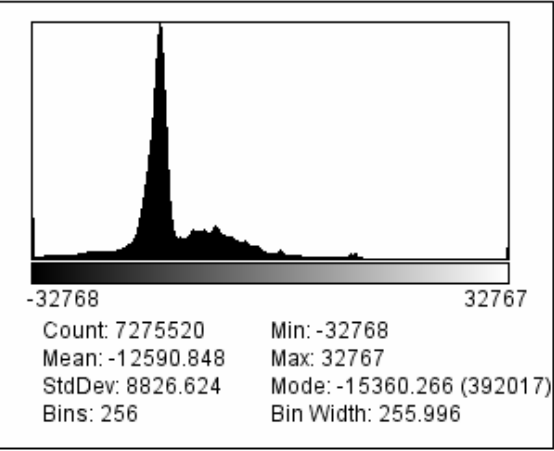

Plot Through Radiation Tracks

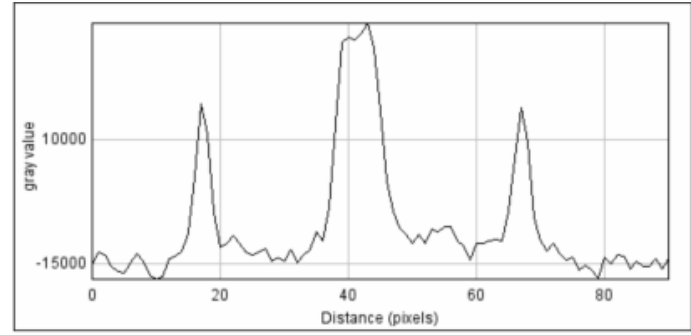




\section{RadBall data analysis sheet}

Experiment Number

Data Number:

Source:

Total Dose:

Collimation thickness:

Distance to source:

Completed by:

Date:

Visible Tracks:
Phase 2 Exp 5 Calibration Facility

N4-3 Calibration Facility

Cs-137 and Co-60 (collinear)

3 Gray

$5 \mathrm{~mm}$

$100 \mathrm{~cm}$

Trevor Foley (SRNL)

November $23^{\text {th }} 2009$

Yes

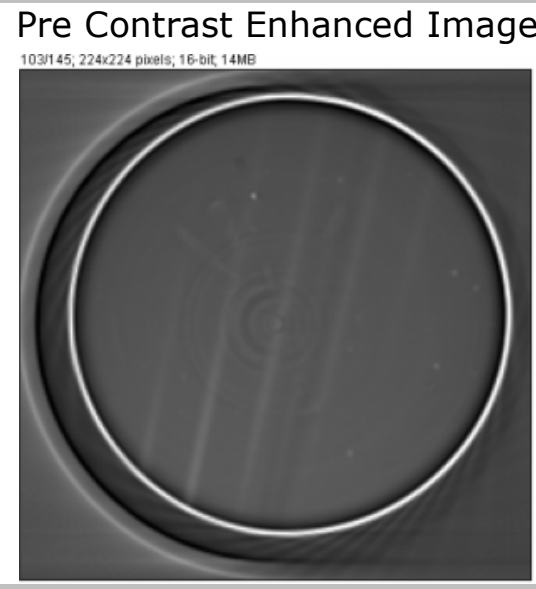

Pre Contrast Enhanced Pixel Histogram

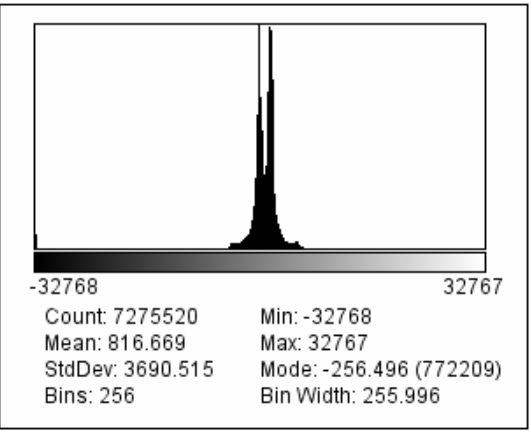

Post Contrast Enhanced Image

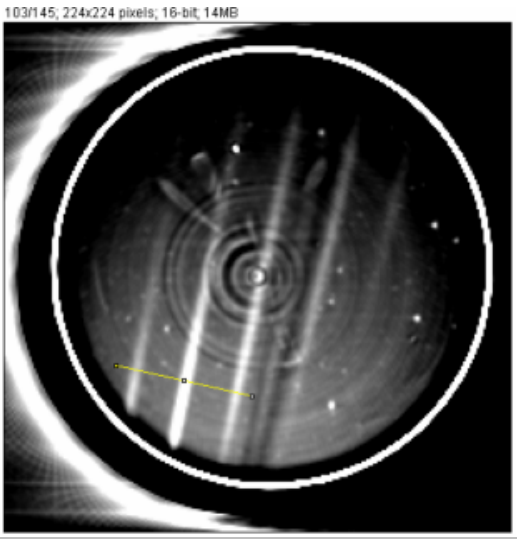

Post Contrast Enhanced Pixel Histogram

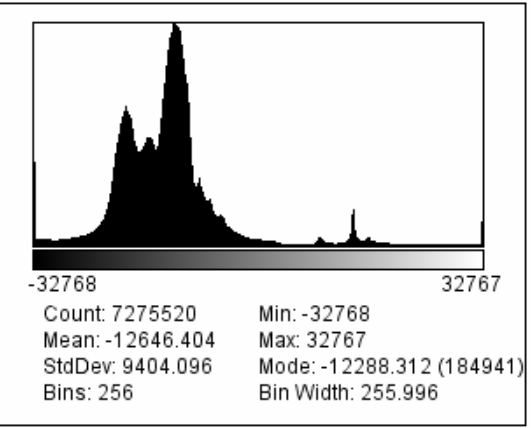

Plot Through Radiation Tracks

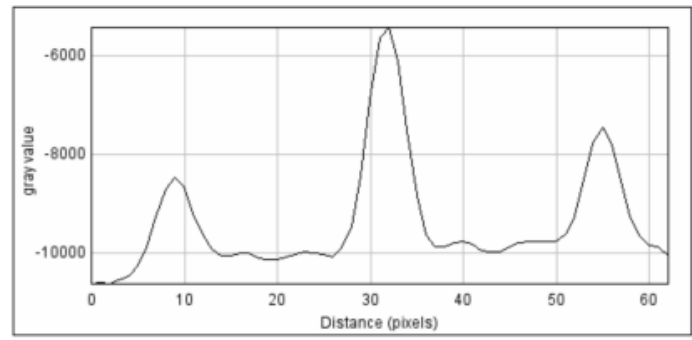




\section{RadBall data analysis sheet}

Experiment Number

Data Number:

Source:

Total Dose:

Collimation thickness:

Distance to source:

Completed by:

Date:

Visible Tracks:
Phase 2 Exp 6 Calibration Facility

N5-6 Calibration Facility

Cs-137 and Co-60 (Colinear)

3 Gray

$5 \mathrm{~mm}$

$100 \mathrm{~cm}$

Trevor Foley (SRNL)

November $23^{\text {th }} 2009$

Yes

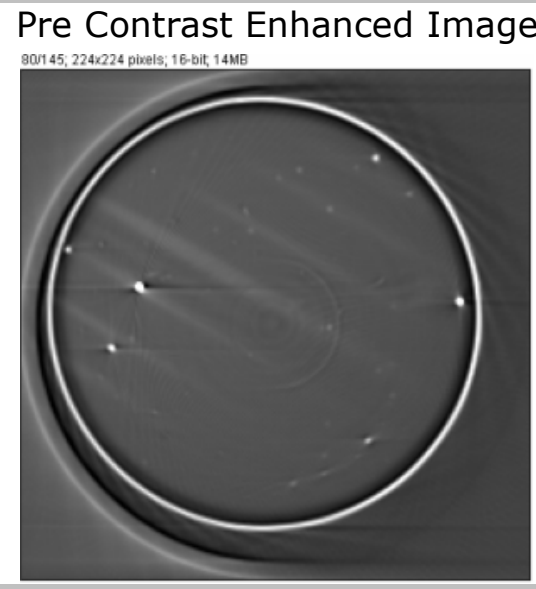

Pre Contrast Enhanced Pixel Histogram

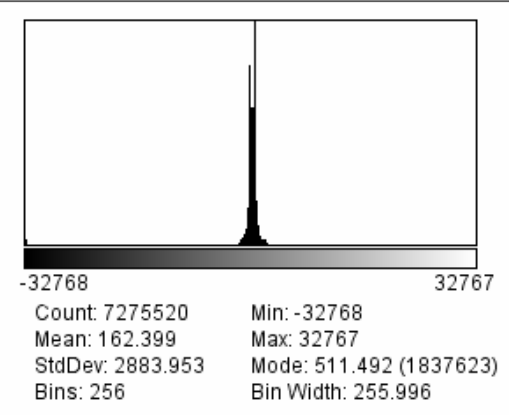

Post Contrast Enhanced Image

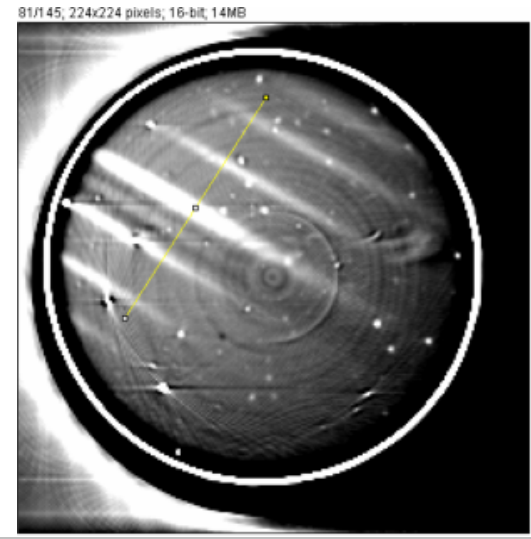

Post Contrast Enhanced Pixel Histogram

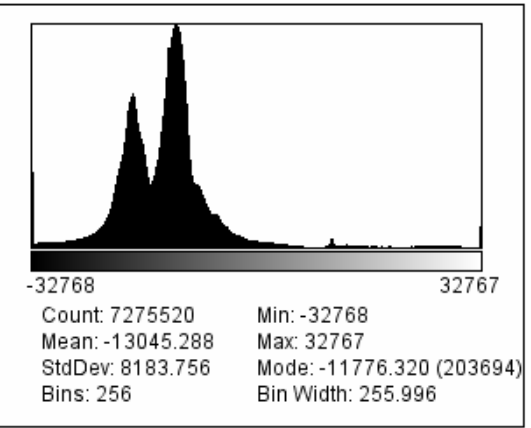

Plot Through Radiation Tracks

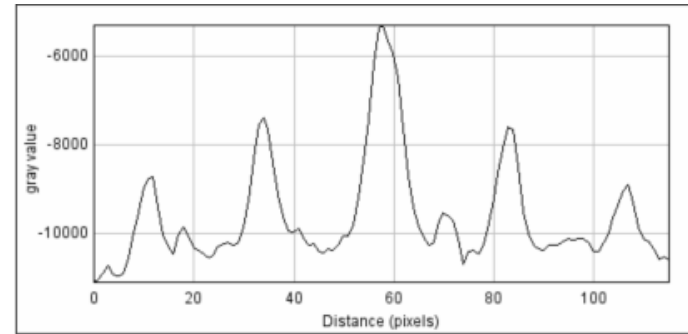




\section{RadBall data analysis sheet}

Experiment Number

Data Number:

Source:

Total Dose:

Collimation thickness:

Distance to source:

Completed by:

Date:

Visible Tracks:
Phase 2 Exp 7 Calibration Facility

N4-2 Calibration Facility

Cs-137 and Co-60 (collinear)

4 Gray

$5 \mathrm{~mm}$

$100 \mathrm{~cm}$

Trevor Foley (SRNL)

November $23^{\text {th }} 2009$

Yes

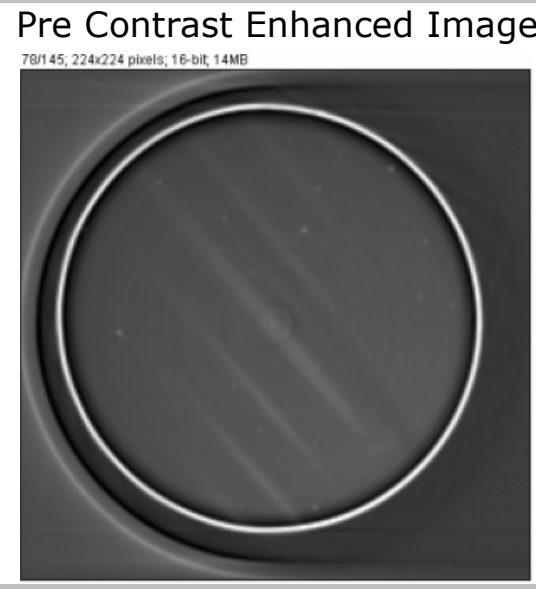

Pre Contrast Enhanced Pixel Histogram

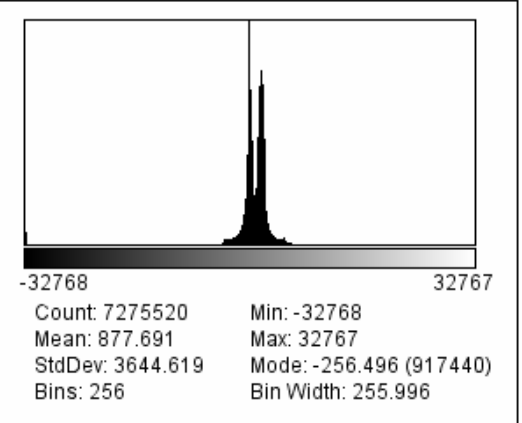

Post Contrast Enhanced Image

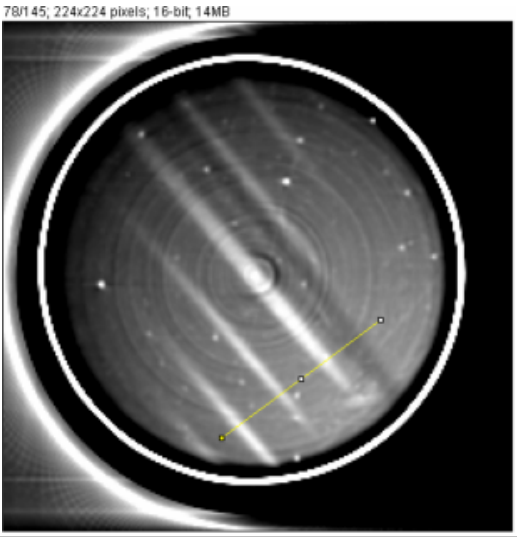

Post Contrast Enhanced Pixel Histogram

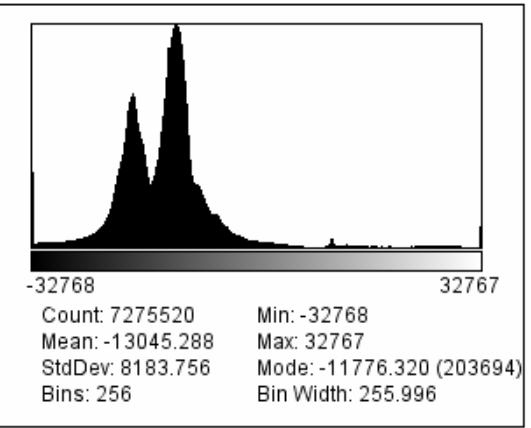

Plot Through Radiation Tracks

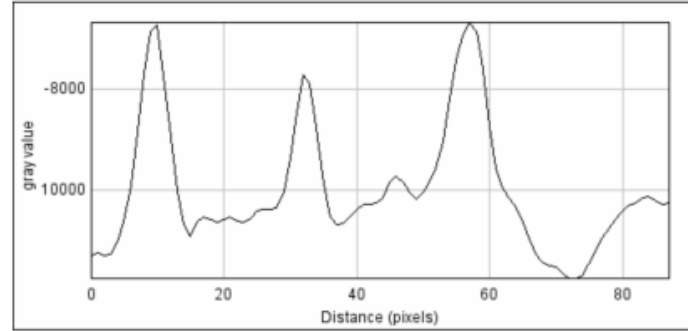




\section{RadBall data analysis sheet}

Experiment Number

Data Number:

Source:

Total Dose:

Collimation thickness:

Distance to source:

Completed by:

Date:

Visible Tracks:
Phase 2 Exp 8 Calibration Facility

N4-1 Calibration Facility

Cs-137 and Co-60 (collinear)

4 Gray

$5 \mathrm{~mm}$

$100 \mathrm{~cm}$

Trevor Foley (SRNL)

November $23^{\text {th }} 2009$

Yes

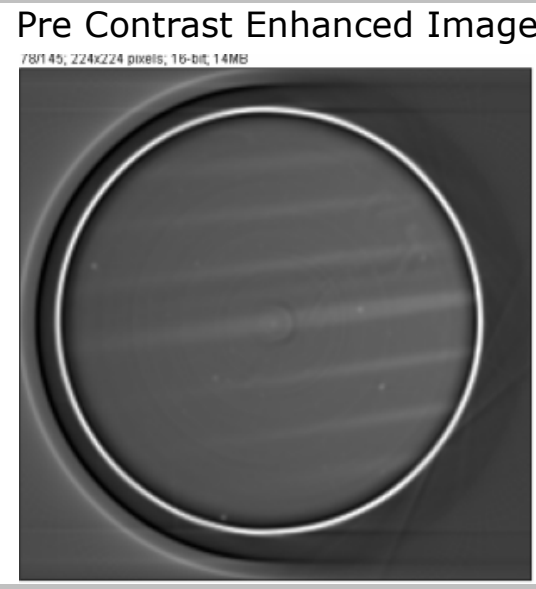

Pre Contrast Enhanced Pixel Histogram

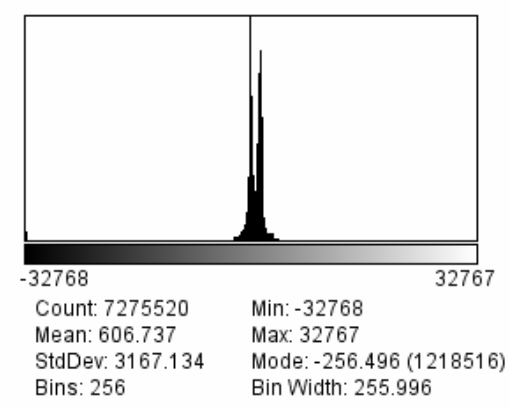

Post Contrast Enhanced Image

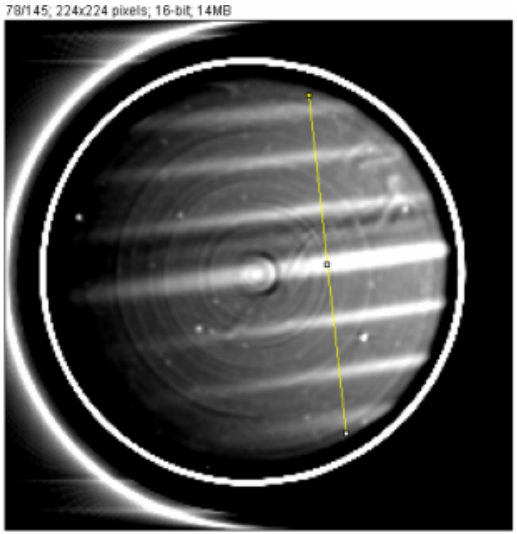

Post Contrast Enhanced Pixel Histogram

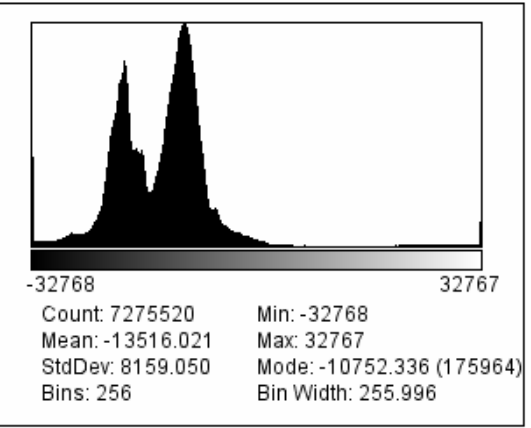

Plot Through Radiation Tracks

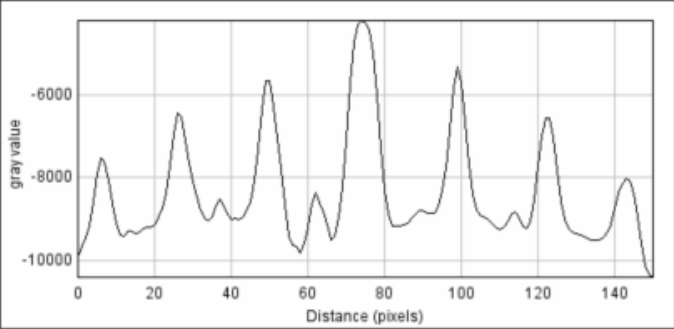




\section{RadBall data analysis sheet}

Experiment Number

Data Number:

Source:

Total Dose:

Collimation thickness:

Distance to source:

Completed by:

Date:

Visible Tracks:
Phase 2 Exp 9 Calibration Facility

N5-1 Calibration Facility

Co-60

3 Gray

$7.5 \mathrm{~mm}$

$100 \mathrm{~cm}$

Trevor Foley (SRNL)

November $23^{\text {th }} 2009$

Yes

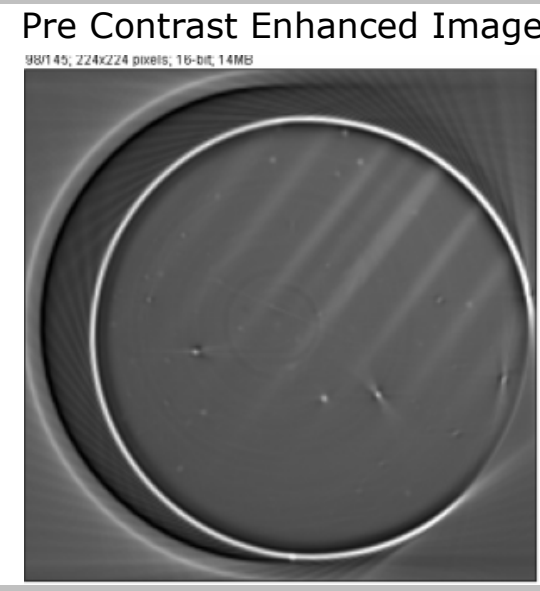

Pre Contrast Enhanced Pixel Histogram

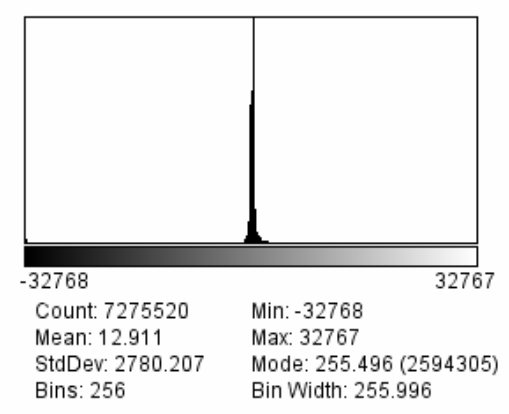

Post Contrast Enhanced Image

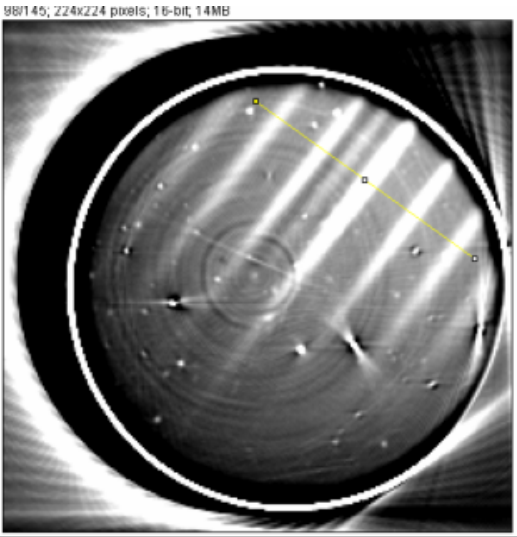

Post Contrast Enhanced Pixel Histogram

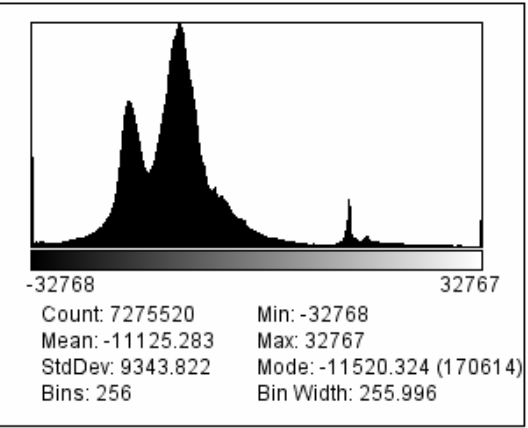

Plot Through Radiation Tracks

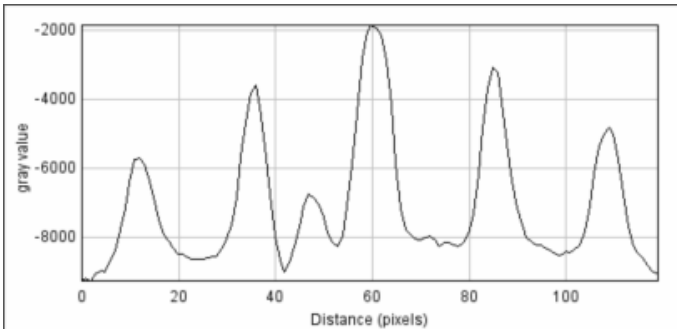




\section{RadBall data analysis sheet}

Experiment Number

Data Number:

Source:

Total Dose:

Collimation thickness:

Distance to source:

Completed by:

Date:

Visible Tracks:
Phase 2 Exp 10 Calibration Facility

N5-3 Calibration Facility

Co-60

3 Gray

$10 \mathrm{~mm}$

$100 \mathrm{~cm}$

Trevor Foley (SRNL)

November $23^{\text {th }} 2009$

Yes

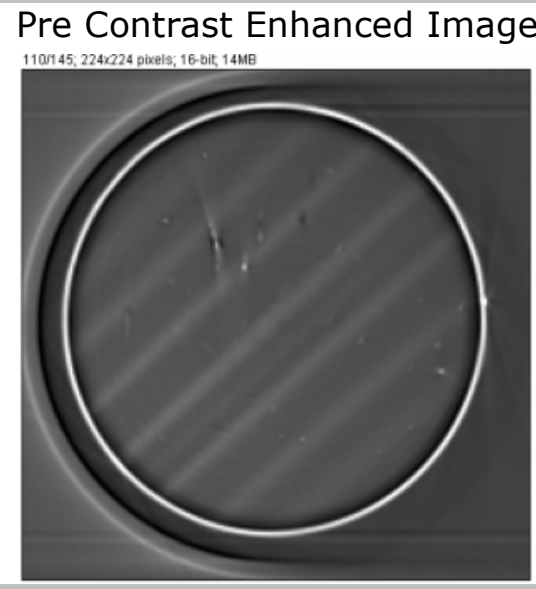

Pre Contrast Enhanced Pixel Histogram

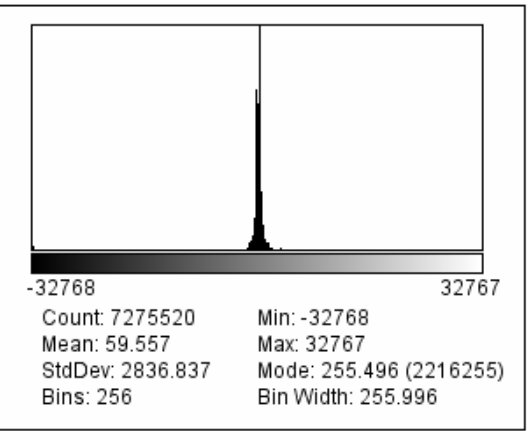

Post Contrast Enhanced Image

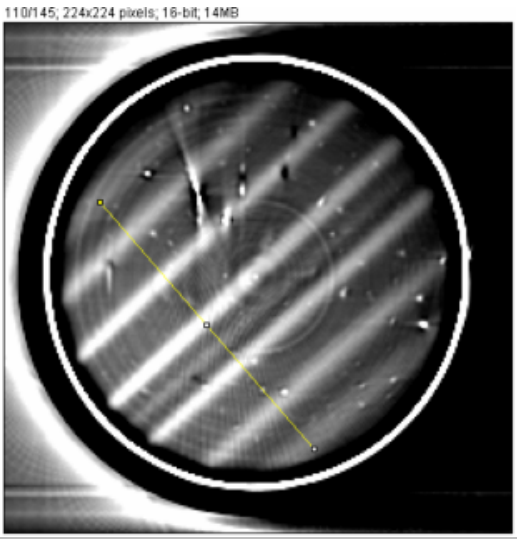

Post Contrast Enhanced Pixel Histogram

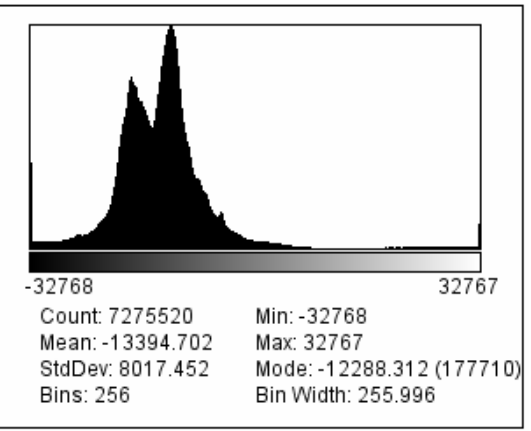

Plot Through Radiation Tracks

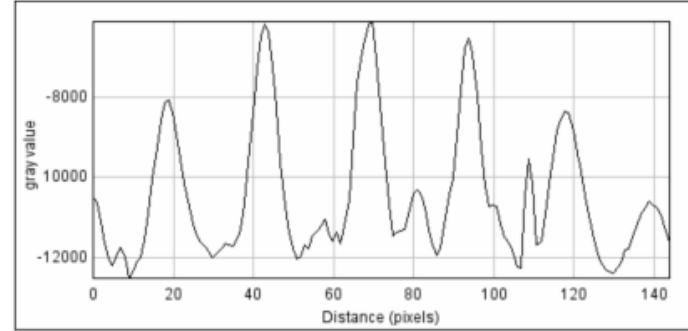




\section{RadBall data analysis sheet}

Experiment Number

Data Number:

Source:

Total Dose:

Collimation thickness:

Distance to source:

Completed by:

Date:

Visible Tracks:
Phase 2 Exp 11 Calibration Facility

N5-2 Calibration Facility

Cs-137

3 Gray

$7.5 \mathrm{~mm}$

$100 \mathrm{~cm}$

Trevor Foley (SRNL)

November $23^{\text {th }} 2009$

Yes

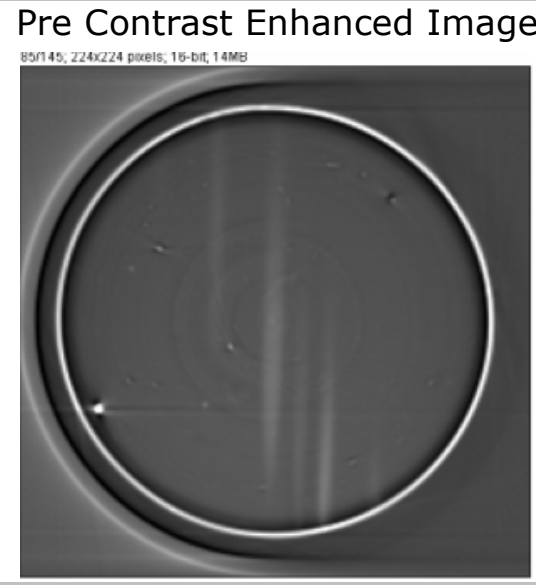

Pre Contrast Enhanced Pixel Histogram

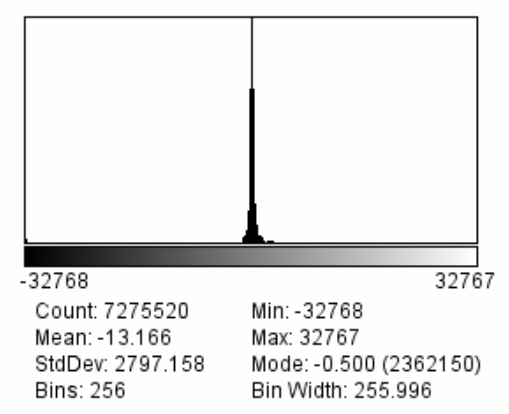

Post Contrast Enhanced Image

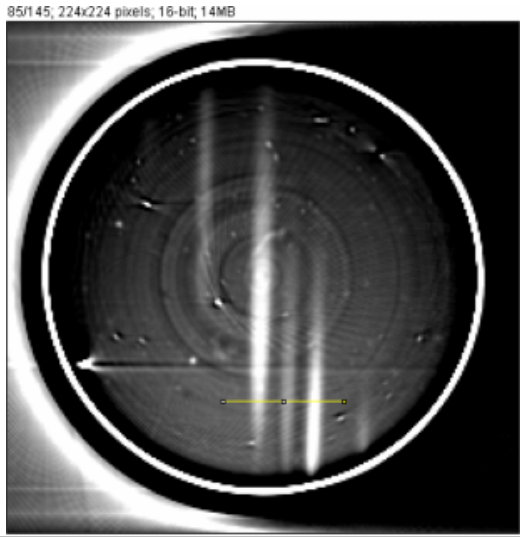

Post Contrast Enhanced Pixel Histogram

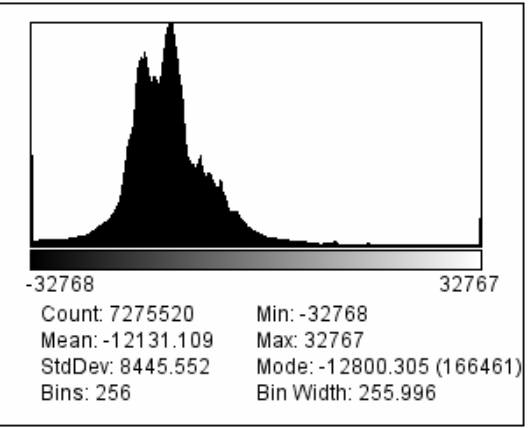

Plot Through Radiation Tracks

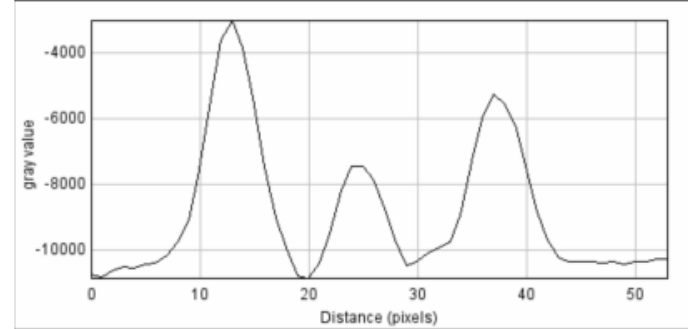




\section{RadBall data analysis sheet}

Experiment Number

Data Number:

Source:

Total Dose:

Collimation thickness:

Distance to source:

Completed by:

Date:

Visible Tracks:
Phase 2 Exp 12 Calibration Facility

N5-4 Calibration Facility

Cs-137

3 Gray

$10 \mathrm{~mm}$

$100 \mathrm{~cm}$

Trevor Foley (SRNL)

November $23^{\text {th }} 2009$

Yes

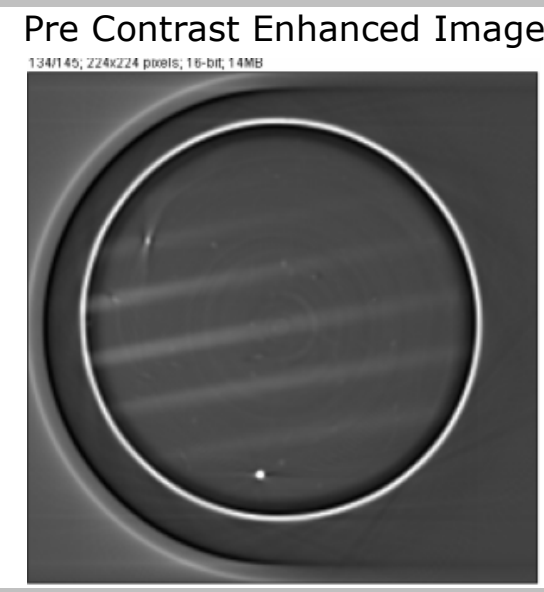

Pre Contrast Enhanced Pixel Histogram

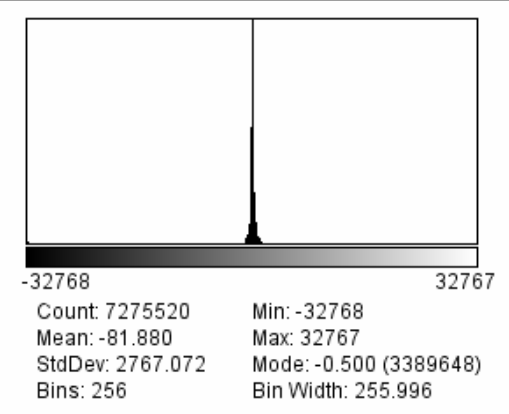

Post Contrast Enhanced Image

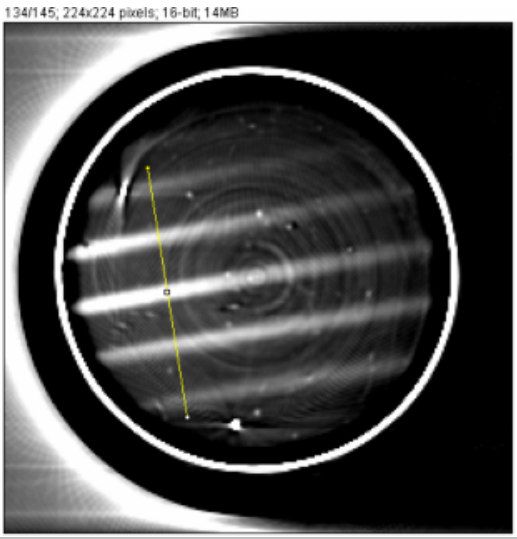

Post Contrast Enhanced Pixel Histogram

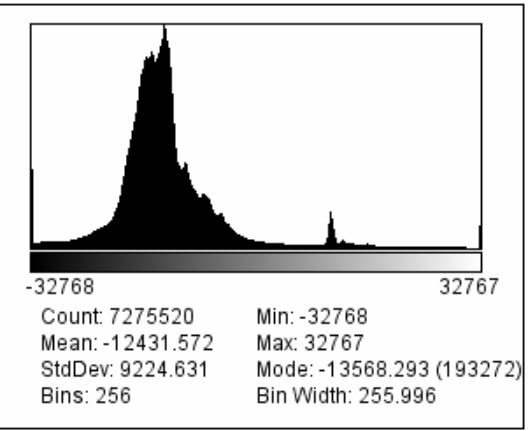

Plot Through Radiation Tracks

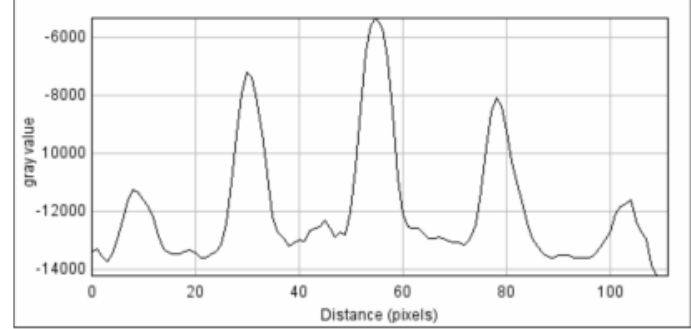




\section{RadBall data analysis sheet}

Experiment Number

Data Number:

Source:

Total Dose:

Collimation thickness:

Distance to source:

Completed by:

Date:

Visible Tracks:
Phase 2 Exp 13 Calibration Facility

N4-4 Calibration Facility

Am-241

0.5 Gray

$5 \mathrm{~mm}$

$100 \mathrm{~cm}$

Trevor Foley (SRNL)

November $23^{\text {th }} 2009$

No

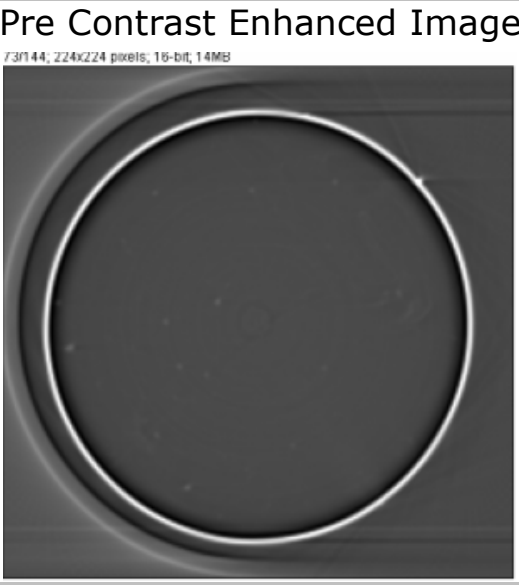

Pre Contrast Enhanced Pixel Histogram

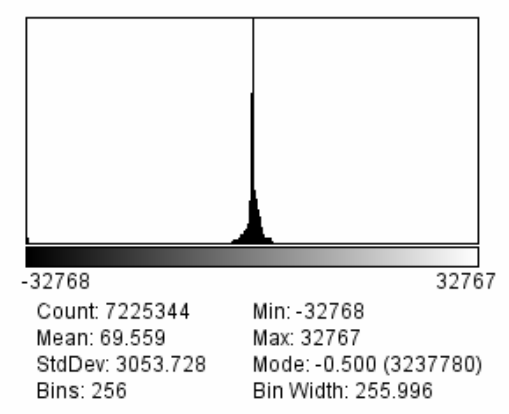

Post Contrast Enhanced Pixel Histogram

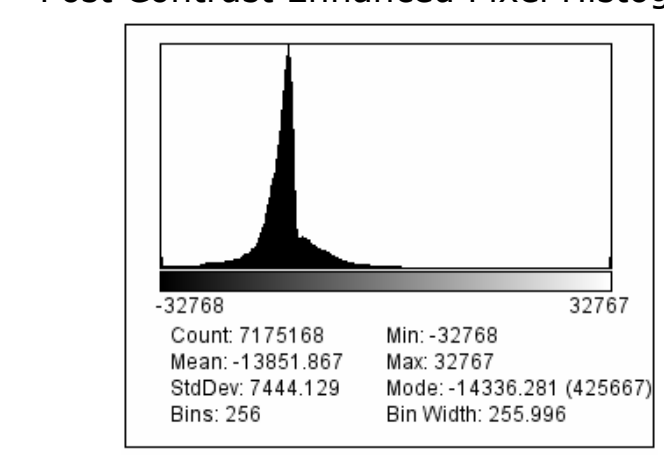

Post Contrast Enhanced Image

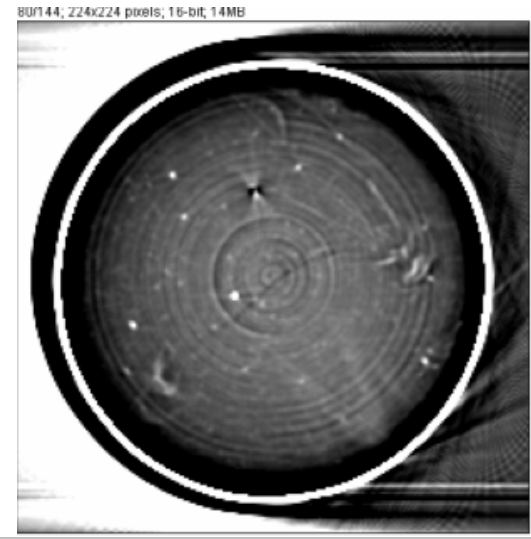




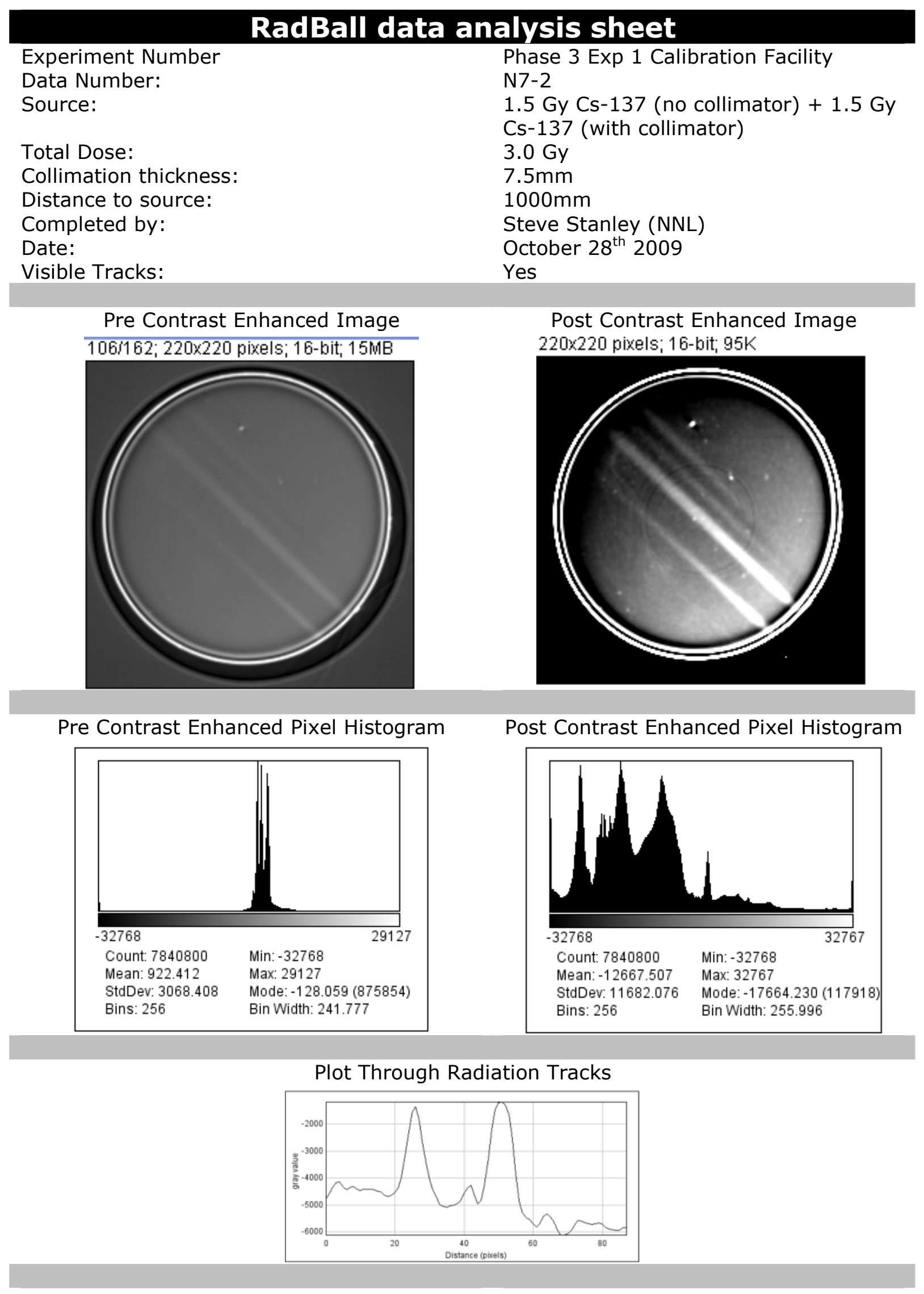




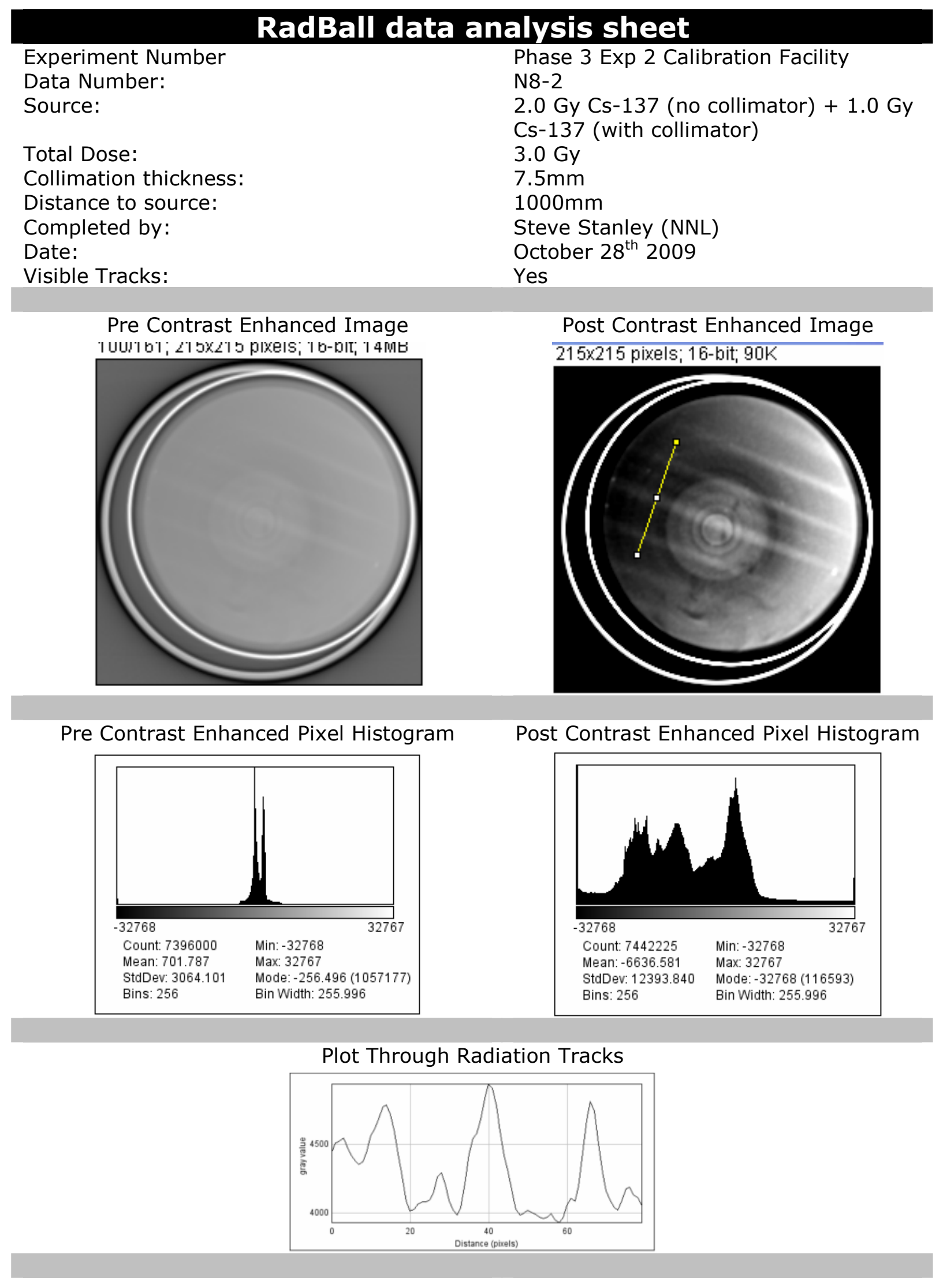




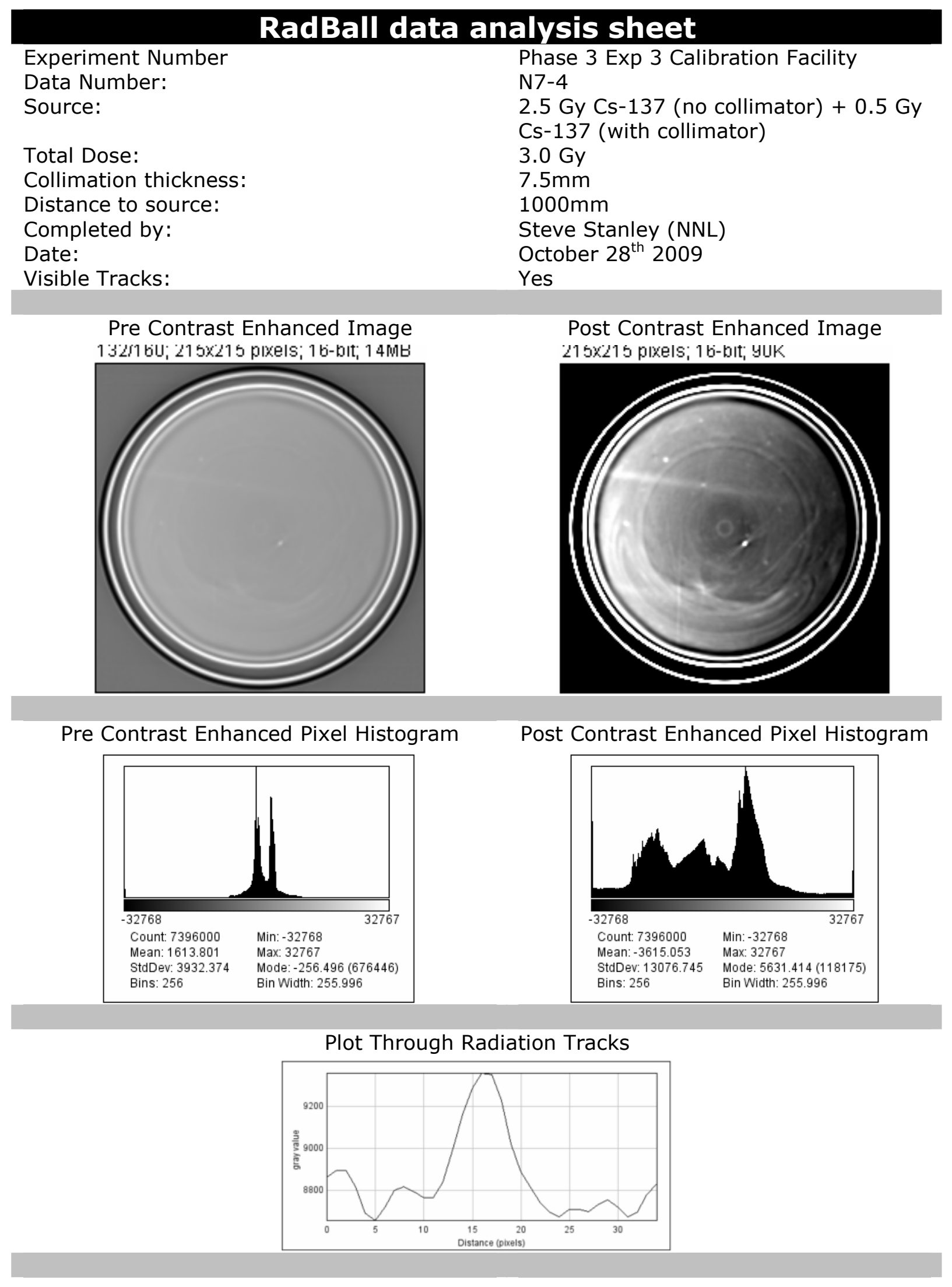




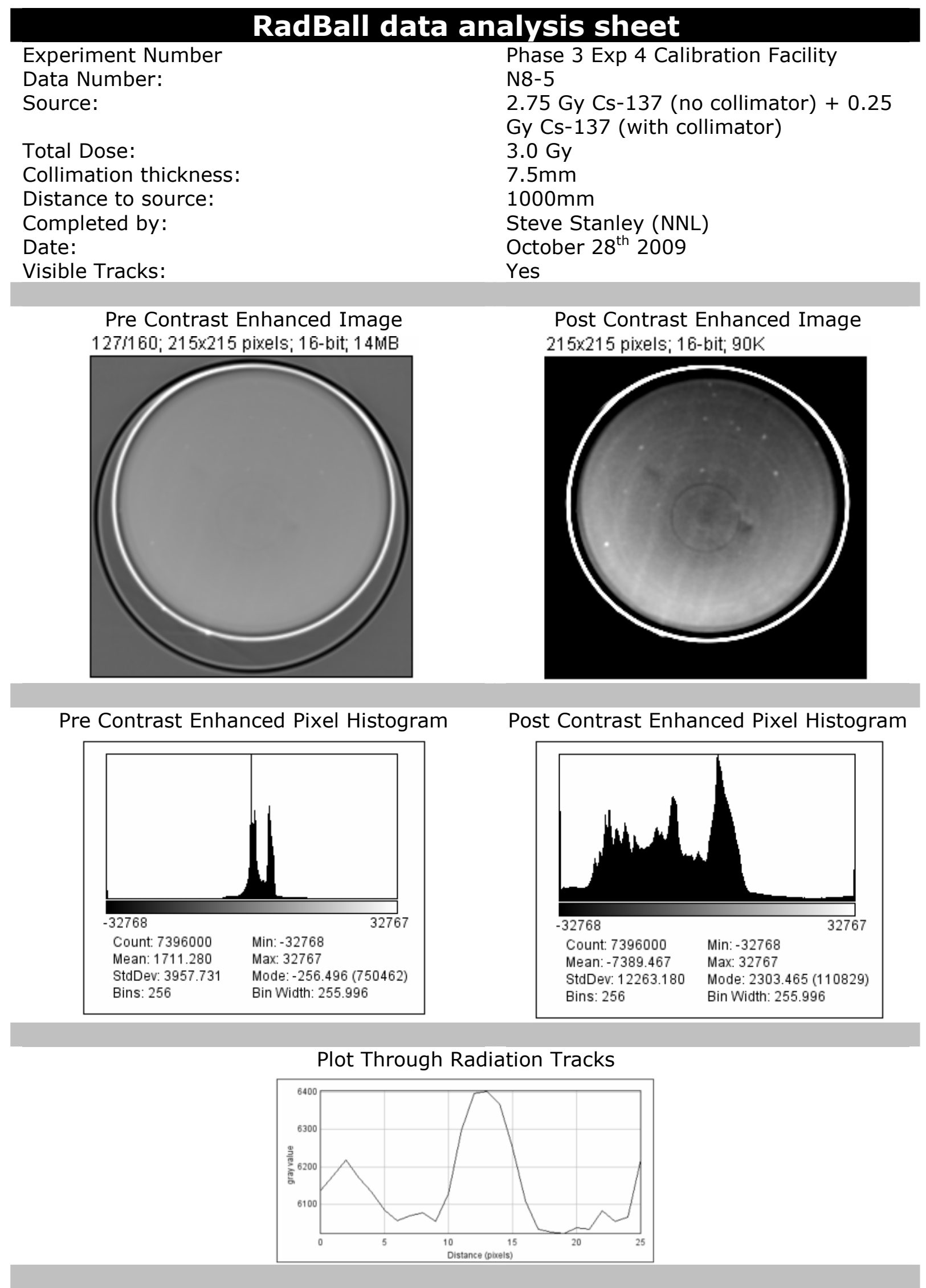




\section{RadBall data analysis sheet}

Experiment Number

Data Number:

Source:

Total Dose:

Collimation thickness:

Distance to source:

Completed by:

Date:

Visible Tracks:
Phase 3 Exp 5 Calibration Facility

N8-3

2.85 Gy Cs-137 (no collimator) + 0.15

Gy Cs-137 (with collimator)

$3.0 \mathrm{~Gy}$

$7.5 \mathrm{~mm}$

$1000 \mathrm{~mm}$

Chris Holmes (NNL)

November $2^{\text {nd }} 2009$

Yes

Post Contrast Enhanced Image

83/162; $220 \times 220$ pixels; 16 -bit; $15 \mathrm{MB}$

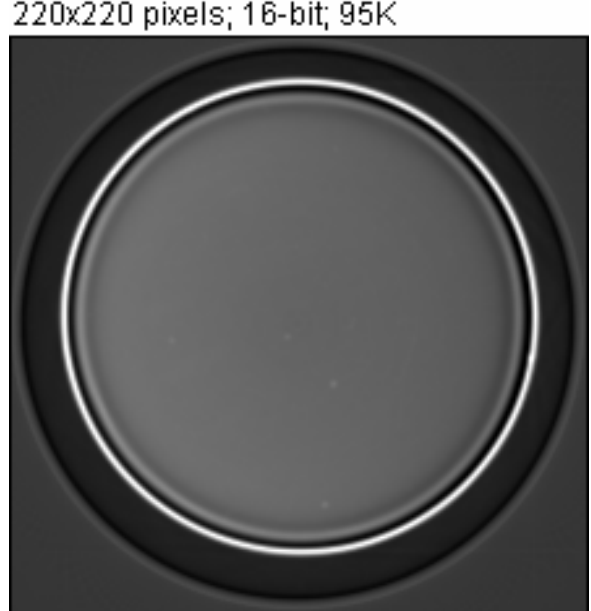

Pre Contrast Enhanced Pixel Histogram

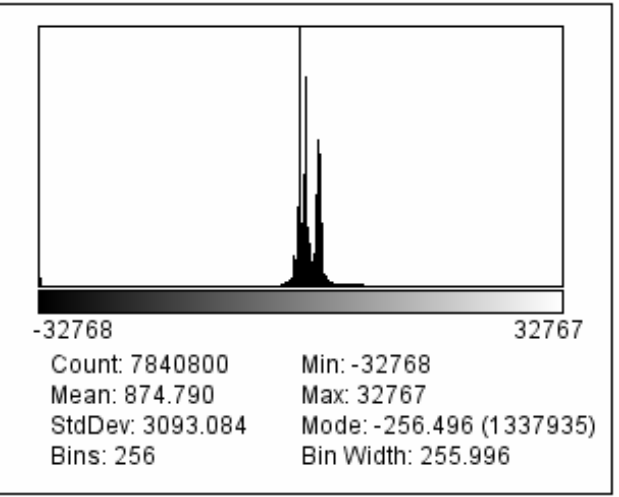

Post Contrast Enhanced Pixel Histogram

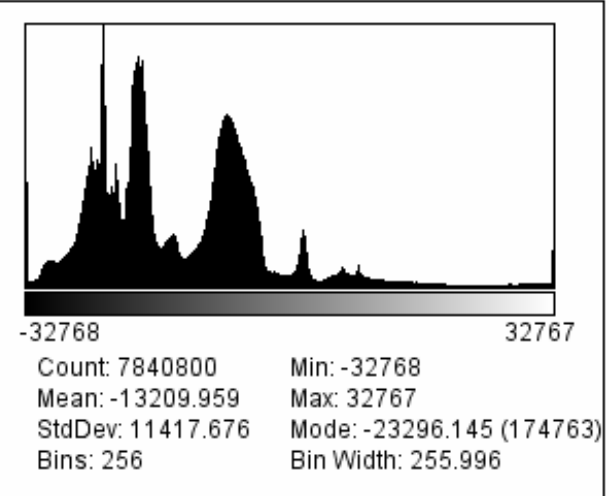

Plot Through Radiation Tracks

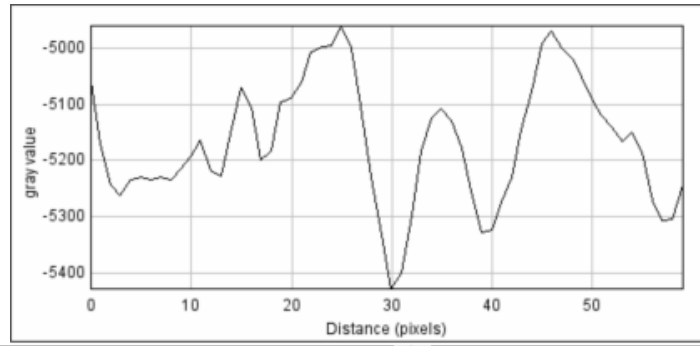




\section{RadBall data analysis sheet}

Experiment Number

Data Number:

Source:

Total Dose:

Collimation thickness:

Distance to source:

Completed by:

Date:

Visible Tracks:
Phase 3 Exp 6 Calibration Facility

N7-1

1.5 Gy Cs-137 (no collimator) + $1.5 \mathrm{~Gy}$ Cs-137 (with collimator)

$3.0 \mathrm{~Gy}$

$10.0 \mathrm{~mm}$

$1000 \mathrm{~mm}$

Chris Holmes (NNL)

November $2^{\text {nd }} 2009$

Yes
Pre Contrast Enhanced Image $67 / 162 ; 220 \times 220$ pixels; 16 -bit; $15 \mathrm{MB}$

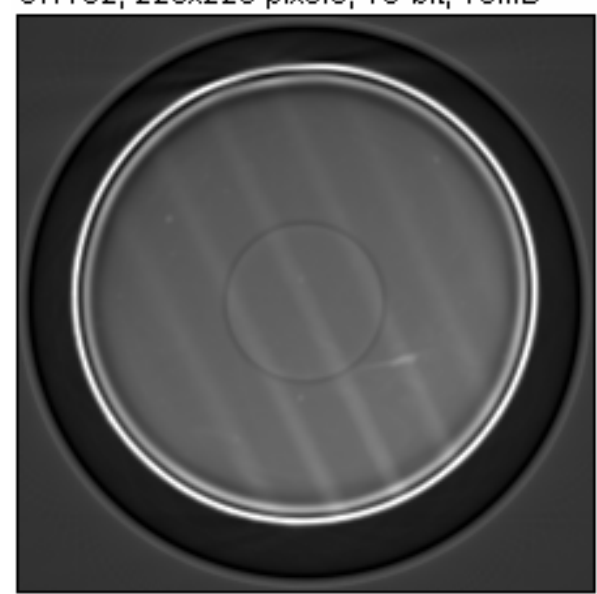

Pre Contrast Enhanced Pixel Histogram

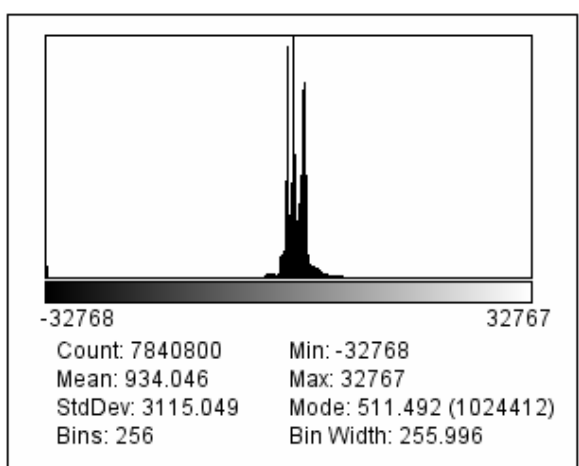

Post Contrast Enhanced Image $220 \times 220$ pixels; 16 -bit; $95 \mathrm{~K}$

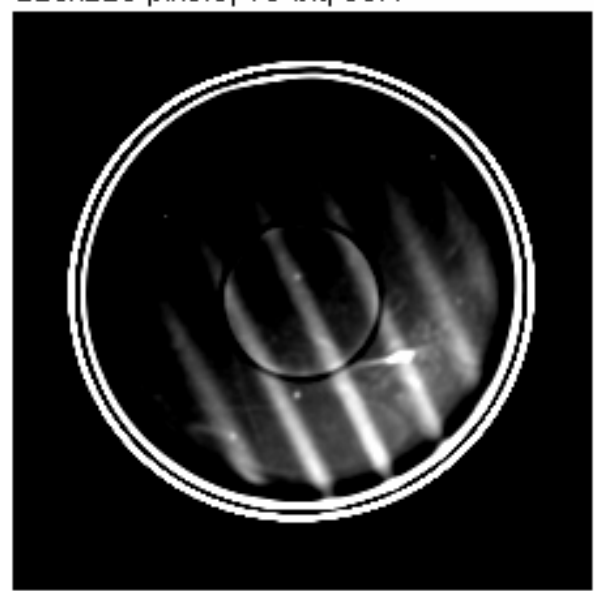

Post Contrast Enhanced Pixel Histogram

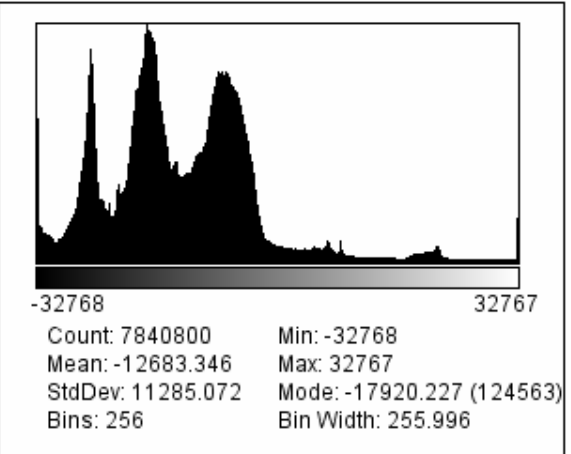

Plot Through Radiation Tracks

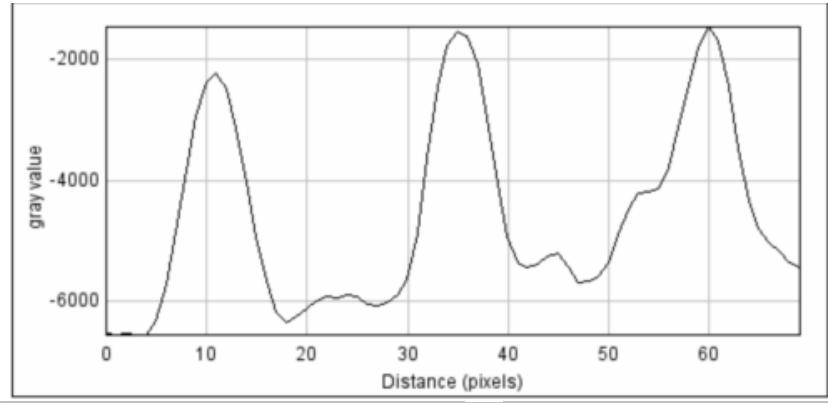




\section{RadBall data analysis sheet}

Experiment Number

Data Number:

Source:

Total Dose:

Collimation thickness:

Distance to source:

Completed by:

Date:

Visible Tracks:
Phase 3 Exp 7 Calibration Facility

N8-1

2.0 Gy Cs-137 (no collimator) + 1.0 Gy Cs-137 (with collimator)

$3.0 \mathrm{~Gy}$

$10.0 \mathrm{~mm}$

$1000 \mathrm{~mm}$

Chris Holmes (NNL)

November $2^{\text {nd }} 2009$

Yes

Post Contrast Enhanced Image

$220 \times 220$ pixels; 16 -bit; $95 \mathrm{~K}$
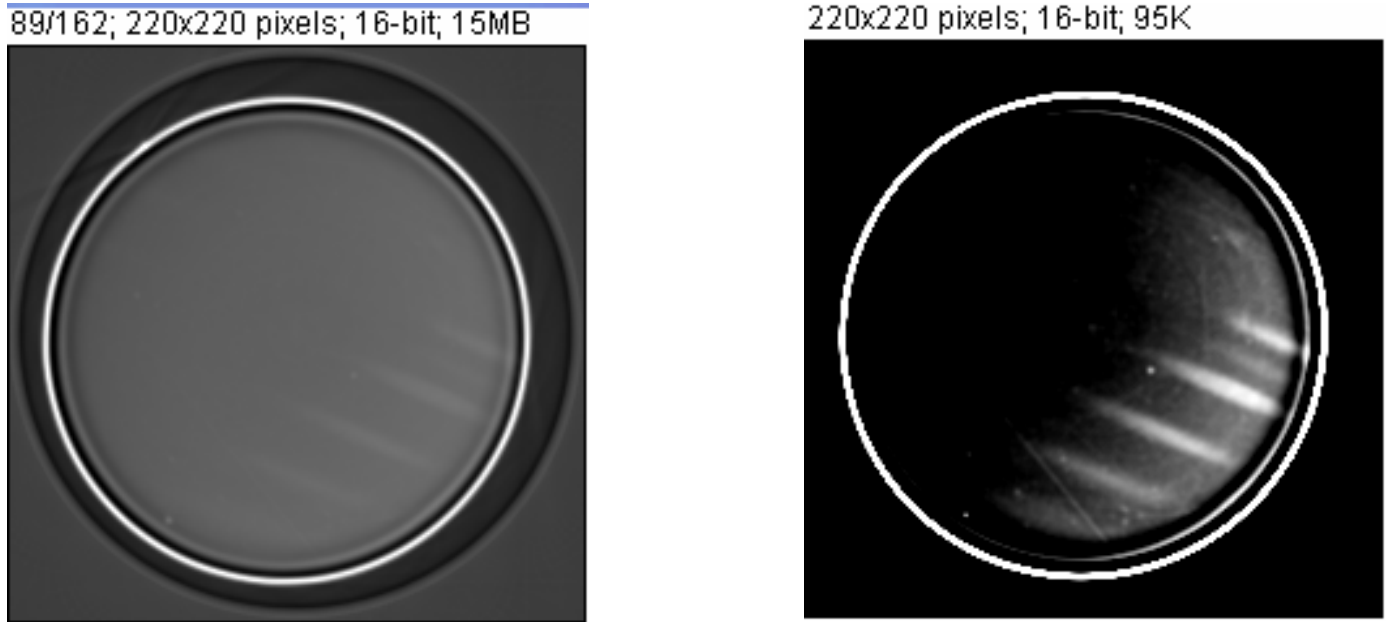

Pre Contrast Enhanced Pixel Histogram

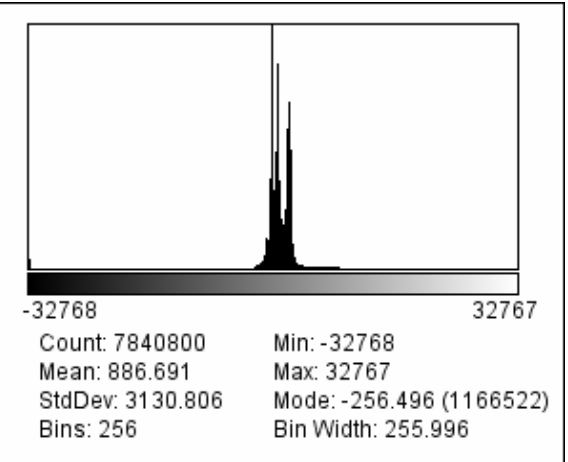

Post Contrast Enhanced Pixel Histogram

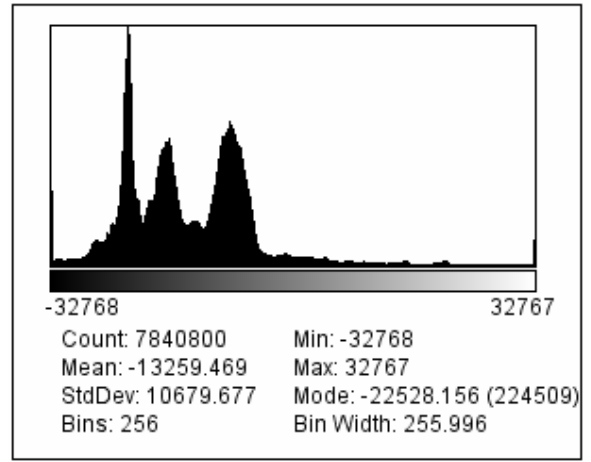

Plot Through Radiation Tracks

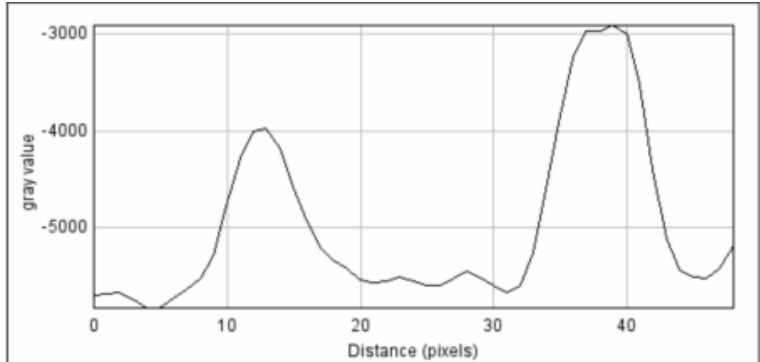




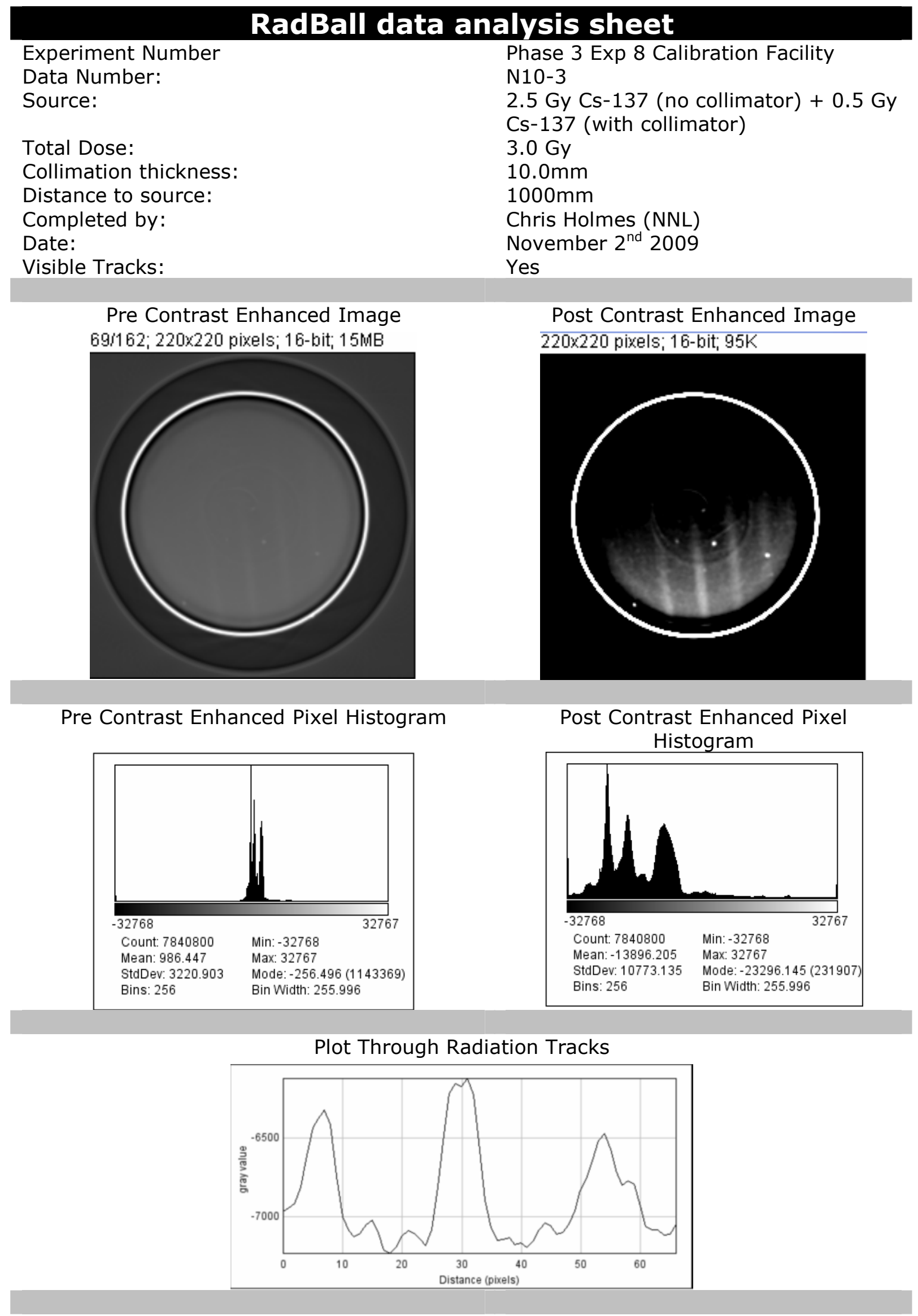




\section{RadBall data analysis sheet}

Experiment Number

Data Number:

Source:

Total Dose:

Collimation thickness:

Distance to source:

Completed by:

Date:

Visible Tracks:

Phase 3 Exp 9 Calibration Facility

N9-1

2.75 Gy Co-60 (no collimator) + 0.25

Gy Cs-137 (with collimator)

3.0 Gy

$10.0 \mathrm{~mm}$

$1000 \mathrm{~mm}$

Chris Holmes (NNL)

November $2^{\text {nd }} 2009$

Yes

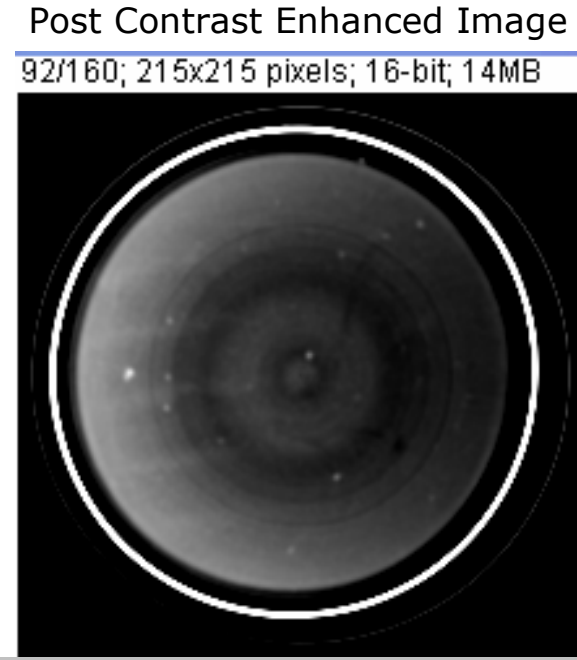

Pre Contrast Enhanced Image

$215 \times 215$ pixels; 16 -bit; $90 \mathrm{~K}$

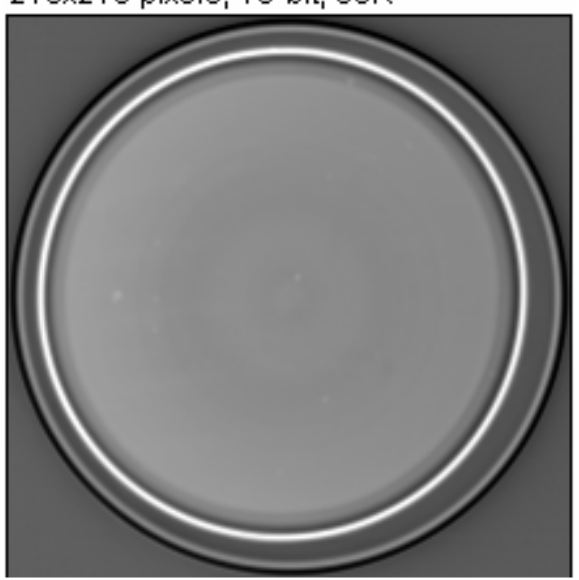

92/160; $215 \times 215$ pixels; 16 -bit; $14 \mathrm{MB}$

Pre Contrast Enhanced Pixel Histogram

Post Contrast Enhanced Pixel Histogram
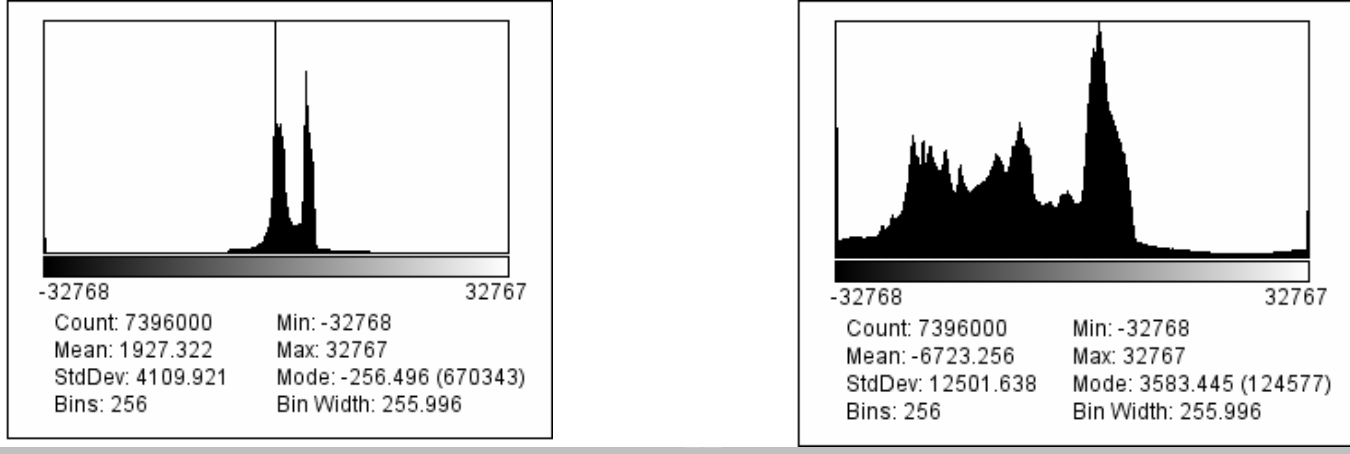

Plot Through Radiation Tracks

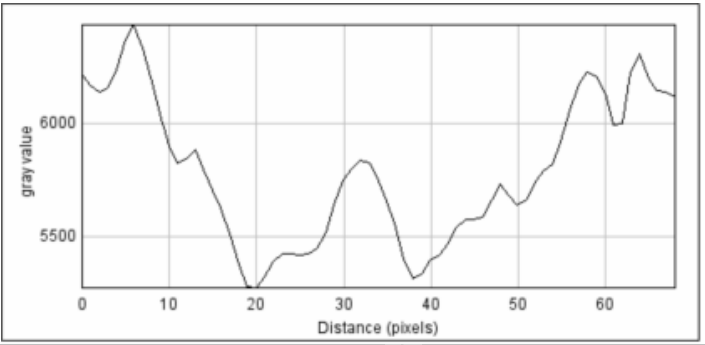




\section{RadBall data analysis sheet}

Experiment Number

Data Number:

Source:

Total Dose:

Collimation thickness:

Distance to source:

Completed by:

Date:

Visible Tracks:
Phase 3 Exp 10 Calibration Facility

N7-3

2.85 Gy Cs-137 (no collimator) + 0.15

Gy Cs-137 (with collimator)

$3.0 \mathrm{~Gy}$

$10.0 \mathrm{~mm}$

$1000 \mathrm{~mm}$

Chris Holmes (NNL)

November $2^{\text {nd }} 2009$

Yes

Pre Contrast Enhanced Image 96:162; $220 \times 220$ pixels; 16 -bit; $15 \mathrm{MB}$

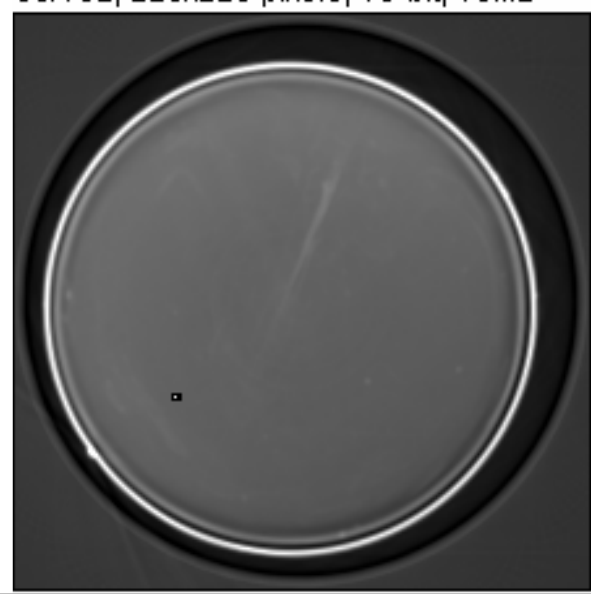
220×220 pixels; 16 -bit; $95 \mathrm{~K}$

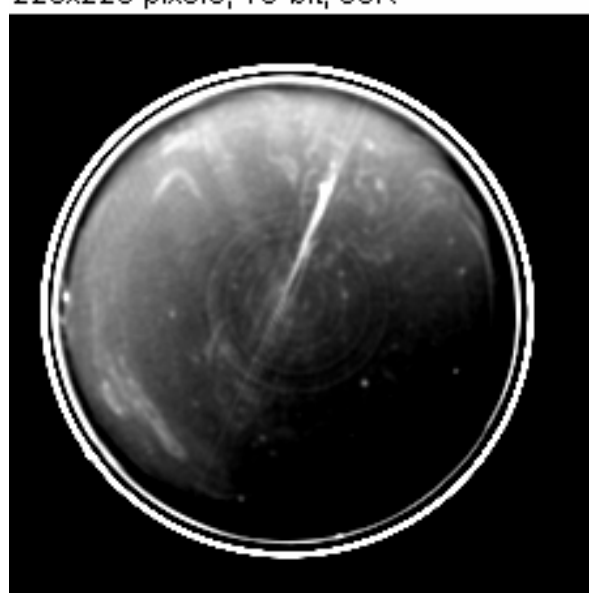

Pre Contrast Enhanced Pixel Histogram

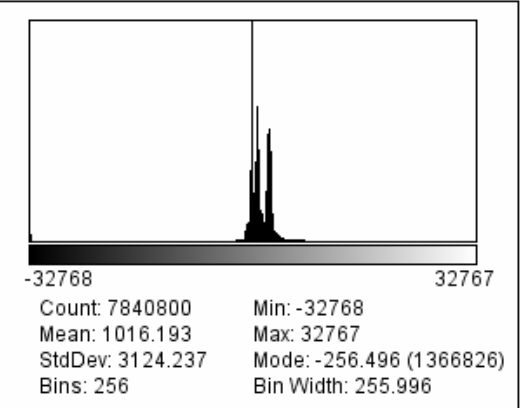

Post Contrast Enhanced Pixel Histogram

Plot Through Radiation Tracks

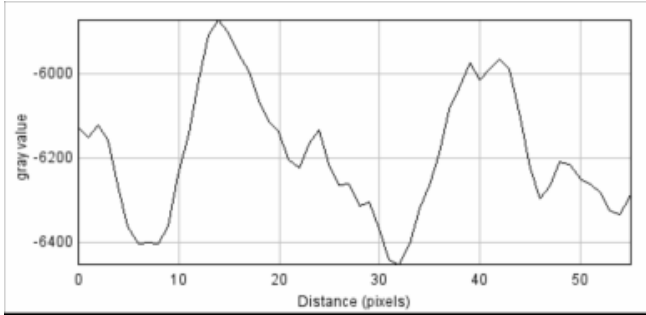




\section{RadBall data analysis sheet}

Experiment Number

Data Number:

Source:

Total Dose:

Collimation thickness:

Distance to source:

Completed by:

Date:

Visible Tracks:
Phase 3 Exp 11 Calibration Facility

N9-2

Co-60 (Mimic distributed source by moving RadBall in direction

perpendicular to the line between the

source and initial position. Irradiate using Cs source to deliver 0.5Gy. Then, move by $0.5 \mathrm{~cm}$ and repeat the $0.5 \mathrm{~Gy}$ exposure. Repeat until dose of $3 \mathrm{~Gy}$.)

\section{$3.0 \mathrm{~Gy}$}

$7.5 \mathrm{~mm}$

\section{$1000 \mathrm{~mm}$}

Chris Holmes (NNL)

November $3^{\text {rd }} 2009$

Yes
Pre Contrast Enhanced Image

215×215 pixels; 16 -bit; $90 \mathrm{~K}$

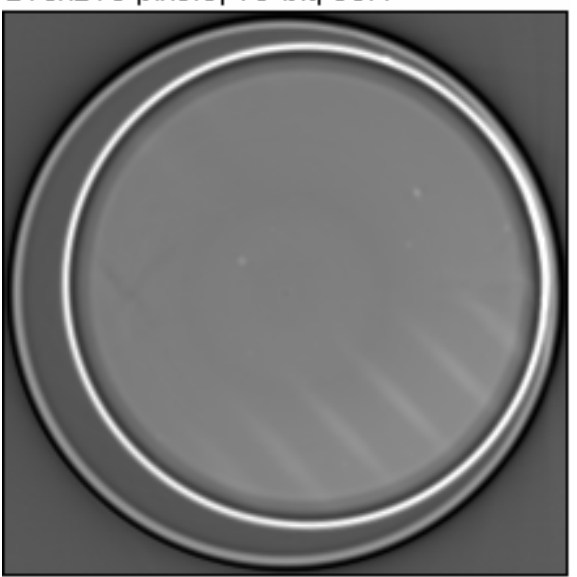

Pre Contrast Enhanced Pixel Histogram

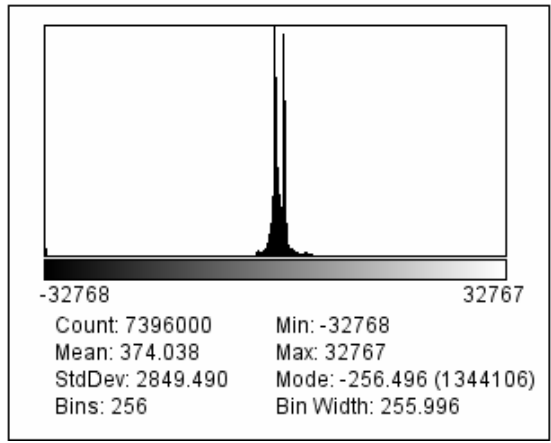

Post Contrast Enhanced Image

95/160; $215 \times 215$ pixels; 16 -bit; $14 \mathrm{MB}$

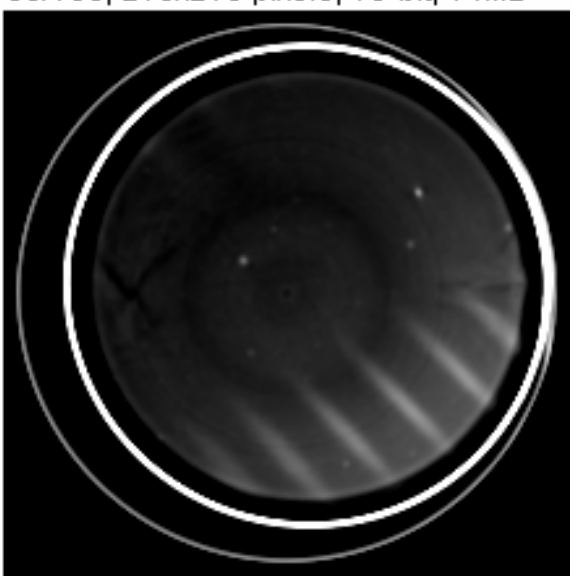

Post Contrast Enhanced Pixel Histogram

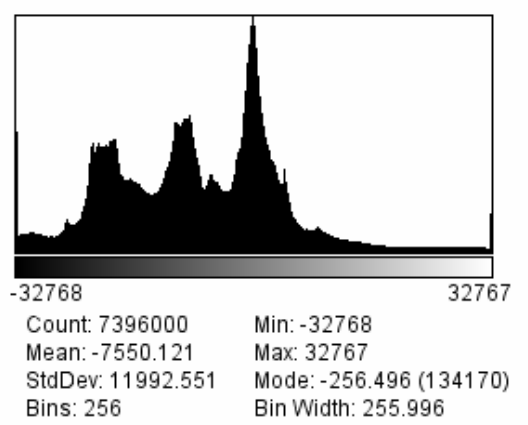

Plot Through Radiation Tracks

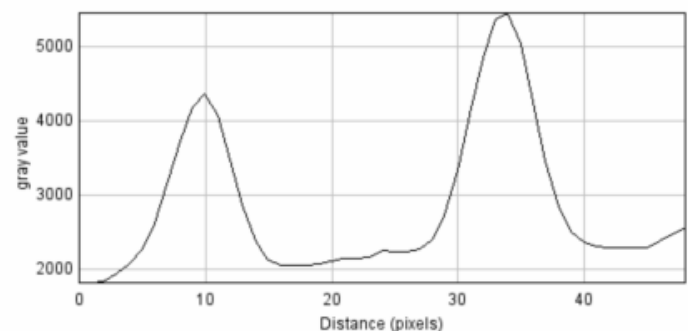




\section{RadBall data analysis sheet}

Experiment Number

Data Number:

Source:

Total Dose:

Collimation thickness:

Distance to source:

Completed by:

Date:

Visible Tracks:
Phase 3 Exp 12 Calibration Facility

N9-3

Co-60 (Repeat experiment 11 moving

the RadBall by $1.0 \mathrm{~cm}$ in each step.)

$3.0 \mathrm{~Gy}$

$7.5 \mathrm{~mm}$

$1000 \mathrm{~mm}$

Chris Holmes (NNL)

November $3^{\text {rd }} 2009$

Yes

\section{Post Contrast Enhanced Image}

$70 / 160 ; 215 \times 215$ pixels; 16 -bit; $14 \mathrm{MB}$
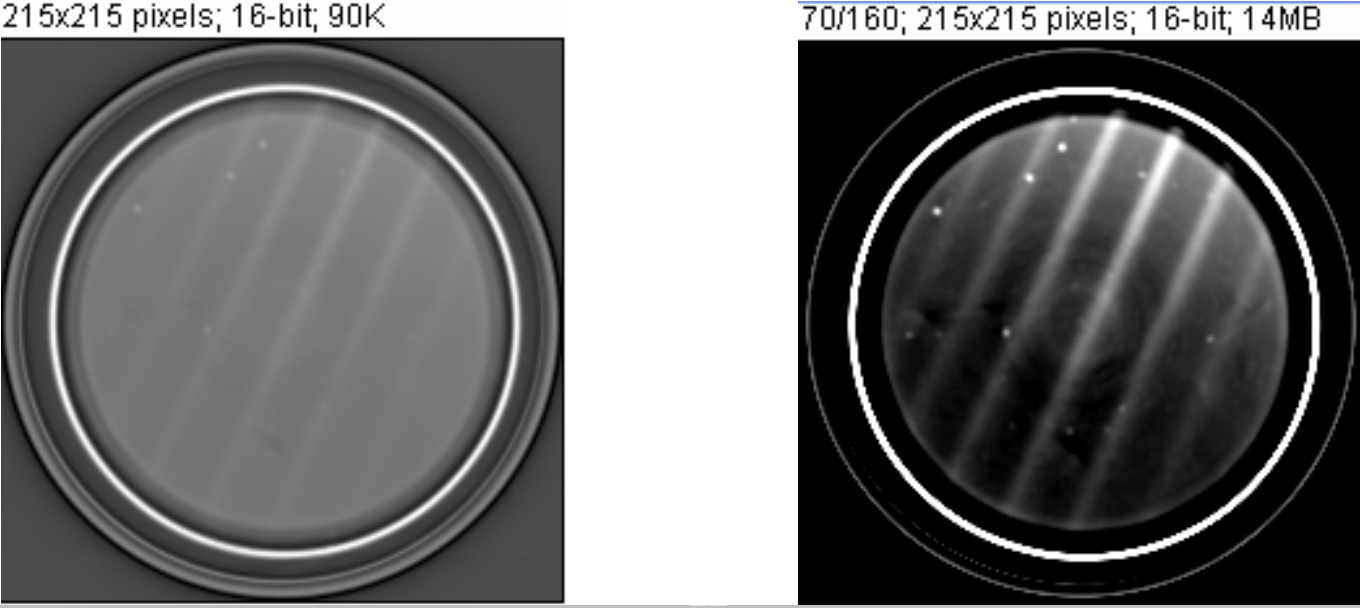

Pre Contrast Enhanced Pixel Histogram

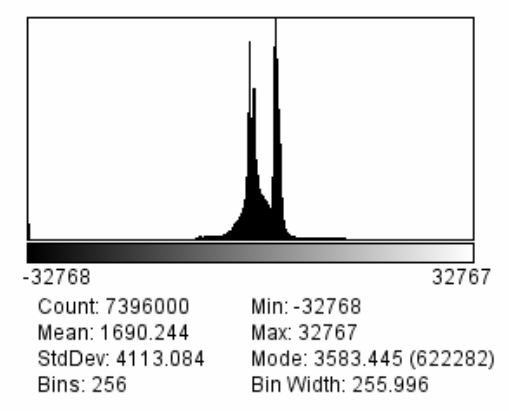

Post Contrast Enhanced Pixel Histogram

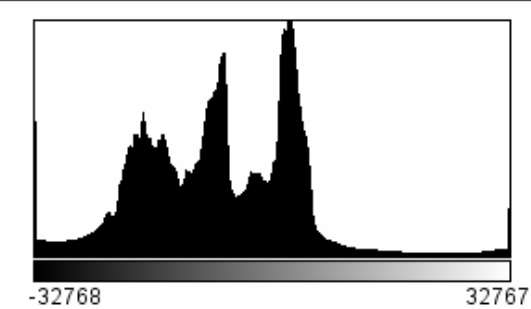

Count: 7396000

Mean: -7100.350

StdDev: 11256.196

Bins: 256
Min: -32768

Max: 32767

Mode: 2047.469 (119429) Bin Width: 255.996

\section{Plot Through Radiation Tracks}

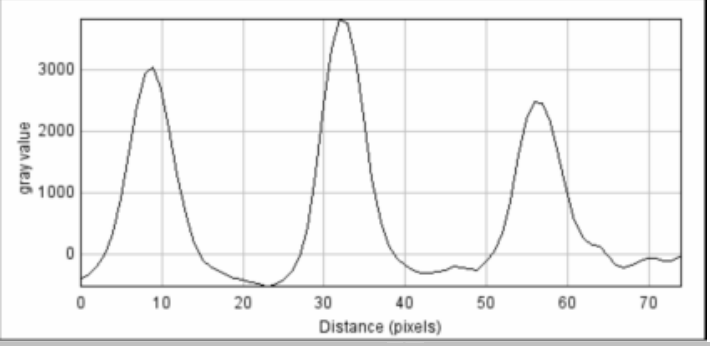




\section{RadBall data analysis sheet}

Experiment Number

Data Number:

Source:

Total Dose:

Collimation thickness:

Distance to source:

Completed by:

Date:

Visible Tracks:
Phase 3 Exp 13 Calibration Facility

N8-6

Co-60 (Mimic multiple sources close to each other). Irradiate with Cs to deliver $0.5 \mathrm{~Gy}$, rotate 5 degrees and repeat exposure $(0.5 \mathrm{~Gy})$. Then rotate by 5 degrees again and repeat exposure (0.5 $\mathrm{Gy}$ ). Six rotations give dose of $3 \mathrm{~Gy}$ ).

$3.0 \mathrm{~Gy}$

$7.5 \mathrm{~mm}$ $1000 \mathrm{~mm}$

Chris Holmes (NNL)

November $3^{\text {rd }} 2009$

Yes
Pre Contrast Enhanced Image $220 \times 220$ pixels; 16 -bit; $95 \mathrm{~K}$

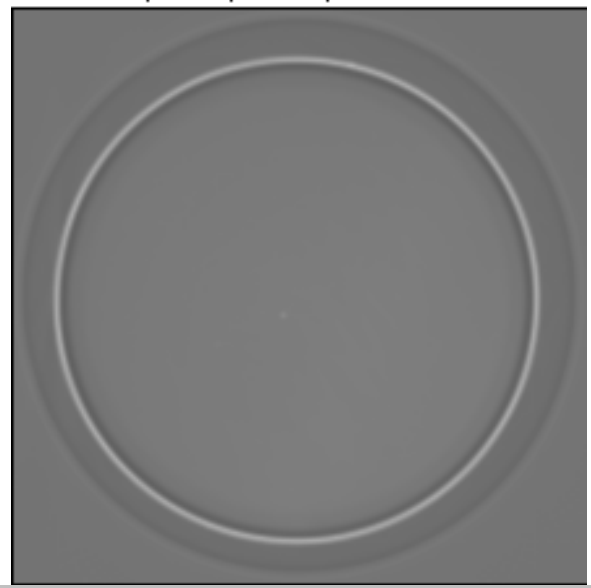

Pre Contrast Enhanced Pixel Histogram

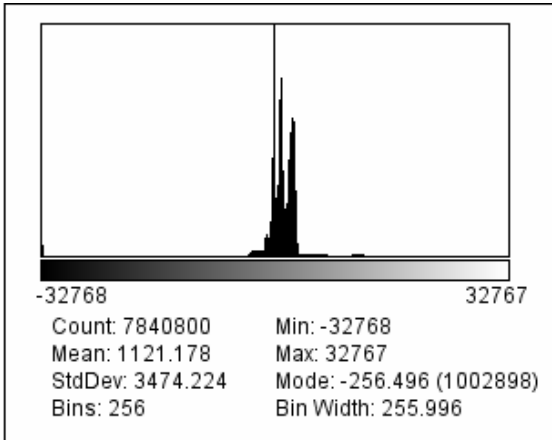

Post Contrast Enhanced Image 124/162; 220×220 pixels; 16 -bit; $15 \mathrm{MB}$

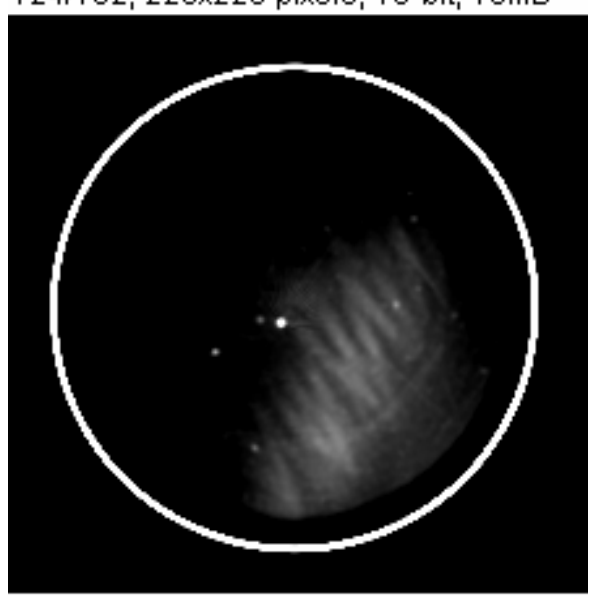

Post Contrast Enhanced Pixel Histogram

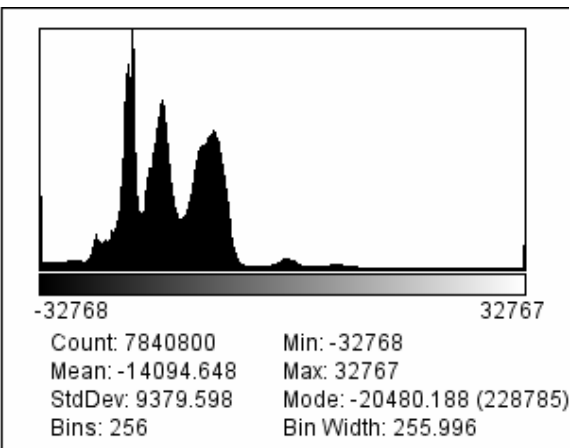

Plot Through Radiation Tracks

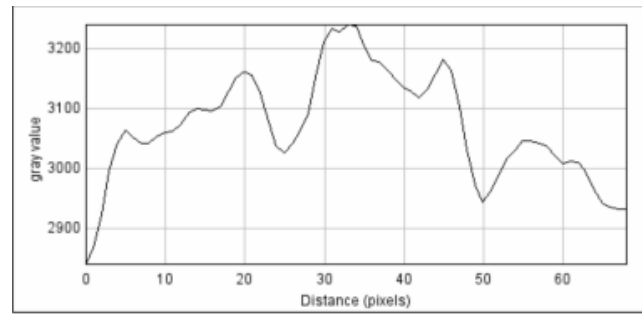




\section{RadBall data analysis sheet}

Experiment Number

Data Number:

Source:

Total Dose:

Collimation thickness:

Distance to source:

Completed by:

Date:

Visible Tracks:
Phase 3 Exp 14 Calibration Facility

N8-4

Co-60 (Repeat Experiment 13 using an angle of rotation of 10 degrees)

$3.0 \mathrm{~Gy}$

$7.5 \mathrm{~mm}$

$1000 \mathrm{~mm}$

Chris Holmes (NNL)

November $3^{\text {rd }} 2009$

Yes
Pre Contrast Enhanced Image 220×220 pixels; 16 -bit; $95 \mathrm{~K}$

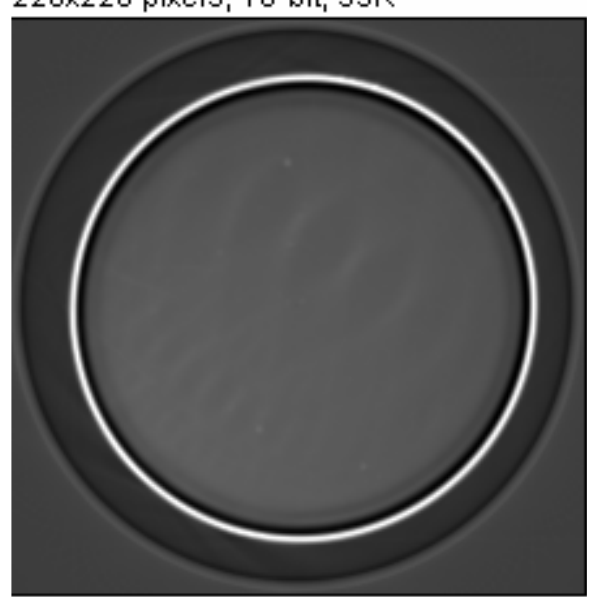

Pre Contrast Enhanced Pixel Histogram

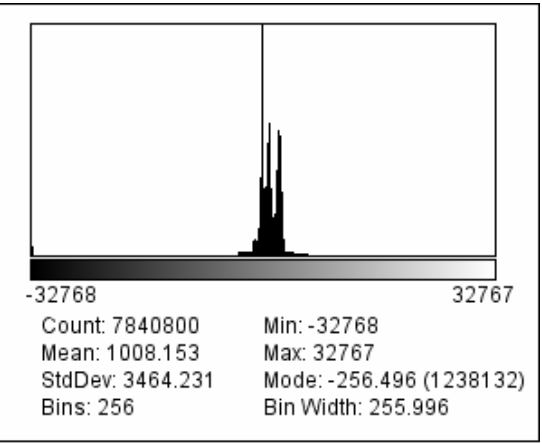

Post Contrast Enhanced Image $83 / 162 ; 220 \times 220$ pixels; 16 -bit; $15 \mathrm{MB}$

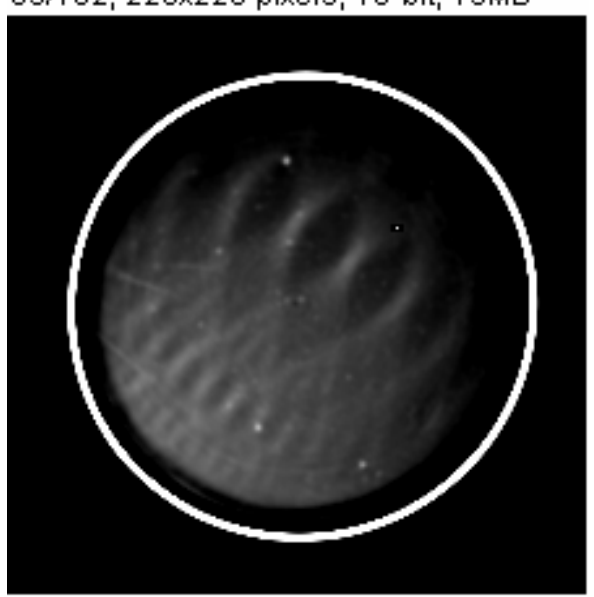

Post Contrast Enhanced Pixel Histogram

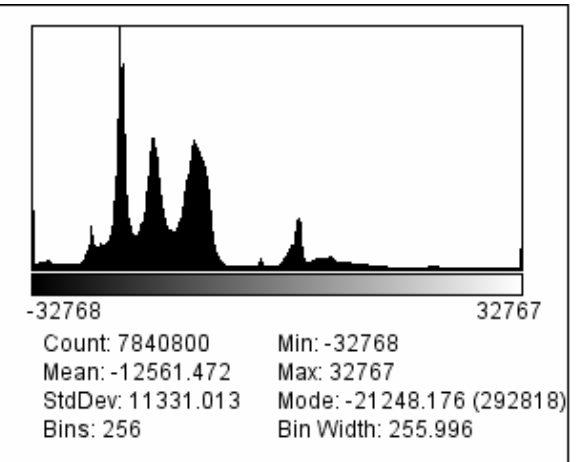

Plot Through Radiation Tracks

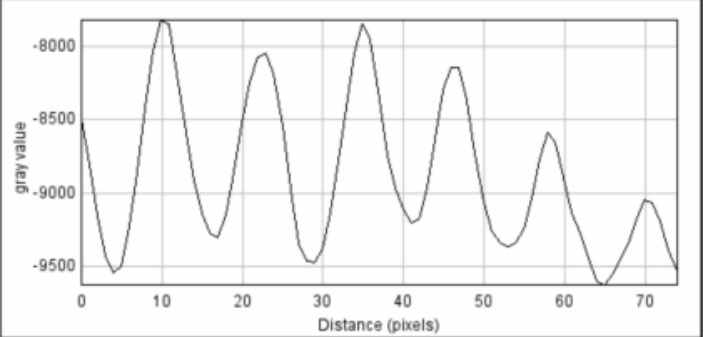




\section{RadBall data analysis sheet}

Experiment Number

Data Number:

Source:

Total Dose:

Collimation thickness:

Distance to source:

Completed by:

Date:

Visible Tracks:
Phase 3 Exp 15 Calibration Facility

$\mathrm{N} 10-2$

Co-60 (An initial dose of $1 \mathrm{~Gy}$, then rotate the RadBall by 60 degrees and give another 1 Gy dose. Repeat rotation and dose until 6 irradiations have been completed, the RadBall has been rotated 360 degrees and has received 6 Gy in total)

$6.0 \mathrm{~Gy}$

$10 \mathrm{~mm}$

$1000 \mathrm{~mm}$

Chris Holmes (NNL)

November $3^{\text {rd }} 2009$

Yes

Post Contrast Enhanced Image

71/162; $220 \times 220$ pixels; 16 -bit; $15 \mathrm{MB}$
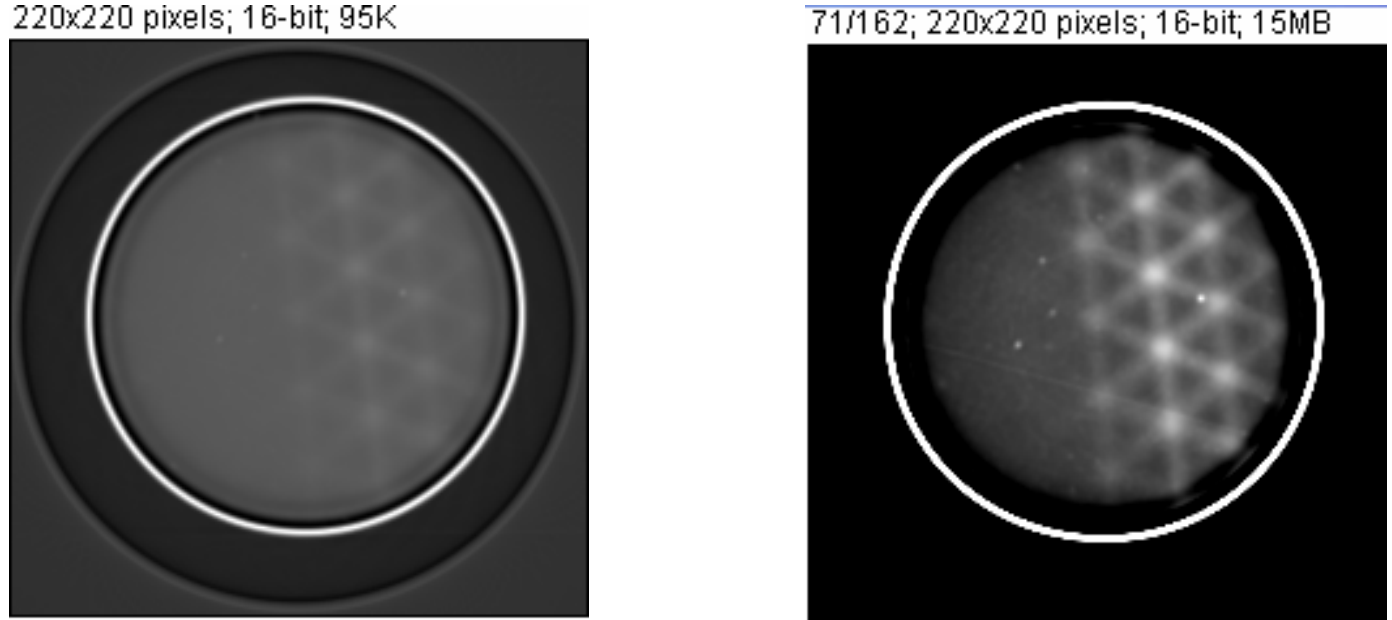

Pre Contrast Enhanced Pixel Histogram

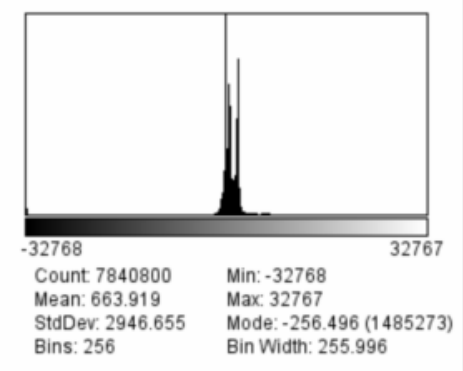

Post Contrast Enhanced Pixel Histogram

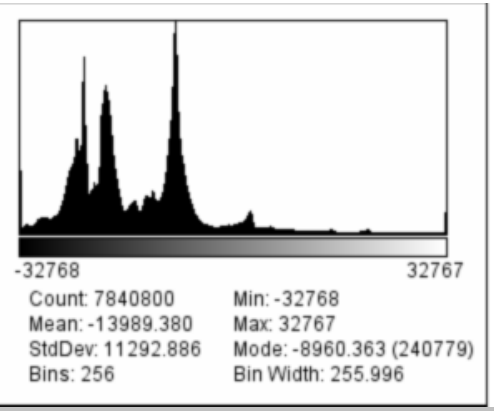

Plot Through Radiation Tracks

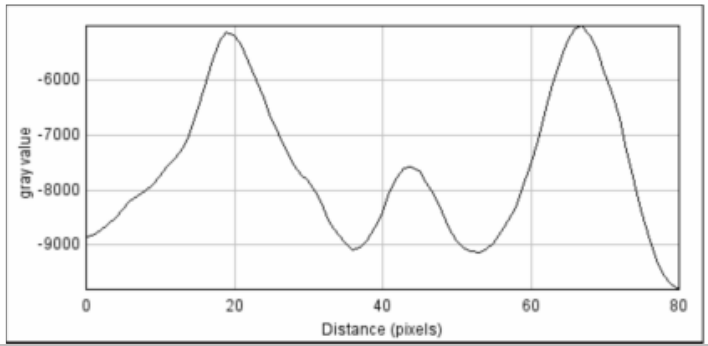




\section{RadBall data analysis sheet}

Experiment Number

Data Number:

Source:

Total Dose:

Collimation thickness:

Distance to source:

Completed by:

Date:

Visible Tracks:
Phase 3 Exp 16 Calibration Facility

N10-1

Co-60 (Repeat experiment 15 with the

RadBall tilted at a 45 degree angle)

$6.0 \mathrm{~Gy}$

$10.0 \mathrm{~mm}$

$1000 \mathrm{~mm}$

Chris Holmes (NNL)

November $3^{\text {rd }} 2009$

Yes

Post Contrast Enhanced Image 89:162; 220×220 pixels; 16 -bit; $15 \mathrm{MB}$

\section{$220 \times 220$ pixels; 16 -bit; $95 \mathrm{~K}$}

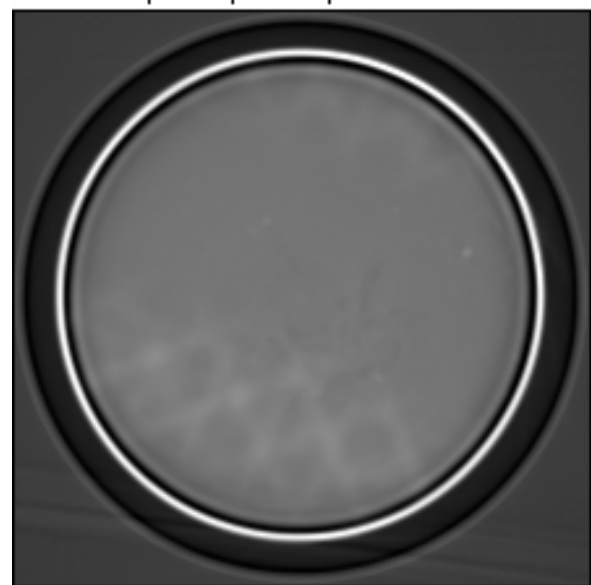

Pre Contrast Enhanced Pixel Histogram

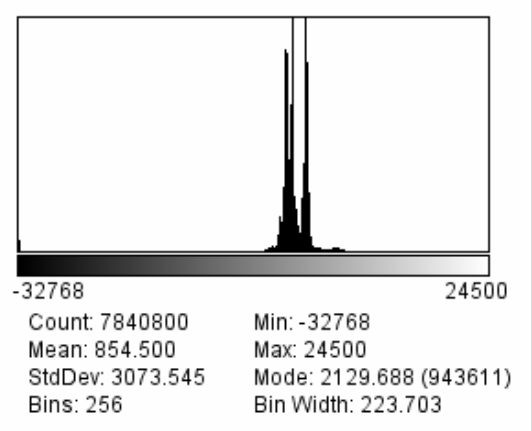

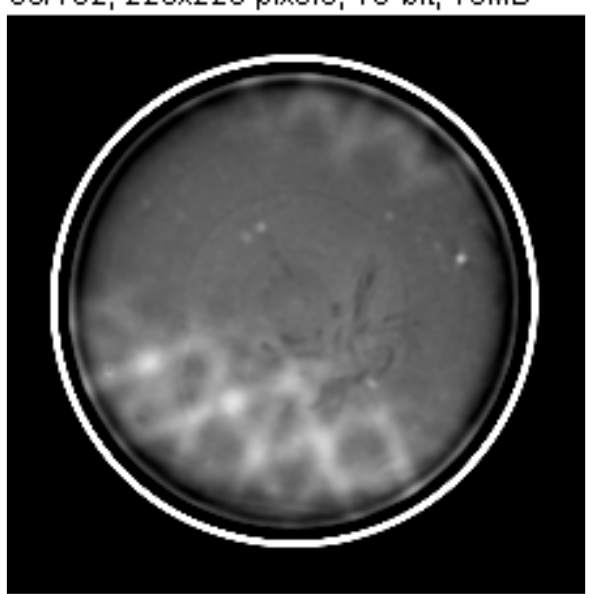

Post Contrast Enhanced Pixel Histogram

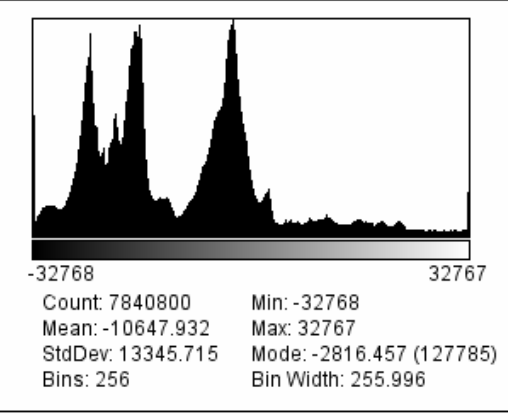

Plot Through Radiation Tracks

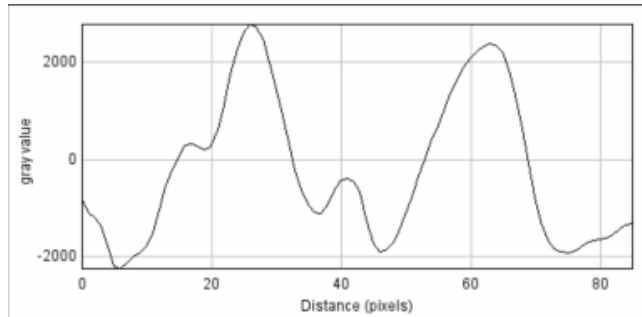


This Page Intentionally Left Blank 


\section{Testing of the RadBall Technology at Savannah River National Laboratory}

\section{DISTRIBUTION (23)}

D.M. Shedrow, 773-A

J.B. Gladden, $\quad 773-42 \mathrm{~A}$

G.T. Jannik, 773-42A

T.Q. Foley, $\quad$ 773-42A

B.N. Attaway, 773-A

R.W. Blessing, 773-A

S.L. Tibrea, $\quad$ 730-A

S.L. Beard. 773-A

L.T. Reid, $\quad$ 773-A

J.R. Gordon, $\quad$ 730-A

L.J. Harpring, 773-A

M.B. Baxter, 742-A

J.H. Olschon, 773-41A

R.J. Butler, 742-A

S.J. Stanley, NNL

C.J. Holmes, NNL

M. Oldham, Duke University

J. Adamovics, Heuris Pharma

SRNL Records(4), 773-52A

EDG Records(5), 773-42A 